A MONOGRAPH OF

THE COLLEMBOLA OF IOWA 



\title{
A MONOGRAPH OF
}

\section{THE COLLEMBOLA OF IOWA}

\author{
By \\ Harlow B. Mills, M. S. \\ Iowa State College
}

Monograph Number Three

Division of Industrial Science

Iowa State College

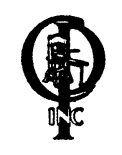

COLLEGIATE PRESS, INC.

AMES, IOWA

1934 
COPYRIGHT, 1934, BY COLLEGIATE PRESS, INC. 


$$
m \cdot C b
$$

$$
\begin{aligned}
& \text { TO } \\
& \text { J. E. Guthrie } \\
& \text { AND } \\
& \text { J. W. FOLSOM }
\end{aligned}
$$


This monograph has been submitted as a thesis to the Graduate Faculty of Iowa State College in partial fulfillment of the requirements for the degree Doctor of Philosophy. 


\section{PREFACE}

Since Guthrie's The Collembola of Minnesota was published in 1903, there has been no inclusive work on this primitive order of insects written in the English language. The present monograph, therefore, should be of value in bringing the rapidly changing nomenclature of this group up to date.

It is the author's desire that this book will prove an aid to beginners in taxonomic work in this field, and will make available numerous forms which heretofore have been insufficiently known.

If this book stimulates future collembolists to more exacting and accurate work, then errors which it may contain will be at least partially excusable.

Prof. J. E. Guthrie, who has been in charge of this work, has given unstintingly of his aid and encouragement, and the author is under deep obligation to him. To Dr. J. W. Folsom, whose aid in identification and in procuring rare literature has been invaluable, and whose opinions and criticisms have been solicited throughout the course of the preparation of this monograph, the author is also greately indebted.

Others have aided materially in various ways, chiefly in obtaining leaf mould from various parts of the state. To Dr. C. J. Drake, Dr. G. C. Decker, Dr. H. M. Harris, B. V. Travis, Floyd Andre, H. D. Tate, Homer Hixson, Lyle Weber, Dr. E. M. Mills, E. L. Mills, and Miss Zella Beck, the author wishes to express his appreciation.

Acknowledgment must also be made for the aid received from J. R. Denis of Banyuls-sur-Mer, France, and from Dr. Jan Stach of Krakow, Poland. 



\section{CONTENTS}

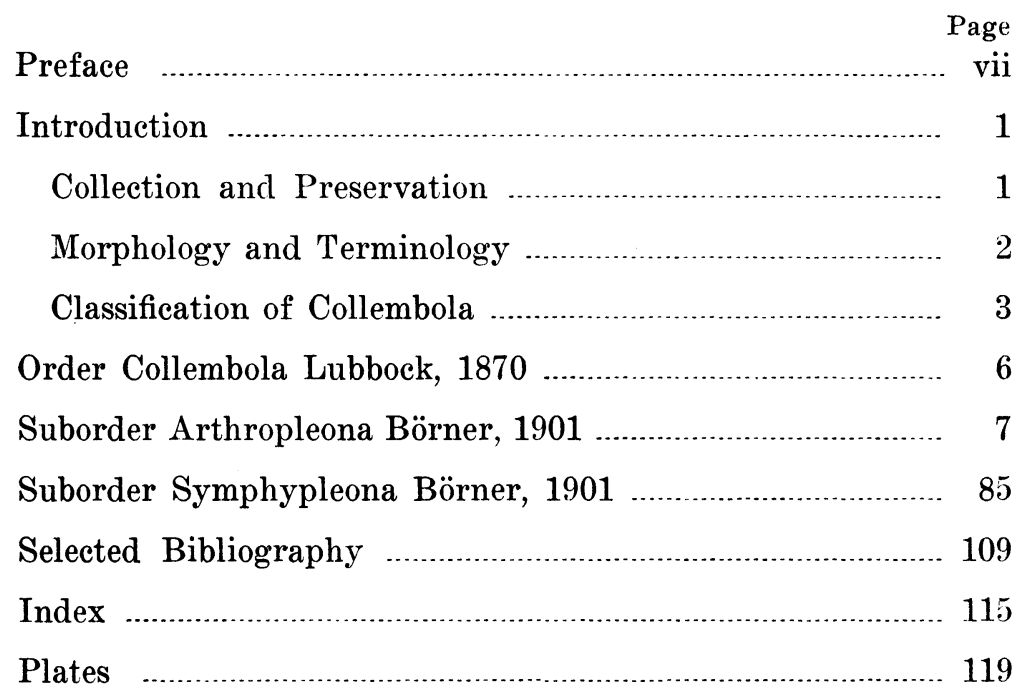



A MONOGRAPH OF THE COLLEMBOLA OF IOWA 



\section{INTRODUCTION}

This work on the Collembola of Iowa is the result of four years' study of a collection of many thousand specimens, taken in all parts of the state. It without doubt contains a great majority of the indigenous species, but it is not complete. Some forms, because the material is insufficient or in too poor condition for complete study, have been omitted.

A number of the species dealt with in this work have not been recorded from North America heretofore. The matter of identifying our forms with exotic forms has been approached with caution, for the collections of foreign material at hand are extremely meager. Some of the inclusions in this work differ in minute, however, distinct, details from European species, but may, upon comparison, prove to be synonymous with them. It is believed better to describe them as new than to commit the oft-repeated mistake of erroneously recording exotic forms as occurring within our territory.

Cotypes of the new species are at present in the collections of the author and of Iowa State College.

\section{COLLECTION AND PRESERVATION}

A great deal of the collecting was done with a Berlese funnel. An instrument of great value in hand collecting was a rubber tube with a glass mouthpiece at one end, and, inserted in the other end, a glass tube drawn out to a small aperture distally and closed with bolting cloth at the base. By quick inhalation, springtails were drawn from cracks into the small nozzle and against the bolting cloth, and were shaken into a bottle of alcohol with the appendages, hairs and scales of the body uninjured.

Specimens were kept in alcohol (80 to 90 percent) until they could be examined. For clearing purposes, diaphanol worked well with the unpigmented forms (Tullbergia, ete.), as did also lactic acid; a concentrated solution of $\mathrm{KOH}$ was used for dark species. Specimens were mounted in Berlese's fluid.*

\footnotetext{
*Gum arabic 12 gm., distilled water 20 gm., chloral hydrate 20 gm., concentrated glycerine $8 \mathrm{gm}$. or 6 c.c.
} 


\section{MORPHOLOGY AND TERMINOLOGY}

The peculiar morphological structure of this group of insects has necessitated a rather distinct terminology. The head may be either prognathous or hypognathous. The antennae are typically four-segmented, but sometimes, however, they are subdivided into five or six segments. The third and fourth segments may be annulated or subsegmented. The eyes are typically eight on each side, but often are fewer in number. Mouthparts are either for chewing or for sucking, and, because of embryonic outgrowths of the genae, they appear to be withdrawn into the head. The type of mouthparts is of importance in classification.

Several kinds of sense organs occur on the head. Directly behind the antennal bases are found the postantennal organs, which in their simplest form are single cuticular swellings. These organs are extremely variable in shape. Near the apex of the third antennal segment is found a sense organ, which, in its simplest form, is composed of two sensory pegs, but in the Onychiurinae it forms a complex organ furnished with papillae, sense clubs, sense rods, and protective hairs. Thick, blunt olfactory hairs occur on the third and fourth antennal segments in the more primitive forms, and a retractile sense knob is often present at the apex of the fourth segment.

The three regions of the thorax are well separated. The prothorax is smallest, often membranous dorsally and devoid of bristles. In some of the Entomobryidae the mesonotum projects over the pronotum and sometimes over the base of the head.

The legs are composed of two precoxae, coxa, trochanter, femur, tibio-tarsus, and a small apical praetarsus or transtarsus. Two claws are typically present, a large claw called the unguis, and a small opposing claw, the unguiculus; the latter may be absent. These claws are often toothed. The ungues of Sinella and Pseudosinella bear large basal paramedian teeth or "wing teeth," besides the smaller, more distal median teeth. Lateral teeth or pseudonychia may also occur on the ungues. On the inner face of the hind tibiotarsus near the apex, in the genus Sminthurides, are sac-like swellings and an enlarged hair, which compose the "tibiotarsal organ."

The abdomen is composed of six segments. In the Arthropleona it is elongate and the segments are well separated. In the Symphypleona it is fused with the thorax into a globular mass, and the segmental sutures are obliterated or indistinct. In the latter 
group, however, the last two segments are usually well separated from the large abdominal region (the furcal segment) and form the anal papilla. The fifth abdominal segment bears ventrally the genital opening and the sixth bears the anus. On each side of the anus in females of most of the Smithuridae are found chitinous structures known as the anal appendages. Dorsally on the head and body in the Onychiurinae are found circular depressions called pseudocelli. The third segment bears ventrally a small structure, the tenaculum, which holds the spring in place beneath the body. The spring or furcula is attached to the venter of the fourth segment (apparently to the fifth in most Entomobryidae). It is composed of a proximal piece, the manubrium, and two distal pieces called the dentes, each of which is tipped by a small chitinous, sometimes lamellate structure, the mucro. The dentes bear ridges basally on their inner surfaces, which are very large and hook-like in the genus Isotomodes, and upon which the teeth of the tenaculum catch when the spring is held beneath the body. In some genera, especially in the Tomocerinae, there are inward-pointing spines at the base of the dentes.

The body may be either clothed with scales or hairs; it sometimes may appear nearly naked. The hairs vary greatly. They may be short and smooth or strongly clavate and fringed. Long, extremely slender hairs, arising from cups in the integument, are sometimes present and are known as bothriotricha.

The Iowa list at present includes 132 species distributed in 43 genera. Of these species, 59 are known to be holarctic or cosmopolitan in their range. Numerous groups which are given a family standing today are not recognized as such in this work. The tendency seems to be to divide and redivide this small group to a point where its classification becomes cumbersome. The conservative classification used here, which follows closely the arrangement of Linnaniemi (1912), is as follows:

\section{CLASSIFICATION OF COLLEMBOLA}

Order Collembola Lubbock.

Suborder Arthropleona Börner.

Family Poduridae Lubbock.

Subfamily Podurinae Börner.

Genus Podura Linnaeus.

Subfamily Achorutinae Börner.

Genus Achorutes Templeton. 
*Genus Beckerella Linnaniemi. Genus Xenylla Tullberg. Genus Willemia Börner. Genus Brachystomella Ågren. Subfamily Neanurinae Börner.

Tribe Pseudachorutini Börner. Genus Friesea Dalla Torre. Genus Pseudachorutes Tullberg. Genus Odontella Schäffer.

*Genus Xenyllodes Axelson. Genus Anurida Laboulbène. Genus Micranurida Börner. Genus Paranura Axelson. Tribe Neanurini Börner.

* Genus Protanura Börner.

*Genus Morulina Börner. Genus Neanura MacGillivray. Subfamily Onychiurinae Börner.

*Genus Tetrodontophora Reuter. Genus Onychiurus Gervais.

* Genus Kalaphorura Absolon. Genus Tullbergia Lubbock. Family Entomobryidae Tömösváry. Subfamily Isotominae Schäffer.

*Genus Uzelia Absolon. Genus Anurophorus Nicolet.

*Genus Tetracanthella Schött. Genus Folsomides Stach. Genus Isotomodes Axelson. Genus Folsomia Willem. Genus Folsomina Denis.

*Genus Guthriella Börner. *Genus Archisotoma Axelson.

*Genus Årenia Börner.

*Genus Axelsonia Börner. Genus Architomocerura Denis. Genus Proisotoma Börner. *Genus Spinisotoma Stach. Genus Isotomurus Börner. Genus Isotoma Bourlet.

\footnotetext{
${ }^{*}$ Genera not as yet found in Iowa.
} 
Subfamily Entomobryinae Schäffer.

Tribe Entomobryini Börner.

Genus Sinella Brook.

Genus Entomobrya Rondani.

*Genus Drepanura Schött.

Genus Sira Lubbock.

Genus Lepidocyrtus Bourlet.

Genus Drepanocyrtus Handschin.

*Genus Lepidocyrtinus Börner.

Genus Pseudosinella Schäffer.

Tribe Orchesellini Börner.

*Genus Typhlopodura Absolon.

Genus Heteromurus Wankel.

Genus Orchesella Templeton.

Tribe Cyphoderini Börner.

Genus Cyphoderus Nicolet.

Subfamily Tomocerinae Schäffer.

Genus Tomocerus Nicolet.

*Genus Tritomurus Frauenfeld.

Suborder Symphypleona Börner.

Family Neelidae Folsom.

*Genus Neelus Folsom.

Genus Megalothorax Willem.

Family Sminthuridae Börner.

Subfamily Sminthuridinae Börner.

Genus Sminthurides Börner.

Genus Arrhopalites Börner.

Genus Sminthurinus Börner.

Genus Neosminthurus new genus.

Subfamily Sminthurinae Börner.

Genus Bourletiella Banks.

Genus Deuterosminthurus Börner.

Genus Sminthurus Latreille.

*Genus Allacama Börner.

*Genus Sphyrotheca Börner.

Subfamily Dicyrtominae Börner.

*Genus Dicyrtomina Börner.

Genus Dicyrtoma Bourlet.

Genus Ptenothrix Börner. 


\section{ORDER COLLEMBOLA LUBBOCK, 1870}

Usually minute insects, without metamorphosis. Modified abdominal appendages are present, forming the ventral tube on the 1st segment, and the tenaculum and spring (both of which may be absent) on the 3rd and 4th segments, respectively. Antennae 4- to 6-segmented. Abdomen 6-segmented, without cerci. Tibiae and tarsi fused, rarely segmented, forming divisions which do not articulate with each other. Eyes present or absent; when present, composed of not more than 8 ommatidia on each side of the head. Body clothed with hairs or scales.

Key to the Suborders of Collembola

Body elongate. Thoracic and abdominal segments usually clearly separated from each other, ankylosis sometimes involving the posterior part of the abdomen. (fig. 3)

Arthropleona Börner, p. 7.

Body subglobose. Thorax and first 4 abdominal segments fused into a single mass with indistinct divisions. The 5th and 6th abdominal segments usually well separated from the rest of the abdomen, forming the "anal papilla." (fig. 13)...

Symphypleona Börner, p. 85. 


\section{SUBORDER ARTHROPLEONA BÖRNER, 1901}

Body elongate. Thoracic and abdominal segments usually well separated; but ankylosis of the last 2 or 3 abdominal segments may occur. Sacs of the ventral tube small, never warty. Anal appendages absent.

Key to the Families of Arthropleona

Prothorax naked dorsally (fig. 7), often membranous and more or less covered by the forward-projecting mesonotum. Integument smooth or rarely minutely granulate, covered with hairs or scales. Furcula absent (in our fauna) only in Anurophorus Entomobryidae Tömösváry, p. 39. Prothorax with dorsal bristles (fig. 1) ; never of a different texture from the terga of the other segments or covered by a projecting mesonotum. Integument granulate or tuberculate, never bearing scales. Furcula often absent.

Poduridae Lubbock, p. 7.

\section{FAMILY PODURIDAE LUBBOCK, 1870}

Body elongate. Abdomen distinctly segmented. Pronotum well developed, furnished with dorsal setae. Abdominal terga usually not imbricate and without well developed intersegmental membranes. Antennae not much longer than the head, usually thick and heavy. Anal horns often present. Mouthparts chewing or sucking. Postantennal organ present or absent, usually present and well developed. Spring present or absent. Integument granulate, often coarsely so.

Key to the Subfamilies of Poduridae

1. Mouthparts developed for chewing, mandibles with well developed grinding surface, or absent.

Mouthparts developed for piercing and sucking, the mandibles rather sharply pointed and without a well developed grinding surface.

Neanurinae Börner, p. 19.

2. Furcula well developed, reaching to the ventral tube. Dentes annulate toward the tip. Unguiculus and postantennal organ absent. Head hypognathous......Podurinae Börner, p. 8. 
Furcula never reaching to the ventral tube, or absent; the dentes never annulate. Unguiculus and postantennal organ usually present. Head prognathous........................... 3

3. Eyes usually present. Postantennal organ, when present, furnished with at the most 12 peripheral tubercles. Pseudocelli absent................................Achorutinae Börner, p. 8.

Eyes absent. Postantennal organ, when present, usually consisting of numerous tubercles in a transverse groove behind the antennal base. Pseudocelli present. Furcula absent or rudimentary in all known North American species

Onychiurinae Börner, p. 30.

\section{SUBFAMILY PODURINAE BÖRNER, 1906}

Mandibles for chewing, with well developed molar surfaces. Eyes 8 on each side. Postantennal organ absent. Spring well developed, reaching to the ventral tube; dentes strongly bowed out, and annulate toward the tip. Unguiculus absent. Head hypognathous.

GENUS PODURA (L.) TULLBERG (1758) 1871

Characters of the subfamily.

Podura aquatica L., 1758.

P. granulata MacGillivray, 1893.

Length up to $1.5 \mathrm{~mm}$. Red-brown to blue-black. Unguis long and slender. Mucrones trilamellate, granular.

Ames: June 10. Gilbert: June 18. Little Wall Lake: Oct. 14 -G. C. Decker. Mt. Pleasant: Feb. 24-H. R. Knight. Shellrock: Oct. $14-$ B. V. Travis.

Ill., Ind., Kans., Mass., Minn., Ohio, Tenn., Tex., Wash., Wis. Alaska, Ontario, Cosmopolitan.

This species, the only representative of the subfamily, is distinctive in the position of the head, the position of the eyespots on the upper part of the head, and the long furcula. It is often present in immense numbers on the surface of stagnant water.

\section{SUBFAMILY ACHORUTINAE BÖRNER, 1901}

Mouthparts for chewing, mandibles with molar surfaces [in Brachystomella Ågren, which lacks mandibles, the maxillae are heavy with numerous teeth, and resemble those found in other genera of the subfamily (fig. 31)]. Eyes present or absent. Postantennal organ present or absent. Spring rarely absent, never 
reaching the ventral tube, the dentes never annulate. Unguiculus present or absent. Pseudocelli absent. Head prognathous.

Key to the Genera of Achorutinae

1. Furcula and eyes absent. Willemia Börner, p. 17.

Furcula and eyes present .............................................. 2

2. Eyes usually 8 on each side. Postantennal organ present.... 3 Eyes 5 on each side. Postantennal organ absent. Unguiculus absent. Xenylla Tullberg, p. 15.

3. Postantennal organ consisting of a single tubercle. Unguiculus and anal horns absent....Beckerella Linnaniemi, p. 15.

Postantennal organ rosette-shaped, often with an independent lateral tubercle or "Nebenhöcker." Anal horns present or absent. Unguiculus rarely absent.

4. Mandibles present. Anal horns usually present.

Mandibles and anal horns absent

Achorutes Templeton, p. 9.

Brachystomella Ågren, p. 18.

GENUS ACHORUTES TEMPLETON, 1835

Hypogastrura Bourlet, 1839.

Eyes usually 8 on each side. Postantennal organ present, furnished with 4 to 7 tubercles and often a "Nebenhöcker." Furcula present. Unguiculus absent only in the subgenus Schöttella Schäffer. Anal horns present. The subgenera represented in our fauna may be keyed out as follows.

Unguiculus well developed. Achorutes s. str., p. 9. Unguiculus absent or rudimentary........Schöttella Schäffer, p. 13.

Key to the Species of Achorutes s. str.

1. Dentes dorsally with large, conical teeth …........................ 2

Dentes without large, conical teeth

2. Body with large, capitate, serrate setae

nothus Macnamara, p. 12.

Body without capitate, serrate setae (one pair of capitate hairs near the anal horns in $A$. harveyi $)$.......................... 3

3. Anal horns minute...........................nivicolus Fitch, p. 12.

Anal horns subequal to the hind unguis.

harveyi Folsom, p. 11.

4. Tenent hairs 2 or 3 on each tibiotarsus macgillivrayi Folsom, p. 13.

Tenent hairs 1 on each tibiotarsus

5. Body with stout capitate, serrate setae dorsally.

packardi Folsom, p. 13. 
Body without erect capitate and serrate hairs.

6. Mucro bluntly rounded, with a triangular external lamella.... armatus Nicolet, p. 10.

Mucro without a large triangular, external lamella 7

7. Mucro heavy and blunt, without a large dorsal lamella. packardi dentatus Folsom, p. 13.

Mucro elongate, with a large dorsal lamella

8. Tip of the mucro straight. Anal horns half the length of the hind unguis. copiosus Folsom, p. 11.

Tip of the mucro hooked. Anal horns a fourth the length of the hind unguis maturus Folsom, p. 10.

Achorutes armatus Nicolet, 1841

A. boletivorus Pack., 1873,

A. pratorum Pack., 1873,

A. marmoratus Pack., 1873.

Length up to $1.5 \mathrm{~mm}$. Color pattern extremely variable, from a dark blue to a canary yellow with various arrangements of spots and irregular stripes. Antennae shorter than the head, the segments as $5: 4: 5: 6$, an eversible sac between the 3rd and 4th segments. Postantennal organ of 4 tubercles. Eyes 8 on each side. Unguis slender, 1 inner tooth near the middle. Unguiculus (in typical form) extending as far as the tooth of the unguis, with an elongate basal lamella. Mucro half as long as the dentes, rounded apically, with a large, triangular, lateral lobe. Anal horns 2, longer than the hind unguis. Clothing abundant, of short curving setae and long serrate hairs.

Ames: April 2, 9-A. R. Rolfs, 10-E. D. Ball; May 7, 14. Central City : Mar. 23. Columbus Junction: Sept. 26. Hancock: Oct. 9-F. Andre. Iowa City: Oct. 4; LeGrand: Mar. 22, April 14, Aug. 4. Leon: Oct. 14, 31-B. V. Travis. Little Wall Lake: Oct. 14-G. C. Decker. Maquoketa Caves: May 8. Ottumwa : Sept. 9-F. Andre. Ruthven: Oct. 2-H. M. Harris and B. V. Travis. Shellrock: Oct. $14-$ B. V. Travis.

Ariz., Colo., Conn., Ill., La., Mass., Me., Minn., Mo., N. H., N. Y., Ohio, Pa., Tex., Wash. Alaska. Greenland. Ontario. Cosmopolitan.

Achorutes maturus Folsom, 1916

A. schötti Guthrie, 1903

Length up to $1 \mathrm{~mm}$. Dark blue to light tan; pigment broken by lighter spots. Antennae shorter than the head, with segments 
as $11: 14: 17: 26$. Postantennal organ of 4 tubercles and a large "Nebenhöcker." Eyes 8 on each side. Unguis heavy. Tenent hair 1, long and knobbed. Mucro to the dens as $2: 5$, the apex upturned, with an external lamella ending before the apex. Anal horns small, about a fourth the hind unguis, curving. Clothing of short setae.

Ames: Mar. 30; July 15-H. M. Harris and F. Andre; Sept. 25. Central City : July 25. Council Bluffs : Sept. 11. Hampton: June 18. Hancock: Sept. 9-F. Andre. Leon: Oct. 1-B. V. Travis. Maquoketa Caves: May 8. New Sharon: Sept. 19-F. Andre. Ruthven: Oct. 2-H. M. Harris and B. V. Travis.

Calif., Ind., Ill., Kans., Minn., Tex., Utah. Mexico.

\section{Achorutes copiosus Folsom, 1916}

A. schneideri Guthrie, 1903

Length up to $2.2 \mathrm{~mm}$. Deep blue-black. Antennae longer than the head, comparatively slender. Eyes 8 on each side. Unguis with an inner tooth beyond the middle. Unguiculus half the unguis, with a large basal lamella. Tenent hair 1, long. Anal horns half the hind unguis, on large, contiguous papillae. Mucro to the dentes as $2: 7$, with a large dorsal lamella; apex not upturned. Clothing of short, curving setae.

Ames: Feb. 22.

Minn. Ontario. Mexico.

\section{Achorutes harveyi Folsom, 1902}

Length up to $2.6 \mathrm{~mm}$. Deep blue-black. Antennae longer than the head, the segments as $10: 13: 13: 20$. Postantennal organ of 4 or 5 tubercles. Eyes 8 on each side. Unguis with a tooth beyond the middle. Unguiculus half the claw length, with an oblong basal lamella. Tenent hair 1 on each tibiotarsus. Anal horns subequal to the hind unguis. Dentes with 7 to 18 large pointed teeth dorsally. Mucro a fourth the length of the dens, the apex emarginate as in $A$. socialis. Clothing of simple setae, with 1 large, weakly knobbed hair just outside of each anal horn.

Ames: Jan. 16-H. M. Harris and F. Andre; Mar. 26. LeGrand : Oct. 27.

Conn., Mass., Me., Md., N. Y. Ontario. 


\section{Achorutes nivicolus Fitch, 1847}

\section{A. socialis Uzel, 1890}

Length up to $2 \mathrm{~mm}$. Deep blue-black. Antennae subequal to the head, segments as $7: 9: 10: 15$. Postantennal organ of 4 (rarely 5) tubercles and a "Nebenhöcker." Eyes 8 on each side. Unguis with an inner tooth a third from the apex. Unguiculus half the claw length, with a large inner basal lamella. Tenent hair 1. Anal horns minute, conical. Dentes dorsally with 4 to 7 large, pointed tubercles. Mucro a fourth the dens, the apex emarginate. Clothing of rather erect, simple setae.

In 1902, Dr. J. W. Folsom reviewed the "snow-flea complex," redescribing Fitch's Podura nivicola, and describing $A$. harveyi and $A$. packardi. The name nivicola was retained for the species fitting most closely the localities and collection dates recorded by Fitch. The types of the species were not known to exist at that time. In 1890 Uzel gave the first definite description of the species under the name $A$. socialis, and that name has been employed since. Dr. Folsom writes me (in lit., March 6, 1933) that the types of $P$. nivicola have been discovered in the United States National Museum, and have been studied by him. All of the 25 specimens are of the species which has been known as $A$. socialis, confirming his deduction of 1902. Fitch's name antedates Uzel's by 43 years, and will have to replace it.

Ames : Jan. 16.

Mass., Me., Mich., Minn., N. Y., Pa. Ontario. Cosmopolitan.

AchoRutes Nothus Macnamara, 1922

Length up to $1 \mathrm{~mm}$. Color deep granular blue, lighter ventrally and along the sutures. Antennae subequal to the head, the segments as $5: 15: 15: 22$. Postantennal organ of 4 tubercles. Eyes 8 on each side. Unguis with 1 inner tooth near the tip. Unguiculus half the unguis, with a broad basal lamella. Tenent hairs 1 on each tibiotarsus. Anal horns heavy, curving, a third the length of the hind claw. Dentes dorsally with 4 or 5 large conical tubercles. Mucro a fourth the dens and inserted subapically on its inner face, the apex emarginate. The body with long, capitate setae and shorter, curving, serrate ones.

Shellrock: Oct. $14-B$. V. Travis.

Ontario. 


\section{AChORUTES PACKaRd Folsom, 1902}

Length up to $2.5 \mathrm{~mm}$. Dark blue-black. Antennae shorter than the head. Postantennal organ with 4 peripheral tubercles. Eyes 8 on each side. Unguis heavy, untoothed. Unguiculus with a basal lamella. Tenent hair 1. Anal horns nearly as long as the hind unguis. Dentes with several dorsal setae, the basal one as long as the furcula. Mucro a fifth the dens. Body with heavy serrate setae, some short and curving, and a series of long, capitate, serrate hairs across each segment.

This is by far the most common cortical species of the genus in Iowa, and it is often found in large colonies.

Ames : Mar. 27-H. Hixson, 30-L. S. Jones; Apr. 9. Jewell : Apr. 9. Mt. Pleasant : Mar. 26-H. R. Knight. Ontario : May 3. Shellrock: Oct. $14-$ B. V. Travis.

Ill., Mass., Me., Md., N. Y., Ohio, Pa. Ontario.

ACHORUtes PaCKardi dentatus Folsom, 1902

Unguis unidentate. Erect body setae knobbed only at the apex of the abdomen, and then indistinctly. Mucro slightly longer than in $A$. packardi, f. p. Otherwise as in the typical form.

Ames: Oct. 20-F. Andre.

Mass., Me., N. Y., Ohio.

Achorutes macGillivrayi Folsom, 1916

Length up to $1.6 \mathrm{~mm}$. Dark to pale mottled blue above, lighter beneath. Postantennal organ of 4 or 5 tubercles. Antennae longer than the head, the segments as $7: 8: 9: 20$. Eyes 8 on each side. Unguis unidentate toward the apex. Unguiculus more than half the unguis in length, with a round basal lamella. Tenent hairs 3 on each tibiotarsus, sometimes 2 on the front legs. Mucrones a fourth the length of the dentes, rather bluntly triangular. Anal horns a fourth the hind unguis, blunt. Clothing of sparse, short setae, longer on the apex of the abdomen.

Central City: July 25. Maquoketa: May 8. Mt. Pleasant: Mar. 15, Apr. 2-H. R. Knight.

Ill., N. Y., Pa. Ontario.

Key to the Species of Schöttella

Eyes 8 on each side glasgowi Folsom, p. 14. Eyes 6 on each side. minutissimus n. sp., p. 14. 
Achorutes (schöttella) glasgowi Folsom, 1916

Fig. 20

Length up to $1 \mathrm{~mm}$. Body deep blue, with lighter interspersed spots; venter, spring, and intersegmental sutures lighter. Postantennal organ about the size of an eye, with 4 peripheral lobes. Antennae subequal to the head, the 4th segment with 7 olfactory hairs. Eyes 8 on each side. Unguis untoothed; unguiculus represented by a small bristle. Tenent hairs 2 on each tibiotarsus. Anal horns minute. Dentes (fig. 20) with 4 or 5 dorsal setae. Mucro pointed and slender. Rami of tenaculum 3-toothed. Mandibles with molar surface as in Achorutes s. str. Clothing of stout, curving, feebly serrate setae.

Ames: Mar. 27-H. Hixson; June 3. Leon: Oct. 10-B. V. Travis.

Ill., N. Y., Tex.

Achorutes (schöttella) minutissimus n. sp.

Figs. 15-19

Length $0.55 \mathrm{~mm}$. Reddish brown to gray. Eyes (fig. 15) 6 on each side. Postantennal organ in a deep triangular groove, composed of 4 unequal tubercles. Antennae clavate, the 3rd and 4th segments fused; shorter than the head, segmnts $1: 2: 3$ and 4 as $13: 14: 32$. Fourth antennal segment with 5 or 6 olfactory hairs, and a small, retractile, apical sense club. Organ of the 3rd antennal segment with 2 small, nearly free sense clubs, and heavy ventro-lateral and dorso-lateral olfactory hairs. Unguis (fig. 18) long and slender, nearly straight, with a minute inner tooth near the middle. Unguiculus about a fourth the unguis, the distinct inner lamella reaching practically to the apex. Knobbed tenent hairs absent. Rami of tenaculum 4-toothed. Mucrones to dentes as $2: 5$, the apex hooked, a dorsal lamella ending before the apex. Dentes (fig. 19) with 5 to 7 dorsal setae. Anal horns absent. Clothing of rather long, curving setae, becoming more abundant but not greatly longer posteriorly. Integument coarsely tuberculate.

This species bears a superficial resemblance to the genus Brachystomella. It has, however, well developed mandibles of achorutine type. It seems to be a rare inhabitant of decaying, matted vegetation. It resembles Microgastrura duodecimoculata Stach (1922b), of Albania.

Ames: Mar. 28, leaf mould. Garden Grove: Oct. 10—B. V. Travis. 


\section{GENUS BECKERELLA LINNANIEMI, 1912}

Eyes 8 on each side. Postantennal organ composed of a single tubercle. Unguiculus and furcul present. Anal horns absent.

This genus has not been found in Iowa. It is possibly represented in North America by Achorutes tigrina Harvey.

GENUS $X E N Y L L A$ TULLBERG, 1869

Eyes 5 on each side. Postantennal organ absent. Anal horns 2. Unguiculus absent. Furcula present but reduced; mucro often fused with the dens.

Key to the Species of Xenylla

1. Mucro separated from the dens..............welchi Folsom, p. 15.

Mucro and dens confluent

2. Mucrodens with a rather broad subapical lamella.

grisea Axelson, p. 15.

Mucrodens with a long, slender dorsal lamella

maritima Tullberg, p. 16.

Xenylla welchi Folsom, 1916

X. subwelchi Denis, 1924

Fig. 22

Length up to $1 \mathrm{~mm}$. Blue to gray irregular pigment; legs, furcula, and venter lighter. Antennae shorter than the head, the 4th segment with a retractile knob and 4 heavy olfactory hairs inserted in irregular integumentary folds. Organ of the 3rd antennal segment with 2 rods behind a fold, and 2 blunt, curving setae, 1 on each side of the fold. Eyes 5 on each side. Unguis slender with 1 inner tooth. Unguiculus absent. Tenent hairs on the 3 pairs of legs 1,2,2. Mucro (fig. 22) well developed, slightly shorter than the dens, separated from it, the apex upturned with a large inner lamella. Anal horns minute. Clothing of sparse, short, backward curving setae.

Xenylla subwelchi Denis is placed as a synonym of $X$. welchi. It differs apparently only in the position of the mucronal lamella, which is given as external in $X$. subwelchi.

Ames: Apr. 3. Pleasant Valley: Sept. 25-H. D. Tate.

Calif., Ill., Kan., Md., N. Y., Pa. Costa Rica. Europe.

Xenylla arisea Axelson, 1900

$X$. gracilis Guthrie, 1903

Fig. 23

Length up to $0.9 \mathrm{~mm}$. Blue to olive, lighter beneath. Body slender and spindle-shaped. Antennae shorter than the head, the 
4th segment with a retractile end club and 4 heavy olfactory hairs. Organ of 3rd segment as in $X$. welchi, with a less pronounced fold. Eyes 5 on each side. Unguis with an inner tooth near the tip. Unguiculus absent. Tenent hairs 2,2,2. Mucro and dens (fig. 23) fused, with a broad, subapical lamella and two dorsal setae. Anal horns comparatively long, from a fourth to a third the hind unguis, on well developed, contiguous papillae. Body clothing of rather long setae.

I am informed by Prof. Guthrie that the peculiar hook of the apex of the mucrodens in his figure of $X$. gracilis (1903, Plate 11, fig. 15) is due to an error of the engraver.

This species occurs in colonies beneath bark, and occasionally in leaf mould. It is the most common species of Xenylla in the state.

Ames : Feb. 21; Mar. 26 ; Apr. 14. Anamosa : Aug. 1. Central City: Nov. 25. Columbus Junction: Sept. 26. Jefferson: Dec. 5-G. C. Decker. LeGrand: Apr. 14. Leon: Oct. 10-B. V. Travis. Mitchellville : Mar. 31.

Minn. Europe.

Xenylla maritima Tullberg, 1869

Fig. 21

Length up to $1 \mathrm{~mm}$. (1.8 $\mathrm{mm}$. after Linnaniemi). Irregularly gray-blue. Antennae shorter than the head, the 4th segment with a retractile knob and 4 olfactory hairs. Organ of the 3rd segment as in the preceding species, except that the integumentary fold, which encloses the 2 sense clubs, also includes the external blunt hair. Eyes 5 on each side. Unguis occasionally with a small inner tooth. Tenent hairs 1,2,2. Mucro and dens (fig. 21) ankylosed, with a long, slender, abruptly ending dorsal lamella, and 2 dorsal setae. Anal horns about a fourth of the hind unguis, on well developed papillae. Body hairs of medium length, straight or a little curving.

I have compared the Iowa form with New York specimens identified and sent to me by Mr. E. A. Maynard. From the New York material the Iowa species differs in having but 1 tenent hair on the anterior legs, more curving body hairs, slightly shorter anal horns, and a darker color.

Central City: Aug. 11.

Calif., N. Y. Ontario. Europe. 
GENUS WILLEMIA BöRNER, 1901

Eyes absent. Postantennal organ present. Anal horns present or absent. Unguiculus present. Furcula absent.

Key to the Species of Willemia

Postantennal organ of 4 tubercles. intermedia n. sp., p. 17.

Postantennal organ elliptical, with 8 to 12 tubercles.

similis n. sp., p. 17.

Willemia INTERMedia n. $\mathrm{sp}$.

Figs. 24, 25

Color white. Eyes absent. Antennae shorter than the head, the segments as $14: 12: 11: 15$, the 3rd and 4th segments nearly fused. The 4th segment with 2 olfactory hairs, 1 outer, and 1 inner dorsal, and a retractile knob. Organ of the 3rd segment (fig. 25) of 2 upcurving rods behind a fold, a blunt lateral hair on each side, and 3 guard setae. Postantennal organ (fig. 24) of 4 tubercles in a pit. Unguis untoothed, slightly curving. Unguiculus nearly half the unguis, acuminate, enlarged basally. Tenent hairs absent. Furcula absent. Anal horns present, including the papillae about half as long as the hind unguis. Body segments from the prothorax to the 6th abdominal segment, inclusive, as $8: 20: 19: 16: 14: 14: 17: 11: 9$. First 2 antennal segments each with a single row of hairs. Setae short and sparse on the head, irregular on the thorax; in 2 rows across each of the abdominal segments but the 4th and 6th, longer on the 5th and 6th. Several up-curving setae below the anal horns on the suranal lobe. Length $0.6 \mathrm{~mm}$.

This species differs from $W$. anophthalma Börner, its nearest relative, in its smaller size, shorter antennae, and in the shape of the organ of the 3rd antennal segment organ. In 3 examples studied critically I have been unable to see more than 2 olfactory hairs on the 4th antennal segment. In the form of $W$. anophthalma which has anal horns, there are also 5 or 6 postantennal organ tubercles.

A resident of moss and decaying vegetation.

Ames : July 15 ; Sept. 16-F. Andre; Sept. 26. Columbus Junction: Sept. 26. Hampton: June 19-G. C. Decker and B. V. Travis. Shellrock: Oct. $14-$ B. V. Travis.

Willemia similis $\mathrm{n}$. $\mathrm{sp}$.

Figs. 26, 27

Color white. Eyes absent. Antennae clavate, to the head as $4: 5$, the segments as $2: 3: 3: 3$, the 3rd and 4th segments nearly 
ankylosed. The 4th segment with 6 olfactory hairs, a simple, retractile knob, and a subapical papilla. Organ of the 3rd segment (fig. 27) with 2 rods curving toward each other and separated basally by a papilla-like fold, a blunt hair on each side, and 3 guard setae. Postantennal organ (fig. 26) elliptical, with 8 to 12 tubercles. Mandibles 2- or 3-toothed at the apex, with a median molar surface and a strong basal tooth. Unguis untoothed. Unguiculus about half the unguis, with an inner basal lamella. Tenent hairs absent, but 3 apical tibiotarsal bristles are longer than the rest and overhang the base of the claw. Furcula absent. Anal horns present, equal in height to their papillae, about a third the hind unguis. Integument finely granulate. Body hairs irregular on the nota, forming 2 transverse rows across the 1st 3 abdominal segments, becoming irregular and longer posteriorly. Length $0.84 \mathrm{~mm}$.

This species is also a resident of moss and leaf mould.

Ames: Mar. 28; Nov. 17. Bixby Ice Cave: May 8. Jefferson: Dec. 5-G. C. Decker. Leon: Oct. 31-B. V. Travis.

Kansas : Atchison : Nov. 27-C. J. Drake and H. M. Harris.

GENUS BRACHYSTOMELLA (ÅGREN) STACH, (1903) 1929

Chondachorutes Wahlgren, 1906

Eyes usually 8 on each side, rarely reduced in number. Postantennal organ 4 to 8 tubercles. Mandibles absent. Unguiculus absent. Furcula present. Anal horns absent.

Key to the Species of Brachystomella

Postantennal organ of 5 to 8 tubercles. Red-violet.

parvula Schäffer, p. 18.

Postantennal organ of 4 tubercles. Blue-gray....stachi, n. sp., p. 19.

Brachystomella Parvula (Schäffer), 1896

Figs. 28-30

Length up to $1 \mathrm{~mm}$. Irregularly red-violet, lighter at the segments, and with 2 irregular longitudinal dorsal stripes. Eyes (fig. 29) 8 on each side. Postantennal organ of 5 to 8 tubercles in a rosette. Mucrones (fig. 30) more than a third the dentes, triangular in outline. Unguis (fig. 28) rather broad, with 2 lateral teeth and one inner tooth. Tenent hairs, unguiculus, and anal horns absent.

Taken from leaf mould by means of a Berlese funnel.

Ames : Sept. 25. Jefferson: Dec. 5-G. C. Decker.

Oregon. Europe. Palestine. North Africa. 
Brachystomella stachi n. sp.

Figs. 31-35

Irregularly light blue, sometimes rusty-colored anteriorly, lighter along the sutures, and with 2 interrupted dorsal stripes. Eyes (fig. 33) 8 on each side. Postantennal organ of 4 tubercles, about twice the diameter of an eye. Antennae shorter than the head, the organ of the 3rd segment as in fig. 32; 4th segment with about 6 olfactory setae, and a simple, retractile end knob. Mandibles absent. Maxillae (fig. 31) with 7 or 8 teeth. Unguis (fig. 34) long and slender, slightly curving, with an inner tooth near the middle. Tenent hairs absent or represented by 1 weakly knobbed hair. Mucrones nearly half the dentes, elongate triangular. Dentes (fig. 35) tuberculate dorsally, with 6 dorsal setae. Sparse, short, curving setae on head and body, longer on the last 2 segments of the abdomen. Length $0.7 \mathrm{~mm}$.

I sent structural drawings of this species to Dr. Stach, who states that it is different from any known species of Brachystomella. I take pleasure in dedicating it to Dr. Stach.

Taken from leaf mould and moss with a Berlese funnel.

Ames: July 15-H. M. Harris and F. Andre.

Florida: Marianna : Feb.-A. C. VanHyning.

SUBFAMILY NEANURINAE BÖRNER, 1901

Mouthparts piercing and sucking, usually projecting in a cone beneath the head. Mandibles present or absent; when present, never with a grinding surface. Unguiculus usually absent. Postantennal organ present or absent. Furcula present or absent. Head prognathous.

Key to the Tribes of Neanurinae

Sixth abdominal segment small, rounded, never bilobed. Body without large segmental tubercles.

Pseudachorutini Börner, p. 19. Sixth abdominal segment comparatively large, strongly bilobed. Body with large dorsal segmental tubercles.

Neanurini Börner, p. 28.

TRIBE PSEUDACHORUTINI BORNER, 1906

Segmental tubercles absent. Furcula present or absent. Anal segment small, round, not bilobed.

Key to the Genera of Pseudachorutini

1. Furcula present .............................................................. 2

Furcula absent (see also Friesea pentacantha) .................... 5 
2. Eyes 8 on each side 3

Eyes 5 or 6 on each side .............................................. 4

3. Anal horns usually present, 3 or more. Furcula greatly reduced or absent. Postantennal organ absent. Mouthparts not produced into a cone. Friesea Dalla Torre, p. 20. Anal horns absent. Postantennal organs present (in all of our species). Furcula not large, but well developed. Mouthparts produced into a cone.

Pseudachorutes Tullberg, p. 22.

4. Mucrones with longitudinal lamellae. Unguiculus present. Anal horns well developed. Postantennal organ 3 lobed.... Xenyllodes Axelson, p. 26. Mucrones with obliquely transverse lamellae, forming 2 cuplike folds. Unguiculus absent. The 2 anal horns greatly reduced. Postantennal organ 4-lobed

Odontella Schäffer, p. 25.

5. Postantennal organ absent...............Paranura Axelson, p. 27.

Postantennal organ present 6

6. Mouthparts reduced, the maxillae lance-like, and without teeth. Micranurida Börner, p. 26. Maxillae not lance-like, bearing numerous teeth at the apex.... Anurida Laboulbène, p. 26.

GENUS FRIESEA (DALLA TORRE) DENIS, (1895) 1931b

Triaena Tullberg, 1871,

Polycanthella Schäffer, 1897.

Eyes 8 on each side. Furcula greatly reduced or absent. Postantennal organ absent. Unguiculus absent. Anal horns usually 3 , varying from none to 7 . Mouthparts not projecting in a pointed cone beneath the head.

Key to the Species of Friesea

1. Anal horns 5. Furcula absent........pentacantha n. sp., p. 20. Anal horns 3. Furcula present

2. Anal horns nearly straight. Furcula without a mucro

grandis $\mathrm{n}$. sp., p. 21. Anal horns curving. Mucro present....claviseta Axelson, p. 21.

Friesea pentacantha n. sp.

Figs. $43-46$

Yellow-gray with light blue dorsal pigment. Eyespots weakly pigmented. An enlarged, granular swelling in the region of the clypeus. Antennae to the head as 5:8. Apex with a retractile knob and 3 olfactory hairs, 2 lateral and 1 dorsal. Organ of the 
3rd segment with 2 minute sense rods and 2 enlarged hairs. Eyes 8 on each side. Postantennal organ absent. Mouthparts typical of the genus. Unguis (figs. 44, 45) broad, unarmed. Unguiculus absent. Tenent hairs absent. Furcula and tenaculum absent. Anal horns 5 (fig. 43), 4 in the anterior row and 1 posteriorly, on small papillae. Short hairs in 2 rows across each body segment, longer and more abundant posteriorly. Length $0.6 \mathrm{~mm}$.

This species resembles $F$. (Polycanthella) quinquespinosa Wahlgren (1900) of Greenland, from which it differs in the absence of a furcula, the number of eyes, size, etc. The specimens may be young. Taken in humus.

Shellrock : Oct. $14-$ B. V. Travis.

\section{Friesea grandis n. sp.}

Figs. 36-42

Body subcylindrical, slender, deep blue but for lighter areas along the sutures and at muscle insertions. Antennae shorter than the head, conical, the 3rd and 4th segments united. The 4 th segment with a retractile sense club and 2 enlarged olfactory hairs dorsally. The 3rd antennal segment with 2 curved rods behind a fold, and large ventro-lateral and dorso-lateral hairs. Eyes 8 on each side. Postantennal organ absent. Unguis (fig. 36 ) regularly curving, untoothed. Each tibiotarsus with 5 tenent hairs. Furcula (figs. 37, 41) composed of 2 papillae, each bearing 3 short setae. Mucro absent. Tenaculum nearly as large as the furcula, rami bidentate. Anal horns 3 (fig. 40) nearly straight. Body covered with short, curving setae and longer, straight hairs, some of which (fig. 42) are serrate. A pair of hairs on each side of the anal horns serrate and knobbed, indefinitely so in young individuals. Length $1.7 \mathrm{~mm}$.

Stach (1922) describes a variety of $F$. claviseta Ax. without a mucro as $F$. claviseta emucronata. The Iowa specimens are so distinct structurally from $F$. claviseta, that I would hesitate to identify them with Stach's variety.

The form is known only from the edge of shallow lakes where it was taken with Anurida tullbergi Schött and Proisotoma schötti D. T.

Little Wall Lake: Oct. 14-G. C. Decker. Ruthven: Oct. 2H. M. Harris and B. V. Travis.

Friesea claviseta Axelson, 1900

F. sublimis Macnamara, 1921

Length up to $0.8 \mathrm{~mm}$. Blue-gray. Antennae shorter than the 
head, 4th segment with 4 to 6 olfactory hairs and a retractile knob. Eyes 8 on each side. Postantennal organ absent. Unguis untoothed. Tenent hairs 5. Rami of the tenaculum 2-toothed. Mucro present, small, hooked. Anal horns 3, curving. Short hairs on the body, with longer knobbed ones posteriorly on the abdomen.

A not uncommon resident of decaying vegetation in the soil in wooded areas. Also occasionally taken beneath bark.

Ames: Jan. 25 ; Feb. 29 ; June 13-J. E. Guthrie; July 15H. M. Harris and F. Andre; Sept. 16-F. Andre. Hampton: June 18-G. C. Decker and B. V. Travis. Leon: Oct. 10-B. V. Travis.

Utah, Wash. Ontario. Europe.

\section{GENUS PSEUDACHORUTES TULLBERG, 1871}

Gnathocephalus MacGillivray, 1893

Eyes usually 8 on each side. Postantennal organ (in all our species) present. Unguiculus absent. Furcula present, with all parts well developed. Anal horns absent.

This genus is in need of revision. The species are numerous, variable, and many are poorly described.

Key to the Species of Pseudachorutes

1. Tenent hairs present

Tenent hairs absent

2. Tenent hairs with large, round, apical knob. Postantennal organ with 5 tubercles in a circle. Length $1 \mathrm{~mm}$.

corticolus Schäffer, p. 22.

Tenent hairs not with a strong round knob. Postantennal organ with 10 to 12 tubercles, oval. Length $3 \mathrm{~mm}$.

lunatus Folsom, p. 23.

3. Body set dorsally with heavy, blunt hairs 4

Body set dorsally with short curving setae

subcrassoides n. sp., p. 24.

4. Postantennal organ oval, with 19 to 28 tubercles. Retractile knob at apex of 4 th antennal segment absent.

saxatilis Macnamara, p. 24.

Postantennal organ round, with 12 to 15 tubercles. Retractile knob of 4th antennal segment present.

aureofasciatus Harvey, p. 23.

Pseudachorutes corticolus Schäffer

Figs. 47-50

Length $1 \mathrm{~mm}$. Slender, flat, body segments not greatly bulg- 
ing. Deep blue, lighter along the sutures. Buccal cone rather long. Mandibles obliquely truncate, weakly 2-toothed. Maxillae styliform. Antennae directed anteriorly, shorter than the head, the segments as $15: 18: 16: 23$; 4th segment (fig. 50) with a slender, subapical, trilobed, retractile knob, and 5 olfactory hairs. Sense organ of the 3rd segment with 2 strongly curving sense clubs and 2 blunt hairs. Eyes (fig. 49) 8 on each side. Postantennal organ circular, with 5 tubercles. Unguis (fig. 48) slightly curving, with an inner tooth near the apex. Unguiculus absent. Tenent hair long, slender, strongly knobbed. Mucro to dens (fig. 47) as $2: 5$, elongate, upturned, with a slender dorsal lamella ending before the apex. Dentes with 5 dorsal setae. Rami of tenaculum 3-toothed. Numerous knobbed hairs apically on the abdomen, appearing as far anteriorly as the 2nd segment.

My specimens differ from the description and figures of Linnaniemi (1912) in the postantennal organ, the knobbed hairs anteriorly on the abdomen, the shape of the retractile knob at the apex of the antenna, and the tooth near the tip of the unguis. Dr. Stach writes me that they resemble more closely specimens from Poland than those from Finland from which Linnaniemi drew up his description.

Taken from leaf mould.

Hancock : Oct. 9-F. Andre. Shellrock : Oct. 14-B. V. Travis. Traer : Nov. $5-$ H. M. Harris.

\section{Europe.}

\section{Pseudachorutes lunatus Folsom, 1916}

Length up to $3 \mathrm{~mm}$. Gray-blue, lighter below. Antennae shorter than the head. Eyes 8 on each side. Postantennal organ oval, with 10 to 12 tubercles. Unguis stout, with 1 inner tooth. Unguiculus tuberculate. A single tenent hair, often but weakly knobbed, on each tibiotarsus. Mucro a third of the dens, subcrescentic, with a pair of dorsal lamellae ending before the upturned tip. Clothing of short hairs, longer at the apex of the abdomen.

The Iowa material differs from the description of the species in that the tenent hair is reduced and not strongly clavate.

Ames : Sept. 4. Hampton: June 18-G. C. Decker and B. V. Travis.

Ill., Tex. Ontario.

Pseudachorutes aureofasciatus (Harvey), 1898

Length $1 \mathrm{~mm}$. (1.5 mm. after Folsom). Gray-blue, with or without the mesothorax and last 2 abdominal segments orange- 
yellow. Antennae shorter than the head, the 4th segment with a trilobed retractile knob and olfactory hairs. Eyes 8 on each side. Postantennal organ of 12 to 15 tubercles in a circle. Mouth cone extending well beyond the tip of the head. Unguis with 1 or 2 inner teeth. Unguiculus tuberculate. Tenent hairs absent. Mucro more than half the dens, spoon-shaped,, slightly curving distally, with a large dorsal lamella ending before the apex. Rami of the tenaculum 3-toothed. The 6th abdominal segment small, well separated from the 5th. Long blunt hairs on head and body, longer on the last 2 segments. Integument coarsely tuberculate, extremely so on the 6th abdominal segment and the dens, where they form large, conical teeth.

The single specimen taken in Iowa lacks the orange crossbands present in the Maine material.

Ottumwa: Nov. 28-F. Andre.

Me., N. Y.

Pseudachorutes saxatilis Macnamara, 1920

Figs. 51-55

Length up to $1.5 \mathrm{~mm}$. Irregularly blue, with lighter spots dorsally. Legs, furcula, and venter lighter. Body heavy and broad, the segments bulging. Antennae subequal to the head, the segments as $23: 28: 27: 35$ : 4th segment with 6 to 8 olfactory hairs, but no retractile end knob. Postantennal organ (fig. 51) elliptical, with 19 to 28 tubercles. Unguis (fig. 52) unidentate internally. Unguiculus tuberculate. Tenent hairs absent. Mucro (fig. 53) about a fourth the dens, with a large dorsal lamella ending before the apex. Body with short, curving hairs and long, blunt ones.

Taken in leaf mould.

Columbus Junction: Dec. 25-L. Weber. Eldora: Nov. 10. Hancock: Oct. 8-F. Andre. Jefferson: Dec. 5-G. C. Decker. Ottumwa: Sept. 9-F. Andre.

Pseudachorutes subcrassoides n. sp.

Figs. 56, 57

Length up to $1 \mathrm{~mm}$. Body with light gray speckled pigment; darker anteriorly. Under parts lighter. Antennae subequal to the head, 4th segment with a retractile 3-lobed knob, and several olfactory hairs. Postantennal organ (fig. 56) oval, with 8 to 10 tubercles. Mouth cone not strongly produced. Body not expanded, rather cylindrical. Unguis with a weak inner basal 
tooth. Unguiculus tuberculate. Tenent hairs absent. Dentes twice the mucro (fig. 57), which is crescentic, and bears a dorsal lamella ending before the apex. Body hairs sparse, short, curving, longer toward the apex. Several down-curving hairs dorsally on the 6th segment.

This species differs in several respects from $P$. subcrassus Tullberg, its closest relative, according to Dr. Stach.

Taken in leaf mould and beneath bark.

Ames : May 9. Jefferson: Dec. 5-G. C. Decker. New Sharon: Sept. 19-F. Andre.

\section{GENUS ODONTELLA SOHÄFFER, 1897}

Eyes 5 on each side. Postantennal organ of 4 (5) lobes, situated in a deep groove. Antennae short and conical. Unguiculus absent. Furcula present, the mucro long, with 2 dorsal, pocketlike lobes. Anal horns usually represented by enlarged cuticular tubercles, 2 in number. Integumentary tubercles very large and coarse.

\section{ODONTELLA CORNIFER, n. sp.}

Figs. 58-61

Color pale speckled blue, lighter beneath, the eyespots dark. Antennae shorter than the head, as $11: 19$, the segments as $16: 16: 17: 18$; organ of the 3rd segment (fig. 59) with 2 clavate rods behind a fold; a heavy, blunt, curving hair on each side; and 2 guard setae. Mouth cone (fig. 60) well developed, reaching to the 3rd antennal segment in specimens expanded in lactic acid. Eyes 5 on each side. Postantennal organ with 4 lobes, in a deep pit. Body somewhat spindle-shaped, the segments from the head to the 6th abdominal segment, inclusive, as $25: 8: 13: 12: 10: 10: 9$ : $11: 8: 7$. Unguis (fig. 61) slender, with a basal inner tooth and lateral teeth. Unguiculus absent. Claw overhung by 2 slender, non-capitate hairs. Dentes with 5 dorsal setae. Mucrones subequal to the dentes, or slightly longer, the apex blunt, dorsally with 2 lamellate, obliquely placed cups. Rami of the tenaculum 3 -toothed. Integument coarsely tuberculate, more so on the 6th segment, which bears 2 distinct anal horns (fig. 58) on the large papillae. Body covering sparse, longer on the 5th and 6th segments. Length $0.9 \mathrm{~mm}$.

Taken from decaying ground cover.

Ames: Apr. 9-R. Roudabush. Columbus Junction: Sept. 26. 
GENUS XENYLLODES AXELSON, 1903

Eyes 5 on each side. Postantennal organ trilobed. Unguiculus present. Furcula well developed. Anal horns 2.

This genus has not as yet been found in our territory.

\section{GENUS ANURIDA LABOULBÈNE, 1865 Aphoromma MacGillivray, 1893, Anuridella Willem, 1896.}

Eyes 10 or none. Postantennal organ present. Maxilla head bearing 3 toothed lamellae. Unguiculus, anal horns, and furcula absent.

Key to the Species of Anurida

Color blue. Eyes 5 on each side. Postantennal organ elliptical, of 17 to 30 tubercles tullbergi Schött, p. 26.

Color white. Eyes absent. Postantennal organ of 12 to 21 tubercles in a rosette.............................. granaria Nicolet, p. 26.

ANURIDa tullbergi Schött, 1891

Figs. 62, 63

Length up to $3 \mathrm{~mm}$. Blue to blue-black, lighter beneath. The 4th antennal segment with 5 olfactory hairs and a retractile 3lobed knob. Postantennal organ (fig. 63) with 17 to 30 tubercles, elliptical. Unguis (fig. 62) unidentate inwardly.

This species is a littoral form.

Ruthven: Oct. 2-H. M. Harris and B. V. Travis.

Fla., Minn., N. Y. Ontario. Europe.

Anurida Granaria (Nicolet), 1847

Length up to $1.8 \mathrm{~mm}$. Pure white. Eyes absent. Postantennal organ with 12 to 21 tubercles in a rosette. The 4th antennal segment with 8 olfactory hairs and an apical 3-lobed knob. Unguis without teeth.

Bixby Ice Cave: May 8. Shellrock: Oct. 14-B. V. Travis.

Ill., Mass., Minn. Throughout the northern hemisphere.

GENUS MICRANURIDA BöRNER, 1901

Eyes present or absent. Postantennal organ present, with 6 to 22 tubercles. Unguiculus and anal horns absent. Furcula absent or represented by a tubercle. Maxilla head simple, stilettolike.

Key to the Species of Micranurida

Eyes 2 on each side. Furcula absent........pygmaea Börner, p. 27. Eyes absent. Furcula represented by a tubercle. 


\section{MicRANURIda Pygamaea Börner, 1901}

Figs. 64, 65

Length up to $0.8 \mathrm{~mm}$. White to blue-gray. Antennae shorter than the head, 3rd segment with 2 capitate sense rods and 2 blunt hairs, 4th segment (fig. 64) with 5 swollen obconical olfactory hairs, and a 3-lobed retractile knob. Postantennal organ (fig. 65) with 6 to 8 tubercles in a circle. Eyes 2 on each side. Unguis unarmed. Unguiculus and tenent hairs absent.

Taken from decaying vegetation with a Berlese funnel.

Ames: Apr. 27. Leon: Oct. 10-B. V. Travis. Ruthven: Oct. 2-H. M. Harris and B. V. Travis. Traer: Nov. 5-H. M. Harris.

Calif. Europe.

\section{MiCRANURIDA FURCIFERA $n$. $s p$.}

Figs. 1, 66-69

Entirely white. Eyes absent. Postantennal organ (fig. 67) with 8 to 11 tubercles in an ellipse. Antennae shorter than the head, the segments as $13: 11: 8.5: 10$, the $3 \mathrm{rd}$ and 4th segments (fig. 66) weakly separated; organ of 3rd segment with 2 sense clubs and 2 large, elongate sense hairs, 4th segment with 6 curving olfactory hairs; retractile end knob of the 4th segment not evident but occasionally a structure which appears to be a thin-walled, eversible, lobed sac may be seen in its place. Mandibles and maxillae long and slender. Unguis (fig. 68) falcate, unarmed. Unguiculus and tenent hairs absent. Furcula represented by a biscuit-shaped tubercle (fig. 69) bearing 6 setae. Abdominal segments with 2 transverse rows of setae, the anterior short and curved, the posterior long and straight. Length $0.7 \mathrm{~mm}$.

Taken from moss and leaf mould.

Ames: Aug. 28. Hampton: June 18-G. C. Decker and B. V. Travis. Ottumwa: Sept. 9-F. Andre.

GENUS PARANDRA AXELSON, 1902

Eyes present or absent. Postantennal organ absent. Unguiculus, furcula, and anal horns absent. Maxilla head slender, pointed, without lamellae.

Key to the Species of Paranura

Eyes absent caeca Folsom, p. 27. Eyes 3 on each side.............................sexpunctata Axelson, p. 28.

Paranura caeca Folsom, 1916

Length up to $2.5 \mathrm{~mm}$. White or light yellow. Antennae shorter than the head, with 9 or 10 olfactory hairs, including 1 extremely 
large one. Eyes absent. Unguis unarmed. Unguiculus tuberculate. Tenent hairs absent. Body covering of long, slender, simple setae.

Taken from leaf mould.

Columbus Junction: Sept. 26.

Ill.

\section{Paranura sexpunctata colorata n. var.}

Fig. 74

Length up to $1 \mathrm{~mm}$. Color white with light blue, granular pigment. Eyes (fig. 74) 3 on each side, 2 anterior and 1 posterior. Antennae conical, 4th segment with 6 or 7 olfactory hairs, organ of 3rd segment with 2 sense rods and 2 long blunt hairs. Mouth cone short and heavy. Unguis unarmed. Unguiculus tuberculate. Several slender, unknobbed hairs overhang the unguis. Integument with large, pointed granules. Body covering of rather long, straight hairs.

This species is a rather uncommon member of the humus fauna. The European forms of this species are white. All the Iowa specimens show the blue coloration, however, and, according to Dr. Stach, the body hairs are considerably longer than in the principal form.

Ames : Mar. 28 ; Sept. 18-F. Andre. Eldora : Nov. 10. Columbus Junction: Sept. 26. Ruthven: Oct. 2-H. M. Harris and B. V. Travis.

Ontario?

TRIBE NEANURINI BÖRNER, 1901

Segmental tubercles (large integumentary humps) present. Furcula absent. Anal segment large, bilobed.

Key to the Genera of Neanurini

1. Maxilla head lance-like, without teeth or lamellae.

Neanura MacGillivray, p. 29.

Maxilla head with both teeth and lamellae. 2

2. The 6 th abdominal segment hidden dorsally by the 5 th, which extends back over it Morulina Börner, p. 29. The 6th abdominal segment visible from above

Protanura Börner, p. 28.

GENUS PROTANURA BöRNER, 1906

Segmental tubercles present. Eyes present. Unguiculus, furcula and anal horns absent. Maxilla head with a toothed lamella.

This genus is not known from the United States. 
GENUS MORULINA BÖRNER, 1906

The 6 th segment practically hidden by the 5 th. Very broad and heavy. Otherwise as the preceding genus.

M. gigantea Tullberg is known in the United States only along the Pacific coast. The genus is not known in Iowa.

\section{GENUS NEANURA MACGILLIVRAY, 1893}

Achorutes of recent European Authors.

Segmental tubercles present. Eyes usually present. Postantennal organ present or absent. Unguiculus, furcula, and anal horns absent. Maxilla head slender, without teeth or lamellae.

Key to the Species of Neanura

1. White. Eyes 2 on each side.............barberi Handschin, p. 29.

Blue to brown. Eyes 3 on each side.

2. Anterior eyes placed mesad to the others, and against the ocular tubercle.......................muscorum Templeton, p. 29.

Anterior eye placed laterad to the others, and away from the ocular tubercle. persimilis n. sp. p. 30 .

Neanura Barberi Handschin, 1928

N. quadrioculata Guthrie, 1903

Length up to $1.8 \mathrm{~mm}$. White. Eyes 2 on each side. Postantennal organ absent. Antennae shorter than the head, the 4th segment with 8 olfactory hairs including a "giant hair." Unguis without teeth. Unguiculus absent. Head with 10 tubercles, prothorax with 4 , mesothorax to 4th abdominal segment with 6 each, 5th with 4 , and 6th with 2.

Taken from humus.

Leon : May 20-B. V. Travis; Oct. 10-B. V. Travis.

Md., Minn., N. Y., Tex., Va. Mexico.

Neanura muscorum (Templeton), 1835

Anoura gibbosa Packard, 1873,

Anoura sextuberculata Harvey, 1896.

Length up to $2 \mathrm{~mm}$. Gray to deep blue, lighter beneath. Eyes 3 on each side, against the ocular tubercle. Postantennal organ absent. Antennae conical, shorter than the head. Tuberculation as follows: head 12, prothorax 6 , mesothorax to 4 th abdominal segment with 8 each, 5 th segment 4 , 6 th segment 2 ; the segments reticulate. Unguis untoothed, unguiculus absent.

A common cortical species, taken also in humus.

Algona: Apr. 16-E. L. Mills. Ames: Mar. 29; Apr. 2, 7, 9, 26 ; May 7, 24; June 10; July 13, 15-H. M. Harris and F. 
Andre; Sept. 4 ; Oct. 20. Eldora : Nov. 14. Leon : Oct. 14-B. V. Travis. Ontario: May 3. Shellrock: Oct. 14-B. V. Travis. Tabor: Sept. 15.

Conn., Ill., La., Mass., Minn., Me., N. H., N. Y., Ohio, Pa. Ontario. Europe.

\section{NeANURA PERSIMILIS, n. sp.}

Fig. 70

Blue-gray, through buff to brown. Lighter beneath. Antennae conical, shorter than the head, the segments as $13: 15: 13: 11$, the 3rd and 4th segments nearly fused. Organ of the 3rd segment with 2 bent sense rods and 2 blunt hairs; 4th segment with 9 olfactory hairs and an apical 3 -lobed knob. Eyes 3 on each side (fig. 70), the 2 posterior ones against the ocular tubercle and the anterior one laterad, away from the tubercle. Postantennal organ absent. Buccal cone well developed. Segmental tubercles not or indistinctly reticulate, arrangement as follows: head with 12 , 3 on each side, 2 dorsal ocular, and 4 in a posterior row; pronotum with 6 , mesonotum to 4th abdominal segment, inclusive, with 8 each; 5 th with 4 ; 6th with 2 . The most evident tubercles are those of the 5th and 6th segments, the 2 external tubercles on each side of the 4th, and the lateral tubercles on each side of the other segments. The dorsal ones are greatly reduced. Unguis heavy, unarmed. Unguiculus absent. Tenent hairs absent. Large hairs of the body pointed and minutely serrate. Length $3.5 \mathrm{~mm}$.

The species closely resembles $N$. muscorum, from which it differs in the position of the eyes, the absence of the large middorsal tubercle on the head, and the absence or near-absence of reticulation on the segmental tubercles. I have taken it in the same situation with the preceding species.

Ames: May 3-H. Hixson; Oct. 3, 17. Columbus Junction : Sept. 25. LeGrand: Apr. 14. Leon: Oct. 31-B. V. Travis.

Texas: Waco: Aug. 7.

\section{SUBFAMILY ONYCHIURINAE BÖRNER, 1901}

Eyes absent. Postantennal organ absent only in Tetrodontophora, usually large and placed in a transverse groove behind the antennal bases. Pseudocelli present. Organ of 3rd antennal segment complex, composed of guard setae, papillae, sense rods, and large sense clubs. Furcula usually absent. Anal horns present or absent. Mandibles with a molar surface. 
Key to the Genera of Onychiurinae

1. Furcula well developed, with manubrium, dentes and mucrones. Postantennal organ absent. Large, 5 to $9 \mathrm{~mm}$. long. Tetrodontophora Reuter, p. 31. Furcula absent or at the most a cuticular fold or tubercle, which may be divided. Postantennal organ well developed. Usually less than $5 \mathrm{~mm}$. in length.

2. The 2 smooth sense clubs of the 3rd antennal segment organ bending toward each other. An accessory club ventrolaterally on the 3rd segment. Body very slender. Furcula absent. Tullbergia Lubbock, p. 36. The 2 large sense clubs of the 3rd antennal segment organ never bending toward each other. No ventro-lateral club on the 3rd segment. Body not markedly slender. Furcula absent or vestigial

3. Pseudocelli with definite chitinous borders. Integument finely granulate. Rudimentary furcula, when present, not bearing branched hairs.................... Onychiurus Gervais, p. 31. Pseudocelli without definite chitinous borders. Integument coarsely granulate. Furcula present, bearing branched bristles Kalaphorura Absolon, p. 35.

GENUS TETRODONTOPHORA REUTER, 1882

Furcula well developed. Postantennal organ absent. Sense organ of the 3rd antennal segment with 14 or 15 papillae. Very large.

This European cavernicolous genus has not been recorded from North America.

GENUS ONYCHIURUS GERVAIS, 1841

Lipura Burmeister, 1838,

Aphorura MacGillivray, 1893.

Postantennal organ present, usually multi-tuberculate. Sense clubs of the 3rd antennal segment organ straight or slightly bent, never bending toward each other; papillae usually 4 or 5 . Head and body rather broad. Anal horns present or absent. Pseudocelli with external chitinous ring. Rudimentary furcula, when present, without branched hairs.

Key to the Species of Onychiurus

1. Vestige of a furcula ventrally on the 4th abdominal segment 2

Vestige of furcula absent 3 
2. Furcula represented by an integumentary fold. Tenaculum absent. Tubercles of the postantennal organ at right angles to the long axis of the organ..........armatus Tullberg, p. 32.

Furcula represented by 2 large tubercles. Tenaculum represented by 2 small warts. Tubercles of the postantennal organ small and irregularly placed......obesus n. sp. p. 35 .

3. Tubercles of the postantennal organ compound (fig. 75) .... 6 Tubercles of the postantennal organ simple (figs. 71, 76).. 4

4. Tubercles of the postantennal organ 8 to 14 , more or less parallel to the long axis of the organ (fig. 76). No pseudocelli on the pronotum...................

Tubercles of the postantennal organ 14 to 25 , more or less at right angles to the long axis (fig. 71). Pronotum with 2 pseudocelli on each side

5. Postantennal organ with 14 to 22 tubercles. Unguiculus about half the unguis. Anal horns about half the hind unguis. Length $0.9 \mathrm{~mm}$............................parvicornis n. sp., p. 33 .

Postantennal organ of about 25 tubercles. Unguiculus extending nearly to the tip of the unguis. Anal horns slightly shorter than the hind unguis. Length $1.3 \mathrm{~mm}$.

encarpatus Denis, p. 32.

6. Anal horns absent.................pseudofimetarius Folsom, p. 34. Anal horns present..............................ramosus Folsom, p. 34.

ONYchiurus armatus (Tullberg), 1869

Length up to $1.8 \mathrm{~mm}$. White. Postantennal organ with 18 to 44 simple tubercles. Antennae subequal to the head; sense organ of the 3rd segment with 5 guard setae, 5 papillae, 2 sense rods, and 2 tuberculate sense clubs. Dorsal pseudocelli on each side as follows : antennal bases 3 , 4th segment 4 (1 lateral), and 5th segment 3. Unguis rarely with 1 inner tooth. Unguiculus gradually tapering, subequal to the unguis. Furcula represented by a cuticular fold. Anal horns nearly as long as the hind unguis.

This species is occasionally taken both in humus and beneath bark, as are most of the species of the genus found in the state.

Ames : Mar. 29 ; Apr. 2, 9 ; June 28 ; July 13 ; Oct. 25. LeGrand : Apr. 14; Aug. 18. Ottumwa: Sept. 16-Zella Beck. Ruthven: Oct. 2-H. M. Harris and B. V. Travis. Tabor: Sept. 15.

Calif., Ill., La., Me., Md., N. Y., Ohio, Utah. Europe.

\section{Onychiurus encarpatus Denis, 1931}

Length up to $1.3 \mathrm{~mm}$. Postantennal organ with about 25 simple tubercles. Antennae subequal to the head; organ of the 
3rd segment with 5 guard setae, 5 papillae, 2 rods, and 2 leaning, granular clubs. The 4th segment with a subapical pit. Abdomen rather dilated and flat. Pseudocelli on each side as follows: antennal base 3, back of head 2, prothorax 2, mesothorax to the 5th abdominal segment 3 each. Unguis unarmed. Unguiculus narrow basally, subequal to the unguis. Anal horns slightly shorter than the hind unguis. Suranal lobe divided into 6 more or less definite smaller lobes.

Ames : Sept. 25 ; Oct. 20. Columbus Junction : Sept. 26. Leon : May 28; Oct. 10-B. V. Travis. Hancock: Oct. 8-F. Andre.

Costa Rica.

\section{ONYChIURUS PARVICORNIS n. sp.}

Figs. 71-73

White. Postantennal organ (fig. 71) with 14 to 22 simple tubercles, placed at right angles to its long axis. Antennae shorter than the head; organ of the 3rd segment with 5 guard setae, 5 papillae, 2 rods, and 2 nearly spherical, smooth sense clubs; 4th segment with 8 to 10 olfactory hairs and a subapical sense pit. Abdomen bluntly rounded apically. Pseudocelli on each side as follows : antennal bases 3 , back of head 2, prothorax 2 , mesothorax to 5 th abdominal segment 3 each. Unguis (fig. 72) rather broad and heavy, unarmed. Unguiculus about half the unguis, with a broad basal lamella and an acuminate apex. Anal horns 2 (fig. 73), slightly curving, to the hind unguis as $5: 11$; papillae greatly reduced, flat, non-contiguous. Body covering sparse, short. Length up to $0.9 \mathrm{~mm}$.

Taken from humus with a Berlese funnel This species approaches closely the armatus form of $O$. zschokkei Handschin. It differs as follows:

\section{O. zschokkei armatus}

End club on the 4 th antennal segment.

Tubercles of the postantennal organ 20 to 28 .

Pronotal pseudocelli absent.

No basal lamella on the unguiculus.

Unguis slender.

Anal horns rudimentary.

\section{O. parvicornis}

Subapical pit on the 4th antennal segment.

Tubercles of the postantennal organ 14 to 22 .

Pronotal pseudocelli 2.

Unguiculus with basal lamella.

Unguis broad.

Anal horns to hind unguis as $5: 11$. 
Ames: Apr. 27 ; Sept. 26. Eldora: Nov. 10. Hampton: June 18--G. C. Decker and B. V. Travis. Leon: May 28; Oct. 10-B. V. Travis. Ottumwa: Sept. 9-F. Andre. Ruthven: Oct. 2H. M. Harris and B. V. Travis. Woodbury Co. : Sept. 28-G. C. Decker.

\section{ONychiurus subtenuis Folsom, 1917}

\section{Fig. 76}

Length up to $2 \mathrm{~mm}$. White. Rather slender. Postantennal organ (fig. 76) of 8 to 14 elongate tubercles. Antennae shorter than the head; organ of the 3rd segment with 5 guard setae, 5 papillae, 2 rods, and 2 tuberculate clubs. Dorsal pseudocelli on each side as follows: Antennal base 2 (3), mesothorax to 2nd abdominal segment 1 each, 4 th segment 2, 5th segment 3 (4). Unguis unidentate inwardly. Unguiculus with a basal lamella, more than half the unguis. Anal horns half the hind unguis.

Algona: Apr. 16-E. L. Mills. Ames: Feb. 21, 23; Apr. 15; July 15-H. M. Harris and F. Andre. Columbus Junction : Sept. 26. Eldora: Nov. 10. Hampton: June 18-G. C. Decker and B. V. Travis. Leon: Oct. 10-B. V. Travis. Ottumwa : Sept. 9-F. Andre, 16-Zella Beck.

Ill., Mo., N. Y., Pa., Utah. Ontario.

\section{Onychiurus ramosus Folsom, 1917}

\section{Fig. 75}

Length up to $1.3 \mathrm{~mm}$. White. Postantennal organ (fig. 75) of 10 to 13 compound tubercles. Antennae shorter than the head; sense organ of the 3rd segment with 3 guard setae, 4 papillae, 2 rods, and 2 tuberculate clubs. Dorsal pseudocelli on each side as follows : behind antennal base 2, mesothorax to 1st abdominal segment 1 each, 4th and 5th abdominal segments with 2 each. Unguis unarmed. Unguiculus half the unguis. Anal horns half the unguis.

Algona: Apr. 16-E. L. Mills. Ames: Feb. 21, 23; Apr. 15; July 15-H. M. Harris and F. Andre. Columbus Junction : Sept. 26. Eldora: Nov. 10. Hampton: June 18-G. C. Decker and B. V. Travis.

Ill. Ontario.

ONychiURUS PSEUdofimetarius Folsom, 1917

Length up to $1.5 \mathrm{~mm}$. White. Postantennal organ with about 16 compound tubercles. Antennae shorter than the head; organ of the 3rd segment with 5 guard setae, 5 papillae, 2 rods, and 2 
smooth oblique clubs. Dorsal pseudocelli on each side as follows : Antennal base 2, behind the antennal base 1, back of head 3, mesothorax to 5th abdominal segment with 3 each. Unguis unarmed. Unguiculus half the unguis, with a basal lamella. Anal horns absent.

Ames: Apr. 2. Leon: May 28-B. V. Travis. Ottumwa: Sept. 9-F. Andre. Shellrock: Oct. $14-B$. V. Travis.

Ill., Minn. Europe.

\section{ONYCHIURUS OBESUS n. sp.}

Figs. 2, 77-81

Yellowish-white. Postantennal organ (fig. 77) with 40 to 50 irregular tubercles. Antennae to the head as 4:5, the segments as $5: 7: 6: 10$. Organ of the 3 rd segment with 4 or 5 guard setae, 4 or 5 papillae, 2 rods, and 2 smooth, oblique, subreniform sense clubs, the 4th segment with numerous olfactory hairs and a subapical pit which is overhung by 3 heavy, short, blunt sense clubs. Body broad and heavy (fig. 2). Pseudocelli small, on each side as follows : Behind the antennal base 3 , mesonotum 1 , metanotum 1 or 0,4 th abdominal segment 2 , 5th segment 3 . Furcula and tenaculum present (fig. 81), each lobe of the furcula bearing 3 setae. Unguis (fig. 80) moderately slender, unarmed. Unguiculus with a broad, elongate basal lamella, and a slender tip reaching to the apex of the unguis. Anal horns 2 (figs. 78, 79) to the hind unguis as $9: 34$, usually obliquely truncate, sometimes pointed. Integument coarsely granulate, the interspaces obscurely reticulate. Clothing of sparse, short, spinelike setae. Length $1.3 \mathrm{~mm}$.

A very distinct species in the shape of the postantennal organ. I have been unable to discern large compound tubercles as in the ramosus and fimetarius groups, the organ seeming to be a single mass of small tubercles as in some of the species of Tullbergia. The Maquoketa specimens differ from the Bixby Ice Cave material in the presence of pointed anal horns, and in the absence of the metathoracic pseudocelli. They may represent a distinct variety. The species is at least partially cavernicolous in its habits.

Bixby Ice Cave: May 8. Maquoketa: May 8. GENUS KALAPHORURA ABSOLON, 1901

Postantennal organ present. Organ of the 3rd antennal segment as in Onychiurus. Anal horns 2. Pseudocelli without ex- 
ternal chitin rings. Rudimentary furcula present, bearing branched hairs.

This genus has not been recorded from North America.

GENUS TULLBERGIA LUBBOCK, 1871

Stenaphorura Absolon, 1900,

Mesaphorura Börner, 1901,

Börneria Willem, 1902.

Postantennal organ present, large. Sense clubs of the 3rd antennal segment organ bending toward each other, papillae present or absent; an accessory sense club ventro-laterally on the same segment. Anal horns 2 to 6 . Head and body extremely slender.

Key to the Species of Tullbergia

1. Pronotum with pseudocelli. Postantennal organ with about 75 tubercles in 4 irregular rows...........collis, Bacon, p. 36.

Protonum without pseudocelli. Tubercles of the postantennal organ in 2 rows (rarely a partial 3rd)

2. The 5th abdominal segment with 2 heavy, spinelike processes posteriorly. Anal horns less than the hind unguis

iowensis Mills, p. 37.

None of the hairs on the posterior margin of the 5th abdominal segment enlarged and spinelike. Anal horns subequal to or longer than the hind unguis

3. Pseudocelli present from the mesothorax to the 5th abdominal segment, inclusive. Dorsum of the 6th abdominal segment with irregular transverse rows of large tubercles.

granulata, n. sp., p. 37.

Pseudocelli absent from the mesothorax, 1st, 3rd, and 6th abdominal segments. Granulation of the dorsum of the 6th abdominal segment not greatly different from that on the rest of the body. clavata, n. sp., p. 38 .

Tullbergia collis Bacon, 1914

Length up to $1.5 \mathrm{~mm}$. White. Postantennal organ with about 75 tubercles in 4 rows. Antennae shorter than the head, the 4th segment with about 8 olfactory hairs and an apical club. Organ of the 3rd segment with 4 guard setae, an inner curving club, and 2 smooth clubs which converge apically and which overhang 2 sense rods behind a basal fold. A large ventro-lateral club is present on the same segment. Pseudocelli on each side as follows : antennal base 1, base of head 1, protonum to 5th abdominal 
segment 1 each. Unguis unarmed, unguiculus spine-like. Anal horns 2, subequal to the hind unguis.

$T$. collis has been known heretofore only from the western part of the country. It was taken from humus with a Berlese funnel. Leon : May 28-B. V. Travis. Shellrock: Oct. 14-B. V. Travis. Calif., Wash. Mexico.

Tullbergia iowensis Mills, 1932

Length up to $0.6 \mathrm{~mm}$. White. Very slender. Postantennal organ broad, with 30 to 40 tubercles in 2 rows. Antennae shorter than the head, the 4th segment with about 5 olfactory hairs and a subapical sense pit. Organ of the 3rd segment with 2 converging sense clubs between which are 2 sense rods which are practically hidden behind an integumentary fold: a ventro-lateral sense club present on the same segment. Rosette-like pseudocelli present on each side as follows : antennal base 1, base of head 1 , mesothorax, 1st, 4th and 5th abdominal segments 1 each. Unguis unarmed, unguiculus tuberculate. The 6th abdominal segment with 2 dorsal semicircular ridges, with their bases against the 5 th segment. The 5th segment with 2 heavy spines posteriorly which overhang the pseudocelli of that segment and are directly anterior to the folds of the 6th segment. Anal horns 2, shorter than the hind unguis, on nearly contiguous papillae.

I have redescribed this species because of the rather incomplete and in some respects inaccurate original description. Since its description I have been able to examine a large series of specimens from various parts of the state. It approaches the European T. krausbaueri Börner. I have submitted specimens to Dr. Jan Stach, who states that it is not T. krausbaueri, but another species, which he has known for some time in Poland.

Taken in moss and humus.

Algona : Apr. 16-E. L. Mills. Ames : July 15-H. M. Harris and F. Andre; Aug. 28. Columbus Junction: Sept. 26. Hampton: June 18-G. C. Decker and B. V. Travis. Leon : May 28-B. V. Travis; Oct. 10-B. V. Travis. Rock Rapids: Aug. 16E. L. Mills. Ruthven: Oct. 2-H. M. Harris and B. V. Travis. Shellrock: Oct. 14 -B. V. Travis. Woodbury Co. : Apr. 8-G. C. Decker.

Calif., Idaho, La., Nebr., Tex., Utah. Poland.

Tullbergia granulata n. sp.

White. About 6 times as long as broad. Postantennal organ elongate, transverse, with 30 to 40 tubercles in 2 rows with an 
occasional partial 3rd row at the outer end of the organ. Antennae shorter than the head, not strongly clavate, the 3rd segment not strongly pedunculate. Organ of the 3rd antennal segment with 2 converging clubs separated by an irregular basal fold which protects 2 clavate rods; guarded by 3 setae. Ventrolateral club heavy, with 3 guard setae. The 4 th segment with a minute apical club and about 6 olfactory hairs. Pseudocelli on each side as follows : antennal base 1, base of head 1, mesothorax to 5th abdominal segment with 1 each. Unguis broad and unarmed. Unguiculus minute, bristle-like. Anal horns 2, on contiguous papillae, subequal to or slightly longer than the hind unguis. Hairs on the body segments in 2 irregular rows of short, curving setae, each with occasional interspersed longer hairs, more abundant posteriorly. Dorsal granulations heavier than the ventral. Irregular rows of coarse granules across the dorsum of the 6th abdominal segment. Length $1 \mathrm{~mm}$.

Taken from moss and humus with a Berlese funnel.

Ames: Aug. 28; Sept. 25. Eldora: Nov. 10. New Sharon: Sept. 19-F. Andre. Valley Junction: May 1.

\section{Tullbergia clavata n. sp.}

Figs. 82-85

White. Nearly 6 times as long as broad. Postantennal organ very slender, consisting of 30 to 45 tubercles in 2 rows. Antennae (fig. 83) shorter than the head, clavate, the 3rd segment pedunculate at the base, rapidly enlarging at about the middle, a suture separating it from the 4th segment. Antennal organ of the 3rd segment (fig. 82) with 2 smooth, converging, sense clubs, separated at the base by a fold which encloses 2 sense rods, and 3 guard setae. Ventro-lateral club (fig. 85) guarded by 3 setae. The 4th segment with 6 or 7 olfactory hairs, and a minute, apical sense club. Antennal bases well developed. Pseudocelli on each side as follows: antennal base 1 , base of the head 1, mesothorax 1, 2nd, 4th and 5th abdominal segments 1 each. Unguis (fig. 84) broad, unarmed. Unguiculus absent. Anal horns 2, nearly twice the hind unguis, on contiguous papillae. Dorsum roughly, venter finely granulate. Posterior third of each segment from the mesothorax to the 5th abdominal segment finely and transversely granulate. Dorso-lateral area on the 3rd and 4th antennal segments coarsely granulate. Body with short, backward-pointing setae and long sensory hairs, the short ones in 2 rows across the first 4 abdominal segments and the longer ones interspersed in 
the anterior row. Long hairs more abundant on the head and the 5th and 6th abdominal segments. Length $1.2 \mathrm{~mm}$.

Taken beneath pieces of decaying wood and in humus.

Ames : Apr. 2, 3, 9-Reid Davis. Traer : Nov. 5-H. M. Harris.

\section{FAMILY ENTOMOBRYIDAE TöMöSVARY, 1883}

Body elongate, distinctly segmented. Pronotum greatly reduced, usually membraneous and devoid of bristles. Mesonotum often projecting more or less over the pronotum. Abdominal terga usually imbricate, with well developed intersegmental membranes. The 4th abdominal tergum often much longer than the 3rd. Antennae subequal to, to much longer than the head, the segments usually slender, the joints easily articulating. Anal horns rarely present. Chewing mouthparts, the mandibles with molar surfaces. Head prognathous. Postantennal organ present or absent. Spring rarely absent. Integument rarely granulate.

Key to the Subfamilies of Entomobryidae

1. Tergum of the 4th abdominal segment subequal to the 3rd. Antennae 4-segmented. Inner edge of the unguis not split longitudinally

Tergum of the 4th abdominal segment much longer than the 3rd (if subequal, then the antennae are 5- or 6-segmented). Postantennal organ absent. Antennae 4- to 6-segmented. Inner edge of the unguis split longitudinally. Posterior abdominal segments never ankylosed (fig. 7).

Entomobryinae Schäffer, p. 63.

2. Body scaled. The 3rd and 4th antennal segments definitely annulate; the 4th segment much shorter than the 3rd. Mucrones elongate and hairy. Postantennal organ absent. Posterior abdominal segments never ankylosed.

Tomocerinae Schäffer, p. 82.

Body not scaled. The 3rd and 4th segments of the antennae rarely annulate; 4th segment subequal to or longer than the 3rd. Mucrones not usually long, never hairy. Postantennal organ very rarely absent. The last 2 or 3 abdominal segments sometimes ankylosed (fig. 5).

Isotominae Schäffer, p. 39.

\section{SUBFAMILY ISOTOMINAE SCHÄFFER, 1896}

Postantennal organ usually present, consisting of a single tubercle. The 3rd and 4th abdominal segments subequal. Antennae 4-segmented, subequal to the length of the head. Body never scaled. Inner edge of the unguis not longitudinally split. $\mathrm{Mu}-$ 
crones sometimes with a single mucronal bristle but never hairy.

Dr. J. W. Folsom has at the present time a monograph of the Nearctic Isotomid forms in press. As it is impossible to tell whether its publication will antedate the publication of this monograph, Dr. Folsom has kindly sent descriptions of new species included in that paper and occurring in Iowa. These descriptions are placed in quotation marks, and credited to him.

Key to the Genera of Isotominae

1. Furcula absent. Anal horns 2, when present..................... 2

Furcula present (absent only in the European Tetracanthella afurcata Handschin, which has 4 anal horns)........ 3

2. Anal horns absent. Unguiculus present

Anal horns present. Unguiculus absent

Anurophorus Nicolet, p. 42.

Uzelia Absolon, p. 42.

3. Anal horns present ........................................................ 4

Anal horns absent ............................................................ 5

4. Furcula never reaching the ventral tube. Anal horns 4, not arranged in a transverse line. Anus ventral.

Tetracanthella Schött, p. 42.

Furcula reaching to the ventral tube. Anal horns arranged in a transverse line across the tergum of the 5th abdominal segment. Anus posterior........Spinisotoma Stach, p. 54.

5. Abdominal segments distinct, the segments not modified in relation to the small furcula, which reaches only to the middle of the 3rd segment. Manubrial hooks not well developed. Eyes reduced in number. Body extremely elongate, white (fig. 3 ) Folsomides Stach, p. 42.

Last 2 or 3 abdominal segments often ankylosed; modified for the insertion of the furcula

6. Antennae inserted on rather well-developed antennal bases, which are approximate on the front. Furcula reaching to the middle of the 3rd abdominal segment. Manubrial hooks well developed, very evident. Sense rods of the 3rd antennal segment organ seated in deep cups. Eyes absent. Body elongate, white (fig. 4)...Isotomodes Axelson, p. 46. Antennae not inserted on well developed antennal bases, placed some distance apart and antero-laterally on the front. Furcula reaching at least to the anterior margin of the 3rd abdominal segment. Sense rods of the 3rd antennal segment free or behind a fold.

7. The last 3 abdominal segments ankylosed. Mucro never 
lamellate, usually slender, 2-toothed or falcate. Body pigment and number of eyes usually reduced. Furcula not reaching the ventral tube. Anus ventro-terminal 8

The last 3 abdominal segments never ankylosed, although the last 2 may be. Mucro variable. Body usually well pigmented; eyes usually 8 on each side. Furcula often reaching to the ventral tube. Anus terminal

8. Mucro 2- (rarely 3-) toothed, never falcate.

Folsomina Denis, p. 49

9. Hind femora with a thorn-like process. Found along sea coasts. Archisotoma Axelson, p. 50.

Hind femur without a thorn-like process. Variable in habitat

10. Organ of the 3rd antennal segment with 15 to 20 clubs Axelsonia Börner, p. 50.

Organ of the 3rd antennal segment with 2 clubs.

11. Unguis with a membranous basal tunica

Unguis without a basal tunica

Agrenia Börner, p. 50.

12. Body segments bulging; with deep intersegumental constrictions. Terga (except genital and anal) not imbricate, without well developed intersegmental membranes. Pronotum tuberculate; not greatly reduced. Tibiotarsus with a distal subsegment. Integument tuberculate. Dark blue Guthriella Börner, p. 49.

Body segments not bulging, without deep intersegmental constrictions. Terga imbricate, with definite intersegmental membranes. Pronotum not tuberculate, the integument rarely so 13

13. The last 2 antennal segments annulate

Architomocerura Denis, p. 50.

The last 2 antennal segments simple. 14

14. The 4th abdominal segment longer than the 3rd, the 3rd not prolonged backward beneath the 4th to any extent. Furcula seldom reaching the ventral tube. Dentes usually subequal to the manubrium, which is naked ventrally, or bears few subapical setae. Corpus of tenaculum usually with 1 to 4 anterior setae. Clothing of short, simple setae. Proisotoma Börner, p. 50.

The 4th abdominal segment subequal to or shorter than the 3rd, which is prolonged ventro-laterally beneath the 4th. 
Furcula usually reaching the ventral tube. Manubrium much shorter than the dentes, with many ventral setae. Corpus of tenaculum usually with several anterior setae. Clothing of rather long setae, the longer ones sometimes fringed

15. Abdomen bearing bothriotricha. The long posterior hairs on the abdomen fringed on all sides. Mucrones lamellate, 4-toothed Isotomurus Börner, p. 54.

Abdomen without bothriotricha; the long posterior hairs on the abdomen smooth or unilaterally serrate. Mucrones rarely lamellate (fig. 5) Isotoma Bourlet, p. 55.

GENUS UZELIA ABSOLON, 1901

Protanurophorus Womersley, 1926

Body slender. Antennae slightly shorter than the head. Eyes 8 on each side. Postantennal organ present. Unguiculus and furcula absent. Anal horns 2.

This genus has been found in Europe and Great Britain, but is not known from North America.

GENUS ANUROPHORUS NICOLET, 1841

Body slender. Eyes 8 on each side. Postantennal organ present. Unguiculus present. Furcula and anal horns absent.

ANUROPHORUS LARICIS Nicolet, 1841

Length up to $1.5 \mathrm{~mm}$. Deep blue, with lighter spots and intersegmental sutures. The 4th antennal segment with a 2-lobed sense knob and several olfactory hairs. Eyes 8 on each side. Postantennal organ elliptical, twice the diameter of an eye. Unguis unarmed. Unguiculus about a fifth the unguis. Tibiotarsus with 3 weakly developed tenent hairs. Furcula and anal horns absent. Anus ventral.

Taken from humus with a Berlese funnel.

Traer : Nov. 5-H. M. Harris.

Minn., N. Y. Europe.

GENUS TETRACANTHELLA SCHöTT, 1891

Eyes 8 on each side. Postantennal organ present. Unguiculus present. Furcula usually present. Anal horns 4.

An alpine and boreal genus, not as yet known from our territory.

GENUS FOLSOMIDES STACH, 1922

“Genotype.-Folsomides parvulus Stach, 1922.

"Body cylindrical, greatly elongate, segments not strongly 
imbricate. Prothorax unusually long. The abdominal segments are simple rings, subequal in length (excepting the anal segment) and without ankylosis; fourth segment slightly longer than the third; genital and anal segments relatively unmodified. Anus caudal. Head prognathous, mandibulate; mandibles with well developed molar surface. Eyes reduced in number (either one or two on each side, in the known species). Postantennal organs present, relatively large, elongate, narrow, straight to feebly curving, with thick wall. Antennae arising relatively far forward, four-segmented. Sense organ of third antennal segment consisting of a pair of papillae, each situated in a pit. Fourth antennal segment with slender curving olfactory setae. Unguiculus present. Tenent hairs absent. Ventral tube emitting a pair of short rounded vesicles. Furcula present, small, appended to the fourth abdominal segment. Manubrium much longer than the dens plus mucro; manubrial hooks undeveloped. Dentes smooth dorsally, not crenulate or tuberculate. Mucro bidentate, either separated from the dens by a suture or confluent with dens. Anal spines absent. Clothing of short simple setae. Body pigment absent.

"Hitherto only a single specimen of this peculiar genus has been known: the genotype, $F$. parvulus, found in Hungary and described by Stach, to whose generic description I have added a little.

"Folsomides is evidently next to Isotomodes, in which, however, the genital and anal segments are ankylosed, the anus is ventral, and the manubrial hooks are strongly developed.

"Folsomides is unique among Collembola in the primitive nature of the segmentation of the body. The abdomen, with its simple, ringlike equal segments is almost vermiform; even the genital and anal segments are relatively unmodified, as compared with those segments in other Collembola. Both Folsomides and Isotomodes show affinities with Folsomia and Proisotoma."

\section{Key to the Species of Folsomides}

Eyes 2 on each side. Mucrodentes about half the manubrium...... parvus Folsom, n. sp., p. 43. Eyes 1 on each side. Mucrodentes about two-thirds the manubrium stachi Folsom, n. sp., p. 45.

Folsomides parvus Folsom, n. sp.

Fig. 3

"White. Greatly elongate: body subcylindrical, six times as 
long as broad. Eyes 2 on each side: equal, one in front of the other, separated, each on a small irregular black spot. Postantennal organ close to the anterior eye, narrowly elliptical or subelliptical, thick walled, varying in length from a little shorter to a little longer than the width of the first antennal segment, with four guard setae. Antennae inserted forward on the head, two-thirds as long as the latter, with segments in relative lengths about as $2: 3: 3: 5$; fourth segment stout, elliptical, with slender curving olfactory setae. Sense organ of third antennal segment with a pair of papillae, each in a shallow pit. Thorax long, three-fifths as long as abdomen, with tergites in relative lengths as $10: 18: 15$. Abdominal segments without ankylosis, in relative lengths about as $13: 14: 13: 15: 13: 9$; fourth segment thus a little longer than the third. Anal segment simple, unmodified. Anus caudal. Ungues feebly curving, simple, untoothed. Unguiculi minute, lanceolate, acuminate, untoothed, extending about onethird as far as the ungues. Tenent hairs absent. Ventral tube simple, with a pair of hemispherical vesicles, side by side. Furcula small, appended to the fourth abdominal segment and extending slightly beyond it. Manubrium stout, not tapering, rounded apically, about twice as long as the dens plus mucro, with several short, stiff dorsal setae. Dens and mucro confluent. Mucrodens gradually narrowing from the base, smooth dorsally, with three short stiff dorsal setae; mesally with a pair of narrow chitinous basal ridges. Mucro subequally bidentate; apical tooth hooked; anteapical feebly hooked. Clothing of sparse minute equal stiff setae, longer and more numerous posteriorly; sensory setae longer, stiff, outstanding, simple, in a row across the middle of the body segments; longest and most numerous on the anal segment. Integument smooth. Length $0.75 \mathrm{~mm}$.

"Folsomides parvus differs from parvulus Stach chiefly in the following respects :

parvulus

Ant. I:II

Postantennal organ Unguiculus

Mucro

Long tibiotarsal hair

\section{$1: 2$}

bent

Stout, subovate demarcated from dens present parvus

$$
2: 3
$$$$
\text { straight }
$$

slender, lanceolate confluent with den absent

"Parvulus was taken in Hungary under a large stone on moist soil in a farmyard near a cowbarn. The five cotypes of parvus 
were found in Douglas fir soil, at an èlevation of 8,500 feet.

"In Homer, Illinois, May 13, 1924, under a log in damp bottom land, I found a single specimen of a species of Folsomides which is extremely close to Stach's parvulus. Additional material is necessary, however, for definite determination.

"Colorado.-Eastern slope of Pikes Peak, July 1, Engelman Canyon, G. W. Goldsmith."-J. W. F.

My records are as follows :

Ames: Apr. 8-G. C. Decker; July 15; Sept. 16-F. Andre; Oct. 15. Columbus Junction: Sept. 26. Hampton: June 18G. C. Decker and B. V. Travis. Ottumwa : Sept. 16-Zella Beck. Rock Rapids : Aug. 16-E. L. Mills. Shellrock: Oct. 14-B. V. Travis. Valley Junction, May 1. Woodbury Co. : Apr. 8-G. C. Decker.

Folsomides stachi Folsom, n. sp.

"White. Greatly elongate; body cylindrical, in length six times the height of the abdomen. Eyes one on each side, each on a small round black spot. Postantennal organ close to the eye, narrowly elliptical, straight or feebly curving, in length about four times the diameter of the eye, with four guard setae. Antennae about two-thirds as long as the head, with segments in relative lengths about as $5: 6: 7: 8$. Body segments in relative lengths about as $14: 27: 25: 21: 23: 24: 27: 20: 15$. Fourth abdominal segment thus a little longer than the third. Genital and anal segments not ankylosed. Anus caudal. Ungues stout, curving, untoothed. Unguiculi extending one-half as far as the ungues on the hind feet, one-third as far on the remaining feet, lanceolate; acuminate, untoothed. Tibiotarsus with a distal subsegment indicated. Tenent hairs absent. Furcula small, appended to the posterior part of the fourth abdominal segment, and extending not quite to the middle of the third. Manubrium longer than the mucrodens (about as $3: 2$ ), gradually narrowing, with five pairs of setae in the dorsal aspect. Dens and mucro confluent. Mucrodens stout, gradually tapering from the base, with three small dorsal setae; mesally with a pair of narrow chitinous basal ridges. Mucro minutely bidentate; apical tooth hooked; anteapical tooth retrorse. Rami of tenaculum tridentate; corpus with an anterior median basal lobe. Clothing of minute stiff simple setae, limited to a few transverse rows across the middle of each body segment, with a few longer erect sensory setae; genital and anal segments with a few longer erect sensory setae. Integument smooth. Length $0.6 \mathrm{~mm}$. 
“This new species, which I dedicate with pleasure to colleague Dr. Jan Stach, was taken by me at Tallulah, Louisiana, April 7, in humus in a cypress forest."-J. W. F.

My data are as follows:

Ottumwa: Sept. 9-F. Andre.

Fla., La., Tex.

GENUS ISOTOMODES AXELSON, 1907

Body long and slender, with little, if any, pigment. The 5th and 6th abdominal segments ankylosed. Anus postero-ventral. Furcula very short, reaching about to the middle of the 3rd abdominal segment. Manubrial hooks greatly enlarged. Antennae inserted close together on the front. Postantennal organ present. Sense rods of the 3rd antennal segment situated in deep cups. Eyes absent.

\section{Isotomodes tenUIS Folsom, n. sp.}

\section{Figs. 4, 86}

"Greatly elongate, length about nine times the height of the body. White, or with a few scattered black specks, largest and most numerous on the posterior part of the abdomen. Eyes absent. Postantennal organ elongate, a little shorter than the width of the first antennal segment, straight or slightly curving, with almost parallel sides, usually emarginate at the middle of the anterior margin, six to eight times as long as broad, with a posterior row of strong guard setae seated on a cuticular thickening. Antennae shorter than the head (as $5: 7$ ), with segments in relative lengths about as $4: 7: 6: 10$. Sense organ of third antennal segment with a pair of rods immersed in a deep pit. Fourth antennal segment with olfactory setae. Body subcylindrical; abdomen slightly dilating posteriorly. Prothorax not unusually long (one-fifth to one-half as long as mesothorax); fourth abdominal segment longer than the third (as $6: 5$ ); anal segment not evident. Anus ventral. Claws largest on third pair of feet. Unguis slender, curving, untoothed. Unguiculus extending less than half as far as the unguis, lanceolate, pointed, untoothed. Tenent hairs absent. Furcula appended to the fourth abdominal segment, short, extending scarcely to the middle of the third abdominal segment. Manubrium stout, longer than dentes (as $5: 3$ ), with several dorsal setae and two pairs of ventral subapical setae. Dens stout, narrowing but little, with unusually thick ventral wall, without dorsal crenulations, with a few setae dorsally and ventrally, and with a pair of basal hooks exceptionally large. 
Mucro half as long as dens, subequally bidentate; apical tooth feebly hooked; anteapical tooth suberect. Rami of tenaculum quadridentate, slender, tapering ; corpus with a single long curving seta. General clothing of short stiff simple setae becoming longer and more curving toward the end of the abdomen; erect sensory setae short and simple. Integument minutely granulate. Maximum length, $1 \mathrm{~mm}$.

"Massachusetts: Arlington, Mar. 20, in damp moss on stones in a bog, J. W. Folsom."-J. W. F.

My Iowa data follow:

Ames : Mar. 1; July 15-H. M. Harris and F. Andre; Nov. 24. LeGrand: Apr. 15-E. M. Mills. Ottumwa: Sept. 16-Zella Beck. Valley Junction: May 1.

\section{GENUS FOLSOMIA WILLEM, 1902}

Eyes usually reduced in number, or absent. Body pigment also often reduced. Unguiculus and furcula present; mucro with 2 (rarely 3 ) teeth. The 4 th to 6 th abdominal segments ankylosed, sometimes, however, with evidence of a dorsal suture between the 4th and 5th segments.

In this genus of well-marked species, 5 forms are known to occur in Iowa although others should be found in the state.

Key to the Species of Folsomia

1. Eyes 8 on each side ........................................................ 2

Eyes less than 8 on each side .............................................. 3

2. Tenent hairs 1 or 2 . The 2 inner proximal eyes on each side reduced

Tenent hairs absent. All the eyes subequal prima Mills, p. 47.

elongata MacGillivray, p. 48.

3. Eyes 2 on each side.................quadrioculata Tullberg, p. 48.

Eyes less than 2 on each side

4. Eyes 1 on each side................diplophthalma Axelson, p. 48. Eyes absent.................................... fimetaria Linnaeus, p. 48.

Folsomia PRIMa Mills, 1931

Length up to $1 \mathrm{~mm}$. Olive to gray. Eyes 8 on each side, the 2 inner proximals smaller. Postantennal organ elongate, usually emarginate on both sides. Antennae subequal to the head. Unguis with a pair of lateral teeth, and 1 minute inner one. Unguiculus broadly rounded inwardly, about 0.6 the unguis. Tenent hairs 1 or 2, feebly knobbed. Furcula reaching to the posterior margin of the 2nd abdominal segment. Manubrium and dentes subequal, or the dentes slightly longer. Mucro 2-toothed. 
Taken beneath bark and in humus.

Ames:- Feb. 21, 23; Mar. 31; Sept. 16-F. Andre; Oct. 3. Columbus Junction: Sept. 26. Hampton: June 18-G. C. Decker and B. V. Travis. Leon : Oct. 10-B. V. Travis.

\section{Folsomia elongata (MacGillivray), 1896}

Isotoma bidenticula Guthrie, 1903

Length up to $1.5 \mathrm{~mm}$. Gray to deep brown. Eyes 8 on each side, subequal. Postantennal organ elongate-oval. Antennae subequal to the head. Unguis unarmed. Unguiculus more than half the unguis. Tenent hairs absent. Furcula reaching the posterior margin of the 2nd abdominal segment. Manubrium longer than the dentes. Mucro 2-toothed.

Found commonly beneath pieces of wood and in humus.

Ames : Mar. 30; Apr. 2, 6, 7; May 9; Oct. 10. Eldora : Nov. 10. Hancock: Oct. 8-F. Andre. Leon: Oct. 31-B. V. Travis. Ottumwa: Nov. 28-F. Andre. Ruthven: Oct. 2-H. M. Harris and B. V. Travis. Shellrock: Oct. $14-$ B. V. Travis. Woodbury Co.: Apr. 8-G. C. Decker.

Colo., Ill., Kans., Me., Minn. Ontario.

Folsomia quadrioculata (Tullberg), 1871

Length $1 \mathrm{~mm}$. Dirty gray. Eyes 2 on each side. Tenent hairs absent. Claws unarmed. Furcula short, mucro bidentate.

Shellrock : Nov. 6-B. V. Travis.

Folsomia diplophthalma Axelson, 1902

Length up to $1.2 \mathrm{~mm}$. White to dirty gray. Eyes 1 on each side. Postantennal organ elongate. Antennae subequal to the head. Unguis unarmed. Unguiculus half the unguis. Tenent hairs absent. Furcula short, dentes as long as the manubrium, mucro 2-toothed.

Columbus Junction: Sept. 26. Leon: Oct. 10-B. V. Travis. Shellrock: Oct. $14-$ B. V. Travis.

Idaho. Europe.

Folsomia fimetaria (L.), 1758

Length up to $2 \mathrm{~mm}$. White. Eyes absent. Postantennal organ elongate. Antennae longer than the head. Unguis toothed or not. Unguiculus slightly longer than half the unguis. Tenent hairs absent. Dentes twice the manubrium. Mucro 2-toothed.

This species occurs with us in 3 forms which may be differentiated as follows: 
1. Unguis unarmed. Large posterior hairs of the abdomen simple fimetaria f. p.

Unguis toothed 2

2. Long posterior hairs of the abdomen serrate

caldaria Axelson.

Long posterior hairs of the abdomen smooth. Unguis strongly unidentate dentata Folsom.

Ames: Sept. 1, 2, 4; Oct. 20. Bixby Ice Cave: May 8. Columbus Junction: Sept. 26. Hampton: June 18-G. C. Decker and B. V. Travis. Leon: Oct. 31-B. V. Travis. Ruthven: Oct. 2H. M. Harris and B. V. Travis.

Calif., D. C., Ill., Kans., Mass., Md., Me., Minn., Mo., N. J., N. Y., Ohio, Utah, Wash. Alaska. Aretic Islands. Europe.

GENUS FOLSOMINA DENIS, 1931b

Eyes and postantennal organs absent. The 4th antennal segment with 2 bulbous, blunt processes, besides several welldeveloped olfactory hairs. Unguiculus and furcula present; mucro falcate. Abdominal segments 4 to 6 ankylosed, an obscure dorsal suture, however, between the 4th and 5th.

\section{Folsomina onychiurina Denis, 1931b}

Figs. 87,88

Length up to $0.6 \mathrm{~mm}$. White. Eyes and postantennal organ absent. Body segmentation as in Folsomia. Antennae longer than the head, 4th segment (fig. 88) with 5 large olfactory hairs, several more slender ones, and 2 large lobes, each with 3 longitudinal ribs. Unguis untoothed. Unguiculus half the unguis. Manubrium to dentes as 2:5. Mucro falcate (fig. 87). Body with numerous short hairs and a row of longer ones across each segment.

Taken from humus with a Berlese funnel.

Ames: July 15-H. M. Harris and F. Andre; Aug. 28. LeGrand: Apr. 14 -E. M. Mills. New Sharon: Sept. 19-F. Andre. Ottumwa: Sept. 9-F. Andre.

Fla. Costa Rica. Australia.

\section{GENUS GUTHRIELLA BöRNER, 1906}

Eyes 8 on each side. Postantennal organ present. Body segments bulging, 5th and 6th abdominal segments alone imbricate, and with intersegmental membranes. Integument, including pronotum, tuberculate.

This genus has not been recorded from Iowa, but should occur in this state. 


\section{GENUS ARCHISOTOMA LINNANIEMI, 1912}

Body broad, Isotoma-like. Eyes 8 on each side. Postantennal organ present. The 5th and 6th abdominal segments ankylosed. Hind femora each with a large, thorn-like process. Corpus of tenaculum with a large, anterior, accessory lobe. Abdomen with naked bothriotricha.

Not found in Iowa.

GENUS AGRENIA BöRNER, 1906

Eyes 8 on each side. Postantennal organ present. Unguiculus and furcula present. Unguis with an external basal tunica. Mucro 2-toothed, over-reached by a long seta.

Unknown in Iowa.

GENUS AXELSONIA BöRNER, 1907

Eyes 8 on each side. Postantennal organ absent. Unguiculus and furcula present. A pair of slender filaments attached to the base of the unguis. Organ of the 3rd antennal segment with 15 to 20 sense rods. Bothriotricha present on the abdomen.

Not known in Iowa.

GENUS ARCHITOMOCERURA DENIS, 1931a

Eyes 6 on each side. Postantennal organ minute. The 3rd and 4th antennal segments annulate. Unguiculus and furcula present. Abdomen with bothriotricha.

Architomocerura crassicauda Denis, 1931a

Length up to $0.75 \mathrm{~mm}$. White but for bluish antennae and blue-black eyespots. Antennae longer than the head, the last 2 segments annulate, segmental proportions as $12: 15: 34: 44$. Eyes 6 on each side. Postantennal organ minute, obscure. Unguis unarmed, unguiculus broadly lanceolate. Tenent hairs absent. Furcula reaching the ventral tube, manubrium to dentes to mucrones as $3: 6: 1$. Mucro bilamellate, with an apical and subapical tooth, and a toothed external lamella. Long bothriotricha present.

Recovered from humus with a Berlese funnel.

Ames : Sept. 4; Oct. 20-F. Andre. Ottumwa: Oct. 9-F. Andre.

Fla., Wash. Europe.

GENUS PROISOTOMA BÖRNER, 1906

Isotomina Börner, 1903

Eyes variable in number. Postantennal organ present. Unguiculus and furcula present. The 4 th abdominal segment longer than the 3rd, which is not prolonged back beneath the 4th to any 
extent. Furcula not generally reaching the ventral tube. Dentes usually subequal to the manubrium which bears few ventral setae. Corpus of the tenaculum usually with 1 to 4 anterior setae, or bare. Tibiotarsus often with a distal subsegment. Tenent hairs present or absent.

\section{Key to the Species of Proisotoma}

1. Eyes 5 on each side. americana, n. sp. p. 51.

Eyes 8 on each side

2. Mucro with 2 teeth

Mucro with 3 teeth

3. Mucro lamellate; 5 th and 6 th abdominal segments distinct.... schötti Dalla Torre, p. 52.

Mucro not lamellate; 5th and 6th abdominal segments ankylosed thermophila Axelson, p. 53.

4. A large, lateral, hyaline bulb at the apex of each dens.

bulbosa Folsom, n. sp. p. 52. Dentes without bulbous appendages....minuta Tullberg, p. 54 .

Proisotoma americana n. sp.

Figs. 89-91

White but for blue eyespots and minute blue spots on the head and rarely on the body. Eyes 5 on each side (fig. 89). Postantennal organ oval, about twice the diameter of an eye. Antennae shorter than the head, segmental proportions $11: 16: 17: 30$; numerous slender olfactory hairs present on the 4th segment. Organ of the 3rd segment with 2 slender rods. Unguis (fig. 90) broad basally, pointed, untoothed. Unguiculus lanceolate, half the length of the unguis. Tenent hairs absent. Furcula not reaching the ventral tube (fig. 91). Manubrium slightly longer than the dens and mucro together, with a few dorsal setae and a pair of ventral subapical bristles. Dentes irregularly roughened dorsally, with 3 dorsal setae and 2 pairs of ventral bristles. Mucro 3 -toothed, with an apical, a subapical, and a lateral tooth, the lateral tooth nearly opposite the subapical one. Rami of the tenaculum 3-toothed, the corpus with 1 anterior seta. Apex of the abdomen bluntly rounded, the 5th and 6th segments separated only by a weak dorsal suture; the 3rd segment to the 4th as $4: 5$. Body covered with hairs of an even length, slightly longer posteriorly. Maximum length $0.9 \mathrm{~mm}$.

Other than in the arrangement of the eyes, this species differs from its nearest relative, $P$. minima Absolon, in the following manner : 


\section{P. minima}

Body hairs short.

Postantennal organ 4 times the diameter of an eye.

"Ant. IV mit plumpen Riechhaaren."-Handschin, 1929.

Dorsal dental setae 5.
P. americana

Body hairs not especially short. Postantennal organ 2 times the diameter of an eye.

Ant. IV with slender olfactory hairs.

Dorsal dental setae 3 .

Taken from humus.

Ames : Oct. 15, 20 ; Nov. 1, 17. Traer : Nov. 5-H. M. Harris.

\section{Рвоготома sснӧтti (Dalla Torre), 1895}

Figs. 93.94

Length up to $2 \mathrm{~mm}$. Blue-brown. Eyes 8 on each side. Postantennal organ oval, twice the diameter of an eye. Antennae subequal to the head, the segments as $5: 5: 6: 13$. The 3rd abdominal segment is to the 4th as $2: 3$. Unguis untoothed (fig. 94). Unguiculus broad basally, half the unguis. Tenent hairs absent. Proportions of the furcula: $10: 8: 3$. Mucro (fig. 93) large, bilamellate, with 2 apical teeth. Dentes heavy, not or slightly tapering dorsally.

A littoral form taken along the shore of Mud Lake.

Ruthven: Oct. 2-H. M. Harris and B. V. Travis.

Calif., N. Y., Wash. Europe.

Proisotoma bulbosa Folsom, n. sp.

Fig. 92

"Blackish blue, including the appendages. A stout species. Eyes eight on each side, one or both of the inner proximal eyes on each side being smaller than the others. Postantennal organ subelliptical but somewhat irregular, twice as long as the diameter of an adjacent eye, with an exceptionally thick bordering ridge. Antennae slightly longer than the head (as $7: 6$ ), with segments variable in relative lengths; third segment usually a little shorter than the second, occasionally a little longer; fourth two to three times as long as second. Sense organ of third antennal segment with a pair of feebly curving rods in a deep groove, with four guard setae. The curving setae of the fourth antennal segment are strong, but not evidently differentiated as olfactory setae. Tibiotarsi not subsegmented. Unguis weakly curving, with a pair of lateral teeth two-fifths from the base, and an inner tooth one-third from the apex. Unguiculus extend- 
ing three-fifths to four-fifths as far as the unguis, sublanceolate, acute, untoothed. One tenent hair, weakly knobbed. Third abdominal segment shorter than the fourth (about as $19: 22$ ). Genital and anal segments ankylosed, with the dorsal suture often indicated, however ; dorsally with coarse tuberculate ridges. Furcula appended to the fifth abdominal segment, not attaining the ventral tube but extending as far as the second abdominal segment, stout. Manubrium about seven-eighths as long as dentes, setigerous on all sides. Dentes stout, not tapering, broad apically, each with a lateral protuberance one-fourth from the base, and with about eight large dorsal semicircular folds. Dentes with a few setae dorsally, and many stiff setae laterally and ventrally. At the end of the dens is a conspicuous lateral expansion in the form of a transparent bladder extending half the length of the mucro. Mucro stout, quadridentate (fig. 92). Apical tooth small, slightly curving or almost straight; second and third in line with the first, subequal, directed slightly forward; fourth tooth lateral, oblique. Ventral aspect of the mucro in lateral aspect almost straight proximally. Rami of tenaculum quadridentate; corpus with three ventral setae. General clothing of short strong curving simple setae, becoming longer in the genital and anal segments. Erect sensory setae apparently absent. Integument minutely tuberculate, becoming smooth and reticulate on the posterior regions of the body segments and on the intersegmental membranes. The coarse dorsal tubercles of the ano-genital segment form several crenulate ridges. Length $1.2 \mathrm{~mm}$.

"Maine.-Orono, March 10, in moss in pine woods, F. L. Harvey.'-J. W. F.

My data are as follows:

A single specimen of this species was taken in humus.

Columbus Junction: Sept. 26.

Proisotoma thermophilia Axelson, 1907

Figs. 95, 96

Length up to $1 \mathrm{~mm}$. Light gray. Eyes 8 on each side. Postantennal organ oval, nearly 4 times the diameter of an eye. Antennae longer than the head, the segments as $8: 13: 14: 26$. The 3rd abdominal segment to the 4th as $13: 16$. Unguis (fig. 96) with 1 inner tooth. Unguiculus half the unguis, unarmed. Tenent hairs absent. Dentes more than twice the manubrium. Mucro 2 -toothed (fig. 95), the apex upturned. The 5th and 6 th abdominal segments ankylosed. 
Taken in moss and humus.

Ames : Sept. 4; Oct. 15, 20. Leon : Oct. 10-B. V. Travis. Pleasant Valley: Sept. 25-H. D. Tate.

Fla., Tex., Utah. Costa Rica. Europe.

\section{Proisotoma minuta (Tullberg), 1871}

Length up to $1 \mathrm{~mm}$. Gray to nearly white. Eyes 8 on each side. Postantennal organ elongate-elliptical, 3 times the diameter of an eye. Antennae longer than the head. The 5th and 6th abdominal segments weakly separated; 3rd and 4th segments subequal. Unguis unarmed. Unguiculus more than half the unguis. Tenent hairs absent. Manubrium and dentes subequal. Mucro 3-toothed.

Ames : Mar. 22 ; Apr. 3 ; May 7, 9, 23 ; July 15-H. M. Harris and F. Andre; Aug. 24; Sept. 2, 25. Bixby State Park: May 8. Hampton: June 16-G. C. Decker and B. V. Travis. New Sharon: Sept. 19-F. Andre. Smithland: Dec. 5-G. C. Decker.

Calif., Conn., Ill., Kans., La., Mass., N. Y., Pa., Tex., Utah. Alberta. Europe.

\section{GENUS SPINISOTOMA STACH, 1926}

Eyes 8 on each side. Postantennal organ present. The 4th abdominal segment not longer than the 3rd. Furcula reaching the ventral tube. The 5th abdominal segment dorsally with 4 heavy spines.

Recorded only from Poland.

\section{GENUS ISOTOMURUS BÖRNER, 1903}

Eyes 8 on each side. Postantennal organ present, of the usual Isotoma type. Unguiculus and furcula present, the dentes long and slender, with dorsal corrugations. Bothriotricha present posteriorly on the abdomen. Mucro 4-toothed, lamellate.

Isotomurus PALUSTRIS (Müller), 1776

Isotoma aequalis MacGillivray, 1896,

I. tricolor Packard, 1873.

Figs. 97, 98.

Length up to $3 \mathrm{~mm}$. Extremely variable in color. Eyes 8 on each side. Postantennal organ oval, somewhat longer than the diameter of an eye. Unguis with lateral teeth and as a rule without an inner tooth. Unguiculus broad basally, two-thirds the unguis. Dentes twice the manubrium. Mucro 4-toothed (fig. 98), lamellate. 
Several color varieties of this species occur in the state. They may be distinguished by the following key :

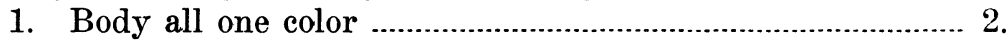

Body with a dark pattern .................................................... 3.

2. Body yellow-green .........................................prasina Reuter.

Body red-violet ..............................................fucicola Reuter.

3. Body greenish, with a dorsal and irregular lateral stripes...... palustris $\mathrm{f} . \mathrm{p}$.

Anterior part of each segment blue-brown, posterior lighter....

balteata Reuter.

Ames : Feb. 21; Mar. 7, 27, 29; June 3, 14; Oct. 10-L. Weber. Columbus Junction: Sept. 25. Little Wall Lake: Oct. 14-G. C. Decker. Mt. Pleasant : Mar. 6-H. R. Knight. Ruthven, Oct. 2H. M. Harris and B. V. Travis.

Calif., Fla., Ga., Ill., Ind., La., Mass., Me., Minn., N. C., N. Y., Va., Ohio, Tenn., Tex., Wis. Greenland. Ontario. Cosmopolitan.

\section{GENUS ISOTOMA BOURLET, 1839}

\section{Desoria Agassiz, 1841}

Eyes variable. Postantennal organ rarely absent. Unguiculus and furcula present. Dentes much longer than the manubrium, which usually bears many ventral setae. Corpus of tenaculum usually with many anterior setae. The 3 rd and 4 th abdominal segments subequal, the 3rd projecting ventro-laterally beneath the 4th. Bothriotricha absent; some of the larger abdominal hairs, however, unilaterally serrate.

This large genus has been divided into 3 subgenera, Isotoma s. str., Vertagopus Börner, and Pseudisotoma Handschin. Pseudisotoma was erected for I. sensibilis Tullberg, in which the 5th and 6th abdominal segments are entirely ankylosed. Vertagopus includes those species which have tenent hairs, and in which the last 2 abdominal segments are distinct. In North America there is a variety of $I$. arborea (L.) with tenent hairs and another without them. Hence I. arborea falls in Isotoma s. str., and its variety nigra MacGillivray falls in the subgenus Vertagopus. This subgenus, although convenient, is not a natural grouping and is not recognized in this work.

\section{Key to the Subgenera of Isotoma}

The 5th and 6th abdominal segments ankylosed. Tenent hairs present. Pseudisotoma Handschin, p. 56. The 5th and 6th abdominal segments distinct. Tenent hairs present or absent. Isotoma Bourlet, p. 5.5. 
Key to the Species of Isotoma

1. Eyes reduced in number. 2.

Eyes 8 on each side 4.

2. Eyes and postantennal organs absent

Eyes and postantennal organs present.

minor Schäffer, p. 57.

3. Eyes 3 on each side. White 3.

Eyes 4 on each side. Blue-gray

andrei n. sp. p. 58.

eunotobilis Folsom, n. sp. p. 58.

4. Tenent hairs present 5.

Tenent hairs absent. 6.

5. Color blue-black. Ventral edge of mucro curved arborea L., p. 57.

Color gray. Ventral edge of the mucro nearly straight. cinerea Nicolet, p. 57.

6. Mucro 3-toothed, or apparently so. 7.

Mucro 4-toothed 8.

7. Unguis unidentate. Apical tooth of the mucro pointed postero-dorsally, long..........trispinata MacGillivray, p. 62.

Unguis bidentate. Apical tooth of mucro strongly upcurved. viridis Bourlet, p. 63.

8. Head extremely large. Antennae to the head as 5:6. Postantennal organ lateral, against the base of the antenna......

grandiceps Reuter, p. 60.

Head not extremely large. Antennae longer than the head. Postantennal organ close to the eyespot. 9.

9. Lateral teeth of the unguis large, scale-like. Body irregularly purple. A broad blue-black band across the front.... nigrifrons Folsom, n. sp., p. 60.

Lateral teeth of the unguis small, pointed. Front of head not with a blue-black band 10.

10. Color white to yellow. Elongate. The 2nd antennal segment straight or bowed albella Packard, p. 62.

Color dark. The 2nd antennal segment straight............. 11.

11. Color blue-black. Postantennal organ subequal to the diameter of an eye........ arborea nigra MacGillivray, p. 57.

Color blue to gray. Postantennal organ about 3 times the diameter of an eye. olivacea Tullberg, p. 61.

Isotoma (Pseudisotoma) sensibilis (Tullberg), 1876.

Figs. 99, 100

Length up to $2 \mathrm{~mm}$. Gray to purple-black, irregularly spotted with light, and lighter along the sutures. Head to the antennae as $4: 5$, the antennal segments as $8: 11: 12: 20$. Eyes 8 on each 
side. Postantennal organ oval, about the size of an eye. The 5 th and 6th abdominal segments ankylosed, showing at times, however, evidence of a dorsal, dividing suture. Unguis (fig. 99) with lateral teeth and 1 inner tooth. Unguiculus often with an inner notch. Tenent hairs 1 to 3 on each tibiotarsus. Manubrium to dentes as 4:11. Mucro (fig. 100) 3-toothed, the 2 subapical teeth not opposite. Longer abdominal hairs unilaterally serrate.

Taken abundantly from moss.

Ames: Sept. 25. Columbus Junction: Sept. 26. Ottumwa : Sept. 9-F. Andre.

Fla., Ill., La., Mass., Minn., N. Y., Ohio. Ontario. Europe.

ISOTOMA CINEREA (Nicolet), 1841

I. latraria MacGillivray, 1896

Length up to $1.5 \mathrm{~mm}$. Gray. Antennae longer than the head. Eyes 8 on each side. Postantennal organ 1 to 2 times the diameter of an eye. Unguis with 1 inner tooth and lateral teeth. Unguiculus with an inner notch. Each tibiotarsus with 2 to 3 tenent hairs. Dentes twice the manubrium. Mucro 4-toothed, the apical tooth short and directed posteriorly. The ventral edge of the mucro nearly straight.

A rather common cortical species.

Ames : Feb. 21 ; Mar. 14; Apr. 21; Oct. 3, 17. Leon: Oct. 31B. V. Travis.

Ill., Mass., Me., N. Y., Ohio. Ontario. Holaretic.

IsOTOMA ARBOREA (L.) 1758 , f. p.

Length up to $2 \mathrm{~mm}$. Deep blue-black. Legs and furcula white or yellowish. Eyes 8 on each side. Postantennal organ oval, about the size of an eye. Antennae longer than the head. Unguis with lateral teeth and 1 inner tooth. Unguiculus with an inner tooth-like notch. Tenent hairs $2: 3: 3$. Dentes more than twice the manubrium. Mucro 4-toothed, the ventral edge curving. I Long hairs on the abdomen serrate.

Isotoma ARborea nigra MacGillivray, 1896

Very similar to the typical form but for the absence of tenent hairs.

Ames: Feb. 23 ; Apr. 2.

Ill., Mass., Me., Minn., N. Y., Ohio. Ontario. Europe.

Isotoma MINoR Schäffer, 1896.

Fig. 101

Length up to $1 \mathrm{~mm}$. White. Eyes and postantennal organs absent. Antennae longer than the head, the 4th segment with 
5 to 8 (commonly 6 ) heavy olfactory clubs lateroventrally (fig. 101). Claws without teeth. Tenent hairs absent. Manubrium to the dentes as $11: 30$. Mucro with 3 teeth. Long hairs of the abdomen serrate.

Taken in humus.

Ames : Apr. 2. Algona : Apr. 16-E. L. Mills. Columbus Junction: Sept. 26. Hampton: June 18-G. C. Decker and B. V. Travis. Ottumwa: Sept. 9-F. Andre.

Fla., Ill., Mass. Europe.

\section{ISOTOMA ANDREI n. sp.}

Figs. 5, 102-104

White. Eyespots and scattered specks on the head black. Body rather broad. Antennae a third longer than the head, the segments as $8: 14: 15: 23$. Eyespots small, each bearing 3 eyes. Postantennal organ large (fig. 104), irregular, the edges lobed. Unguis curving (fig. 103), with baso-lateral teeth, 1 inner tooth, and basal folds as in I. viridis. Unguiculus half the unguis, with a large inner tooth. Tenent hairs absent. Manubrium with numerous ventral setae; to the dentes as $2: 7$. Dentes long and slender, terminated by tridentate mucrones (fig. 102). Tenaculum with numerous anterior setae, the rami 4-toothed. The 3rd and 4th abdominal segments subequal. Body covered with short, reclinate hairs, and long, unilaterally serrate setae. Length 1.2 $\mathrm{mm}$.

Taken from moss with a Berlese funnel. This species is named for Mr. Floyd Andre, who collected this and other interesting species of Collembola in the state.

Ottumwa: Sept. 9-F. Andre, 16-Zella Beck; Nov. 29-F. Andre.

\section{Isotoma eunotabilis Folsom, n. sp.}

"General color grayish, greenish, or bluish. Head and body finely mottled with bluish gray pigment interrupted by closelyset round pale spots. Body segments narrowly bordered posteriorly with blackish. Eyes connected anteriorly by a narrow $\Lambda$-shaped mark. Legs and furcula pale. Antennae pale, with segments more or less purplish distally. Young individuals may be white, with minute specks of blackish pigment. Eyes four on each side, equal, arranged as in fig. 338 , on a small roundish black patch. Postantennal organ relatively large, elliptical, close to the eyes, three or four times as long as the diameter of an eye. 
Antennae longer than the head (as $1.5: 1$ ), with segments in relative lengths about as $10: 16: 16: 33$. Sense organ of third antennal segment with a pair of small, slightly curving rods, subtended by a chitinous ridge. Fourth antennal segment with a few stout, slightly curving olfactory setae. Unguis simple, without lateral or inner teeth. Unguiculus extending half as far as the unguis, broadly sublanceolate, pointed, untoothed. Tenent hairs absent. Third abdominal segment slightly shorter than the fourth (as 28:33). Genital and anal segments ankylosed, with often a trace of a dorsal suture. Furcula appended to the fifth abdominal segment, extending to the ventral tube. Manubrium much shorter than dentes (as $6: 17$ ), with many stiff setae on all sides. Dentes slender, gradually tapering, crenulate dorsally, with many ventral setae and a few erect dorsal proximal setae. Mucro small, tridentate. Apical tooth small, hooked. Anteapical tooth smaller than the apical, inclined or suberect. Third tooth proximo-lateral, curving dorsally more or less and projecting caudo-laterally. Dentes with a strong subapical ventral seta projecting as far as the end of the mucro or slightly beyond it. Rami of tenaculum quadridentate, corpus with two ventral setae (rarely with three). General clothing of numerous short setae, most of which are simple; the longest setae, near the extremity of the abdomen, are, however, feebly unilaterally spinulate. Sensory setae simple, or with two or three branches unilaterally, erect, scarcely longer than the inclined setae. Length, $0.7 \mathrm{~mm}$.

"In moderately pigmented individuals the minute specks of pigment form a loose network, outlining the hypodermis cells.

"This species is very close to the European notabilis Schäffer, of which I have studied three specimens from Finland, sent to me by Linnaniemi. Both species have four eyes on each side, but the arrangement of the eyes differs in the two species. In notabilis the third abdominal segment is to the fourth as $46: 47$; while in eunotabilis the ratio is $56: 66$. In notabilis the larger posterior setae of the abdomen are more strongly feathered than in eunotabilis. I do not know whether notabilis ever has the interocular $\Lambda$-shaped mark; my specimens from Finland having very little pigment. In other respects this species agrees with notabilis, even to the presence of feathered setae on the bases of the legs.

"Isotoma eunotabilis belongs to the fauna of the soil. It is common on damp ground under logs and among dead leaves. I have often taken it under damp boards on grass. 
“Illinois.-Homer, February 28, March 3, 14, 25, April 2, 11, 12, 14, 15, 16, 21, 25, May 2, 3, 14, 16, June 6.

"Wisconsin.-Beloit, October, V. G. Davidson.

"Canada, Ontario, November, C. Macnamara."-J. W. F.

My Iowa data are as follows:

Ames: Apr. 2. Columbus Junction: Sept. 26. Hampton: June 18-G. C. Decker and B. V. Travis. Leon: May 28-B. V. Travis. Rock Rapids : Aug. 16-E. L. Mills. Ruthven : Oct. 2-H. M. Harris and B. V. Travis. Smithland: Dec. 5-G. C. Decker.

Isotoma GRANDICEPS Reuter, 1891

I. macnamarai Folsom, 1918

Figs. 105, 106

Length up to $1.7 \mathrm{~mm}$. Body deep blue, head greenish. Antennae purple toward the apex. Legs lighter at the tip. Dentes pale. Head extremely large, to the antennae as $6: 5$. Eyes 8 on each side. Postantennal organ oval, placed laterally at the base of the antenna. Unguis (fig. 106) with large lateral teeth and an inner tooth. Unguiculus broad, with an inner tooth. Tenent hairs absent. Manubrium to dentes to mucrones as $4: 7: 1$. Mucro 4-toothed (fig. 105). Long hairs of the abdomen smooth.

Taken from humus. The occurrence of this horeal species in Iowa is of interest.

Columbus Junction: Dec. 25-L. Weber.

Mass. Ontario. Siberia.

IsOTOMA NIGRIFRons Folsom, n. sp.

Figs. 107, 108

"Pigment purple. In moderately pigmented individuals the front is covered with a large blackish patch that includes the antennal bases, connects the eyespots anteriorly, and extends backward between the eyes as a triangular mark, at the apex of which there is a median transverse irregular mark, or two such marks, one in front of the other. Occiput whitish. Usually the first four body segments are pigmented throughout, and the second, third and fourth abdominal segments have each a broad white posterior band. Often the thorax is heavily pigmented with purple, while the posterior part of the abdomen is paler in color. Antennae purplish throughout, or with the first three segments whitish except apically. Legs purple basally, otherwise whitish, tinged with brownish or greenish. Furcula white. Eyes eight on each side, the two inner proximal eyes smaller than 
the others. Postantennal organ elliptical, from one-fourth longer to twice as long as the diameter of the adjacent eye. Antennal bases well developed. Antenuae longer than the head as $7: 5$, with segments in relative lengths about as $12: 25: 23: 36$. Sense organ of third antennal segment with a pair of linear curving rods and a chitinous ridge. Fourth antennal segment without special olfactory setae. Third abdominal segment slightly longer than the fourth. Genital and anal segments not clearly ankylosed, though the dorsal suture is sometimes faint. Unguis with a pair of lateral teeth and an evident tooth at the middle of the inner margin. Unguiculus lanceolate, acuminate, strongly unidentate, extending about half as far as the unguis on the second and third pairs of feet, and less than half as far on the first pair. Tenent hairs absent. Furcula extending not quite to the ventral tube. Manubrium with many stiff setae dorsally and ventrally, crenulate dorsally, the crenulations ending distally before the apex, leaving a smooth surface three times as long as the mucro. Mucro half as long as hind unguiculus, quadridentate; apical tooth large, hooked; anteapical tooth large, subconical, erect; third and fourth teeth small, subequal, erect or oblique, almost opposite each other; fourth tooth lateral. Rami of tenaculum quadridentate; corpus with about twelve setae. Clothing of dense simple setae of moderate length, longer posteriorly; sensory setae long, outstanding, simple. Maximum length, $2.1 \mathrm{~mm}$.

"This new species occurred in large numbers in moss on rock bluffs, and in some individuals the intestine was full of moss spores.

"Illinois : Alto Pass, Mar. 4; Makanda, Mar. 5; T. H. Frison and H. H. Ross."-J. W. F.

In Iowa I have the species from Ottumwa : Nov. 28-F. Andre, and Ledges State Park: Apr. 10, also from moss.

Isotoma olivacEA Tullberg, 1871

Figs. 109, 110

Length up to $2.5 \mathrm{~mm}$. Yellow-brown to gray; blue in the variety neglecta Schäffer. Antennae longer than the head, the segments as $13: 25: 27: 42$. Eyes 8 on each side. Postennal organ (in the Iowa forms) 2 to 3 times the diameter of an adjacent eye. Unguis with lateral teeth and 1 inner tooth. Unguiculus often with an inner tooth. The manubrium is to the dentes as $18: 41$. Mucro 4-toothed (figs. 109, 110). Long bristles of the abdomen smooth. 
This species is found in Iowa in 2 forms which may be separated in the following manner:

Yellow-brown. Apical tooth of the mucro pointing posteriorly...... grisea Lubbock.

Gray. Apical tooth of the mucro pointing postero-dorsally olivacea f. $p$.

Ames: Feb. 29 ; Apr. 27. Columbus Junction: Sept. 26 ; Dec. 25-L. Weber. Woodbury Co. : Sept. 28-G. C. Decker.

Ill. Canada. Europe.

\section{Isotoma ALBELLA Packard, 1873}

I. walkeri Packard, 1873

Length up to $1.5 \mathrm{~mm}$. White, buff, or rarely gray. Body elongate. Antennae longer than the head, the 2nd segment often bowed out. Eyes 8 on each side. Postantennal organ oval, 3 times the diameter of an eye. Unguis long and slender, with lateral teeth and 1 inner tooth. Unguiculus with a broad basal lamella. Tenent hairs absent. Spring long and slender, the dentes twice the manubrium. Mucro with 4 teeth; a far-reaching apical tooth, a large anteapical one, and a pair of smaller, opposite, basal ones. The few longer hairs of the abdomen smooth.

This species is very characteristic of the cortical fauna, being found abundantly beneath the moist, loosening bark of newly fallen trees, especially cottonwood (Populus) and elm (Ulmus).

The 2 varieties of the species found in Iowa are differeniated as follows :

Color white albella $f . p$. Color yellow to buff leonina Packard.

Ames : Apr. 11, 25, 26 ; May 7; July 12; Aug. 24.

Ill., Mass., Me., N. Y. Europe.

Isotoma tRISPINAta MacGillivray, 1896

Length up to $1.5 \mathrm{~mm}$. Bluish-gray; legs, furcula and venter lighter. Antennae longer than the head. Eyes 8 on each side. Postantennal organ broadly oval, about twice the diameter of an eye. Unguis unarmed. Unguiculus unarmed, the inner margin, however, sometimes sharply angular. Dentes long and slender. Mucro 3-toothed, the 2 subapical teeth not opposite. Longer abdominal hairs smooth.

Taken in humus. 
Bixby State Park: May 8. LeGrand: Oct. 27. Leon: Oct. 10B. V. Travis. Ottumwa: Sept. 16-Zella Beck.

Ill., N. Y.

Isotoma viRIDIs Bourlet, 1839

I. Belfragei Packard, 1873,

I. tricolor Packard, ad. p., 1873,

I. purpurascens Packard, 1873,

I. plumbea Packard, 1873,

I. capitola MacGillivray, 1896 ,

I. glauca MacGillivray, 1896.

Figs. 111, 112

Length up to $4 \mathrm{~mm}$., rarely as much as $7 \mathrm{~mm}$. Extremely variable in color. Usually deep blue-green with darker pigment. Antennae longer than the head, the segments as $9: 20: 20: 24$. Eyes 8 on each side. Postantennal organ oval, about the size of an eye. Unguis (fig. 112) with lateral and 2 inner teeth, and basal folds. Unguiculus with an inner notch. Tenent hairs absent. Manubrium to the dentes as 2:5. Mucro (fig. 111) 3(rarely 4-) toothed, when 4-toothed the apical one is minute and obscure; the 2 basal ones opposite. Longer body hairs serrate.

The Iowa varieties may be distinguished by the following key: 1. Mucro with an obscure apical tooth...............catena Guthrie.

Obscure apical tooth absent 2.

2. Deep green, without color pattern........................viridis $\mathrm{f} . \mathrm{p}$.

Deep green with a dark mid-dorsal line......riparia (Nicolet).

I. viridis is a large, conspicuous species, taken commonly in humus soil.

Ames : May 10-J. E. Guthrie ; 19. Hampton: June 18-G. C. Decker and B. V. Travis. Leon: Oct. 10-B. V. Travis. Malvern : Sept. 10, 14.

Calif., Colo., D. C., Ill., La., Mass., Me., Minn., N. Y., Ohio, Okla., Tenn., Tex., Utah, Va., Wash. Alaska. Ontario. Greenland. Cosmopolitan.

\section{SUBFAMILY ENTOMOBRYINAE SCHÄFFER, 1896}

Postantennal organ absent in all of our species. The 4th abdominal segment usually much longer than the 3rd dorsally, if subequal then the antennae are 5- or 6-segmented or the 4th antennal segment is as long as the body; otherwise the antennae are 4-segmented and the 4th segment is much shorter than the body. Unguiculus and furcula always present. Inner edge of 
the unguis split longitudinally. Body scaled or hairy. Bothriotricha present.

Key to the Tribes of Entomobryinae

1. Antennae 4- to 6-segmented (if 4-segmented the 4th segment is annulated and as long as the whole body). The 4th abdominal tergite usually subequal to or a little longer than the 3rd. Mucro with an apical tooth, an anteapical and a basal spine. Orchesellini Börner, p. 77.

Antennae 4-segmented, the 4th segment never approaching the length of the body. 2.

2. Mucro as in the Orchesellini, or falcate. Dentes dorsally crenulate, bare or with fringed setae.

Entomobryini Börner, p. 64. Mucro long and slender, with apical and usually dorsal teeth. Dentes not dorsally crenulate, bearing large fringed scales on the upper surface. Cyphoderini Börner, p. 81.

TRIBE ENTOMOBRYINI BÖRNER, 1906

Antennae 4-segmented. The 4th abdominal segment usually at least 2.5 times the 3rd dorsally. Dentes dorsally crenulate. Mucro usually with an apical and an anteapical tooth and a basal spine; rarely falcate.

Key to the Genera of Entomobryini

1. Scales absent 2.

Scales present 4.

2. A double row of smooth bristles on the inside of the tibiotarsus. Tenent hair not strongly developed. Unguis often with a pair of strongly developed paramedian teeth. Eyes usually reduced

Sinella Brook, p. 65.

Smooth bristles (other than 1 subapical one) usually absent from the inner side of the tibiotarsus. Tenent hair well developed. Unguis without well developed paramedian teeth. Eyes 8 on each side

3. Mucro falcate 3.

Mucro with 2 teeth and a basal spine.

Entomobrya Rondani, p. 66.

4. Dentes ventrally with hairs. Scales with pointed tips and coarse, heavy ribs

Sira Lubbock, p. 71.

Dentes ventrally with scales. Body scales with rounded apices and with fine, short striations.............................. 5 .

5. Mucro with 2 teeth and a basal spine.................................. 7 .

Mucro falcate 6. 
6. The 4th antennal segment annulate

The 4th antennal segment simple

Lepidocyrtinus Börner, p. 73.

Drepanocyrtus Handschin, p. 73.

7. Unguis with well developed paramedian teeth. Tenent hair usually reduced. Pigmentation and eye number usually reduced, many species entirely white and blind

Pseudosinella Schäffer, p. 73.

Unguis with normal basal teeth. Tenent hair well developed. Pigmentation usually well developed. Eyes 8 on each side

Lepidocyrtus Bourlet, p. 72.

GENUS SINELLA BROOK, 1882

Pigmentation usually pale or absent. Eyes usually reduced in number. A pair of well developed paramedian teeth present at the base of the unguis. A double row of long, naked (or nearly so) hairs inwardly on the tibiotarsus. Tenent hairs reduced. Scales absent.

Key to the Species of Sinella

Eyes absent. Mucro falcate. höfti Schäffer, p. 65. Eyes 2 on each side. Mucro with 2 teeth and a basal spine. curviseta Brook, p. 6.5.

Sinella HöFti Schäffer, 1896

Entomobrya caeca Schött, 1896, S. tenebricosa Folsom, 1902.

Figs. 113, 114

Length up to $2 \mathrm{~mm}$. White. Eyes absent. Unguis (fig. 113) with 1 external, 2 lateral, and 3 inner teeth. Unguiculus with a large, acute, external lobe on the basal half. Tenent hair greatly reduced. Mucro (fig. 114) falcate, with a long basal spine. Body thickly covered with short, plumose hairs, and longer, clavate, fringed ones.

Taken in a cellar and in a sewage filter.

Ames : Sept. 2. Slater : May 16-H. E. Gorseline.

Calif., Mo., D. C. Cosmopolitan.

Sinella CURviseta Brook, 1882

Length up to $2 \mathrm{~mm}$. White, with minute rusty spots. Eyes 2 on each side. Unguis with 2 lateral and 3 inner teeth. Ungui- 
culus lanceolate, serrate on the outer edge. Tenent hair reduced. Mucro with an apical and an anteapical tooth and a basal spine.

Taken in a greenhouse.

Ames : May 18.

Calif., Wash. Cosmopolitan.

\section{GENUS ENTOMOBRYA RONDANI, 1861}

\section{DegeErIa Nicolet, 1841.}

Eyes 8 on each side. Pigment well developed. Basal teeth of the unguis not developed into large paramedian teeth. Bare bristles on the inner surface of the tibiotarsus usually absent. Mucro with an apical and a subapical tooth and a basal spine. Tenent hair well developed. Scales absent.

\section{Key to the Species of Entomobrya}

1. Unicolorous, or with the posterior margins of the segments darker. Body blue, gray or brown.................................. 2.

Not unicolorous. Pigment present in a definite pattern.... 4 .

2. Color gray to buff, rarely bluish. Posterior margins of the body segments darker. Inner face of the tibiotarsus with 2 rows of smooth hairs as in Sinella.

purpurascens Packard, p. 67.

Color blue or olive-gray, posterior margins of the body segments distinctly lined with dark. Inner face of the tibiotarsus without 2 rows of smooth hairs............................ 3.

3. Olive-gray. Antennae blue at the apices, segments 1 and 2 as $7: 14$. Abdominal segments 1 and 3 as $8: 9$.

griseo-olivata Packard, p. 68.

Blue-purple. Antennae all blue, segments 1 and 2 as $7: 19$. Abdominal segments 1 and 3 as $5: 10$. marginata Tullberg, p. 67.

4. Body with several transverse bands 5 Body with 1 transverse band which includes several segments 6.

5. Posterior margin of each segment with a well defined blue band and another across the middle of the 4th segment. Body yellow to white. multifasciata Tullberg, p. 69. Body irregularly banded (figs. 7, 8) .......assuta Folsom, p. 69 .

6. Body gray to bright yellow, with a broad blue band across the dorsum including the metathorax and the 1st 3 abdominal segments. clitellaria Guthrie, p. 70. 
Body red to black, with a broad dorsal band including the 1st, 2nd and part of the 3rd segment.

bicolor Guthrie, p. 70.

Entomobrya purpurascens (Packard), 1873

Figs. 6, 115, 116

Length up to $2.5 \mathrm{~mm}$. Color extremely variable, blue, brown or tan, the posterior margins of the segments dark. Furcula pigmented nearly to the tip. Legs colored but for the apices of the tibiotarsi. Antennae dark at the base, changing to blue at the tip. Eyes 8 on each side, the 2 anterior eyes larger than the rest. Antennae slender, usually about 2.7 times the head. The 4th abdominal segment 4 times the 3rd. Unguis (fig. 116) straight, with an external, 2 lateral, and 3 pairs of inner teeth. The basal pair are not opposite, the posterior one being more proximal. Unguiculus lanceolate. Tenent hair shorter than the unguis. Manubrium to the dentes as $59: 88$. Mucro normal. Tibiotarsus with a double row of smooth bristles on the inner face (fig. 115).

This species is the dominant Entomobryan form in the state. It is extremely abundant beneath bark. It is possibly the form described from Washington, D. C., by Moniez (1894) and redescribed by Denis (1923), as $E$. dissimilis.

Algona: Apr. 16-E. L. Mills. Ames: Apr. 7, 10; May 23; June 14, 17 ; July 15-H. M. Harris and F. Andre; Aug. 14; Oct. 4. Columbus Junction: Sept. 26. Ledges State Park: Oct. 31-L. Weber. LeGrand: Apr. 13; Aug. 18. New Sharon: Sept. 19-F. Andre. Shellrock: Oct. 14-B. V. Travis.

Ill., La., Mass., Me., Minn., N. D., N. H., N. Y., Tenn., Tex., Wis. Canada.

\section{Entomobrya marginata (Tullberg), 1871}

Fig. 117

Length up to $2 \mathrm{~mm}$. Deep blue-purple, the posterior borders of the segments dark; a broad, straight line between the eyes, and a dark lateral line on the body. Legs and furcula light. Antennae deep blue, lighter blue at the base. Eyes 8 on each side. Unguis with an outer, 2 lateral, and 3 inner pairs of teeth. Unguiculus slender. Tenent hair longer than the unguis. The 4th abdominal segment 3 or 4 times the 3 rd. The 1st antennal segment is to the 2nd as $7: 19$, and the 1st abdominal segment to the 
3rd as 5:10. Apical tooth of the mucro (fig. 117) rather long and out-reaching.

E. marginata bears a close superficial resemblance to the following species.

Ames : July 15-H. M. Harris and F. Andre; Nov. 24. Ill., Utah, Wash. Europe.

\section{Entomobrya GRISEo-olivata (Packard), 1873}

\section{Fig. 118}

Length up to $1.5 \mathrm{~mm}$. Olive-gray, the posterior borders of the body segments with a fine, dark line. A dark V-shaped line connecting the eyespots, and extending between the antennal bases. A dark line is also present along the lateral margins of the meso- and metathorax, extending onto the precoxae of the last 2 pairs of legs. Antennae yellow with the apices of the segments blue. Legs and furcula light. Eyes 8 on each side. Unguis (fig. 118) with an outer, 2 lateral, and 3 pairs of inner teeth. Unguiculus lanceolate. Tenent hair slender, longer than the unguis. The 4th abdominal segment about 3 times the 3rd. Manubrium to the dentes as $7: 11$. The 1 st antennal segment is to the 3 rd as $7: 14$, and the 1 st abdominal segment to the 3rd as $8: 9$. Apical tooth of the mucro roundly curving.

Not uncommonly taken in ground cover.

This species may be distinguished from the preceding by the following comparative table arranged by Dr. Folsom:

\section{E. griseo-olivata}

A V-shaped mark between the eyes.

Apices of the antennal segments blue.

Body olive-gray.

1st antennal segment to the 2nd as $7: 14$.

1st abdominal segment to the 3rd as $8: 9$.

Smooth distal part of the dens

3.5 times the mucro.

Apical mucronal tooth roundly up-curving.
E. marginata

A wide, straight line between the eyes.

Antennae colored throughout.

Body purple-blue.

1st antennal segment to the 2 nd as $7: 19$.

1st abdominal segment to the 3rd as $5: 10$.

Smooth distal part of the dens 2 times the mucro.

$\Lambda$ pical tooth of the mucro long, extending postero-dorsally.

Ames: July 15. Iowa City: Oct. 4. Malvern: Sept. 8. Mass., N. Y., Ohio, Tenn., Wash. 


\section{Entmobrya multifasciata (Tullberg), 1871}

Deegeria decemfasciata Packard, 1873.

Length up to $2 \mathrm{~mm}$. Yellow to white wtih blue pigment. A line connecting the eyespots. Mesonotum with anterior, lateral, and posterior pigment. An irregular posterior transverse line across each body segment, and an extra one across the middle of the 4th segment. Antennae blue. Eyes 8 on each side. Antennae 2.5 times the head. The 4th abdominal segment about 3 times the 3rd. Unguis with 1 outer, 2 lateral, and 3 pairs of inner teeth. Tenent hair heavy, subequal to the unguis in length. Mucro normal.

The specimens referred to E. multifasciata in the list of Iowa Collembola (Mills, 1930), were heavily pigmented specimens of E. purpurascens. It is surprising that it has not been met with more commonly in the state, as it is abundant throughout the country.

Ames : Nov. 24, 30.

Ariz., Calif., Colo., Conn., Idaho, Ill., Kans., Mass., Me., Mich., Minn., Tenn., Tex., Utah. Ontario. Cosmopolitan.

\section{Entomobrya assuta Folsom, 1924}

Figs. 7, 8

Length up to $2 \mathrm{~mm}$. Light yellow, with blue pigment. Head with a connecting line between the eyes, and darker shading behind the eyespots. Pronotum banded anteriorly and posteriorly with blue, occasionally some blue on the disk. Metanotum light only on the anterior margin. The 1st abdominal segment with a broken, transverse line; 2nd segment with the posterior half colored; 3rd entirely blue dorsally; 4th with the posterior half irregularly colored; 5th and 6th light only dorsally. Eyes 8 on each side. Antennae about twice the head. The 4th abdominal segment 3 to 4 times the 3rd. Unguis with 3 pairs of inner and 1 pair of lateral teeth. Unguiculus slender. Tenent hair well developed. Manubrium 0.6 the dentes. Mucro of the usual shape.

I have seen a completely dark form of this species in Texas.

Not uncommon beneath bark, in company with $E$. purpurascens.

Ames : Mar. 21-J. E. Guthrie; Apr. 7, 26, 28 ; May 27 ; June 28; Aug. 21-J. A. Kartchner. Anamosa : July 25. Central City: Aug. 11. Columbus Junction: Sept. 25. Hancock: Oct. 9-F. 
Andre. Ledges State Park: July 16. Mt. Pleasant: Mar. 15; Apr. 2-H. R. Knight. Shellrock: Oct. 14-B. V. Travis.

Ill., Kans., N. Y., Tex., Vt.

\section{Entomobrya clitellaria Guthrie, 1903}

Figs. 10, 119

Length up to $1.8 \mathrm{~mm}$. Color usually light yellow with blue pigment. All specimens taken in Iowa were much darker than the typical Minnesota form. Head with irregular lateral marks. Mesonotum anteriorly and laterally blue, the disk white. A dorsal blue band including the segments from the metathorax to the 3rd abdominal segment; 3rd paratergite blue; 4th abdominal segment clouded laterally and posteriorly, and 5th and 6th segments dorsally. Legs and furcula light. Antennae blue. Eyes 8 on each side. Antennae about 2.5 times the head, the segments as $4: 7: 6: 7$. The 4 th abdominal segment from 4 to 5 times the 3rd. Unguis (fig. 119) with 1 outer, 2 lateral, and 3 pairs of inner teeth. Unguiculus slender. Tenent hair longer than the unguis. Mucro typical.

Taken beneath bark.

Ames : Mar. 26 ; Apr. 2; Oct. 3. Ledges State Park: July 16. Leon: Oct. $31-$ B. V. Travis.

Ill., Minn., N. Y. Ontario. Australia.

\section{Entomobrya BICOLOR Guthrie, 1903}

Length up to $3 \mathrm{~mm}$. Color varying from red through chocolatebrown to black, with a yellow-white transverse band including the 1st, 2nd and part of the 3rd abdominal segments. Under parts lighter. Legs, furcula and antennae yellow, the antennae becoming purple toward the tip. Eyes 8 on each side. Antennae 3 to 4 times the length of the head, the segments as $10: 17: 17: 23$. The 4th abdominal segment 6 to 7 times the 3rd. Unguis with a pair of lateral teeth and 3 pairs of inner teeth. Unguiculus slender. Tenent hair well developed. Dentes long and slender. Mucro typical but small.

This is the largest and most striking species of the genus in our territory. Its large size and conspicuous color make it at once evident to the collector. Taken in grass and under bark.

Ames : Mar. 30 ; May 16, 23 ; June 10; July 15-H. M. Harris and F. Andre; Aug. 18; Sept. 16-F. Andre. Central City: Nov. 24.

Kans., Minn., N. C. 
GENUS DREPANURA SCHÖTT, 1891

Entomobryan forms with falcate mucrones.

This genus is known to me in North America in Calif., Tex., Utah, and Wash.

GENUS SIRA LUBBOCK, 1869

Eyes 8 on each side. Body scaled, the scales pointed, with heavy ribs. Tenent hairs well developed. Mucro as in Entomobrya. Mesonotum not projecting to any extent over the pronotum. Dentes with hairs ventrally.

Key to the Species of Sira

Body blue to violet, the head lighter. buski Lubbock, p. 71. Body yellow to gray with blue spots and crossbands platani Nicolet, p. 71.

SiRA BUSki Lubbock, 1869

Length up to $2 \mathrm{~mm}$. Blue to violet, the head, legs, furcula and antennal bases lighter. Eyes 8 on each side. Unguis nearly straight, with 2 lateral and 2 pairs of inner teeth. Unguiculus lanceolate. Tenent hair well developed. The 4th abdominal segment 3 to 4 times the 3rd. Mucro normal.

A rather common resident of dwelling houses, also occasionally met with beneath bark.

Ames: Mar. 30; Apr. 1, 2; May 3, 27 ; June 12, 28 ; July 13; Aug. 8. Marshalltown: Aug. 7.

Colo., Fla., Ill., Mass., Me., Minn., N. Y., Pa., Vt., Wash. Alberta, Ontario. Europe.

\section{Sira Platani (Nicolet), 1841}

S. nigromaculata Lubbock, 1870,

S. mimica Harvey, 1894,

Lepidocyrtus americanus Marlatt, 1896.

Length up to $2 \mathrm{~mm}$. Yellow to silver-gray. Irregular blue markings anteriorly on the mesonotum and laterally along the body; crossbands occurring posteriorly on the 3rd, 4th and 5th abdominal segments, the 6th partially or completely blue. A blue spot occurs near the middle on each side of the 4 th segment. Antennae darker apically. The 4th abdominal segment 4 to 7 times the 3rd. Unguis with 2 lateral and 2 pairs of inner teeth. Unguiculus lanceolate. Tenent hairs well developed. Mucro normal. 
Handschin (1926) has shown that S. nigromaculata is a color form of $S$. platani (Nic.). As far as I am aware, the nigromaculata form is the only one which occurs in North America, however.

Taken in buildings and rarely beneath bark.

Ames : Mar. 27, 29 ; Apr. 1, 3, 7; May 19; June 12. Anamosa : July 25. Des Moines: Aug. 15, 26. LeGrand: Aug. 9, 18. Washington : May 19 -J. E. Guthrie.

Fla., Ill., Kans., La., Mass., Me., Minn., N. Y., Tex. Ontario. Europe.

\section{GENUS LEPIDOCYRTUS BOURLET, 1839}

Eyes 8 on each side. Body scaled, the scales rounded or irregular, with numerous, fine striations. Basal teeth of the unguis not greatly enlarged. Tenent hair well developed. Mucro as in Entomobrya. Mesonotum usually projecting more or less over the pronotum. Dentes ventrally with scales.

Key to the Species of Lepidycyrtus

Color blue to gray. Prothorax massive, projecting but little anteriorly. cyaneus Tullberg, p. 72.

Color white, with antennae and occasional diffuse pigment anteriorly blue. Pronotum projecting anteriorly over the head. curvicollis Nicolet, p. 73.

LePIdocyrtus cyaneus Tullberg, 1871

L. metallicus Packard, 1873

Length up to $1.5 \mathrm{~mm}$. Blue to gray, pigment rarely broken to form indefinite crossbands, the anterior borders of the body segments usually lighter. Antennae 2 or 3 times the length of the head. Eyes 8 on each side. Mesonotum massive, but not projecting greatly. The 4 th abdominal segment 3 to 4 times the 3rd. Unguis with lateral and 2 pairs of inner teeth. Unguiculus lanceolate. Tenent hair well developed. Manubrium shorter than the dentes. Mucro normal.

$L$. cyaneus is extremely common throughout the state, beneath bark, in humus, and in moss. It is represented by 3 varieties which may be separated as follows:

1. Blue pigment separated into 5 crossbands

aenescens Guthrie.

Pigment lighter anteriorly on the body segments, but not separated into crossbands.

2. Deep blue. 2.

Blue-gray. cyaneus f. p. cinereus Folsom. 
Ames : humerous collections. Central City: July 25. Columbus Junction: Sept. 26. Jewell: Apr. 9. Ledges State Park: Oct. 31-L. Weber. Leon: May 28-B. V. Travis. Little Wall Lake: Oct. 14 -G. C. Decker. Mitchellville: Mar. 31. Ruthven: Oct. 2-H. M. Harris and B. V. Travis.

Ill., Kans., La., Mass., Me., Md., Minn., N. Y., Ohio, Tenn., Tex., Utah, Wash. Alaska. Greenland. Ontario. Cosmopolitan.

LePIDOCYRTUs CURVICOLLIS Bourlet, 1839

Figs. 9, 120, 121

Length up to $3 \mathrm{~mm}$. Entirely white but for the black eyespots, diffuse pigment on the head, point of mesonotum, coxae, precoxae, and antennae. Antennae to the head as $8: 5$, the segments as $13: 22: 22: 27$. Eyes 8 on each side. The 4 th abdominal segment about 6 times the 3rd. Unguis (fig. 120) straight, with an external tooth, 2 large pseudonychia, and 3 pairs of inner teeth. Unguiculus slender, sometimes outwardly serrate. Tenent hair well developed. Manubrium to the dentes as $3: 4$. Mucro normal (fig. 121), the apical tooth not strongly up-curved. Mesonotum projecting strongly anteriorly.

Taken in a cellar and occasionally in humus. The specimens from the cellar were considerably larger than those taken in humus, the latter reaching a length of $1.3 \mathrm{~mm}$.

Central City: July 25; Aug. 11. Eldora: Nov. 10. Ledges State Park: July 16; Oct. 31-L. Weber. Ottumwa : Nov. 28F. Andre. Ruthven: Oct. 2-H. M. Harris and F. Andre.

Ill., Me., N. Y., Pa. Ontario. Europe.

GENUS DREPANOCYRTDS HANDSCHIN, 1925

Lepidocyrtus forms with falcate mucrones, and the 4th antennal segment simple.

A species of this genus occurs in the college greenhouse. 1 have been unable to identify it.

\section{GENUS LEPIDOCYRTINUS BöRNER, 1903}

Lepidocyrtus forms with the mucro falcate and the 4th antennal segment annulate.

Not known in the United States.

GENUS PSEUDOSINELLA SCHÄFFER, 1897

Eyes usually reduced in number or absent. Pigment usually absent. Body scaled as in Lepidocyrtus. Paramedian teeth of the 
unguis present. Tenent hair usually weakly developed. Mucro as in Entomobrya.

Key to the Species of Pseudosinella

1. Eyes present 2.

Eyes absent 5.

2. Eyes 8 on each side candida Folsom, p. 74.

Eyes less than 8 on each side

3. Eyes 4 on each side 3. Eyes less than 4 on each side

4. Eyes 3 on each side.

5. Tenent hair heavy, with octopunctata Börner, p. 74. 4. sexoculata Schött, p. 75. Mesonotum extremely massive, cape-like, extending laterally. Broadest at mesonotum rolfsi Mills, p. 76.

Tenent hair slender, but slightly knobbed. Mesonotum not strikingly broadened. Body usually spindle-shaped

violenta Folsom, p. 76.

\section{Pseudosinella candida Folsom, 1902}

Figs. 122, 123

Length up to $1.1 \mathrm{~mm}$. White but for traces of pigment where the eyespots usually occur, and occasionally a V-shaped interocular mark. Eyes 8 on each side (fig. 122). Antennae slightly longer than the head, the segments as $7: 12: 10: 19$. Body segments from the mesonotum posteriorly as $30: 14: 10: 15: 15: 48: 9: 8$, thus the 4th segment is more than 3 times the 3rd. Unguis (fig. 123) rather straight, with a minute external tooth, and 3 inner teeth, the posterior paramedian tooth proximad of the anterior one. Unguiculus outwardly serrate. Tenent hair weak, not capitate. Manubrium to the dentes as $6: 7$. Mucro slender.

I am identifying this species as $P$. candida, although it differs from the type material in several respects. As the original description (Folsom, 1902) was from 3 specimens, and as I have seen but 2 , the variation in the species is unknown.

Taken in sod and beneath bark.

Ames : Oct. 25; Nov.

D. C.

\section{Pseudosinella octopunctata Börner, 1901}

Fig. 124

Length up to $1 \mathrm{~mm}$. White, rarely with rusty spots; antennae blue, head light blue-gray. Eyes (fig. 124) 4 on each small, cir. 
cular eyespot. Antennae half again as long as the head, the segments as $3: 7: 8: 16$. The 4 th abdominal segment about 3 times the 3rd. Unguis with a pair of lateral and 3 inner teeth, the 2 paramedian teeth not opposite. Unguiculus lanceolate. Tenent hair slightly capitate. Manubrium and dentes subequal. Mucro of the usual type.

The identification of this species has been verified by Dr. Stach, to whom I sent specimens.

Taken in humus and on the surface of soil.

Ames: July 15-H. M. Harris and F. Andre; Sept. 18- F'. Andre. Hampton: June 18-G. C. Decker and B. V. Travis. LeGrand: Nov. 1. Rock Rapids : Aug. 16-E. L. Mills.

Calif., Wash. Europe.

Pseudosinella sexoculata Schött, 1902

Lepidocyrtus sexoculatus Guthrie, 1903

Fig. 125

Length up to $1 \mathrm{~mm}$. White, speckled with red. Eyes black, 3 on each side (fig. 125). Antennae longer than the head, the segments about as $9: 13: 8: 16$. The 4 th abdominal segment 3 to 4 times the 3rd. Unguis with 2 lateral and 3 inner teeth, the paramedians not opposite. Unguiculus often serrate outwardly. Tenent hair reduced, but slightly capitate. Manubrium slightly shorter than the dentes. Mucro as usual.

Taken in cellars and rarely beneath bark.

Ames : Mar. 7-J. E. Guthrie, 28 ; June 30 ; Sept. 2. Anamosa : July 25. Central City: July 25.

Calif., Minn., N. Y., Utah, Wash. Europe.

\section{Pseudosinelia alba (Packard), 1873}

Length up to $1 \mathrm{~mm}$. White. Eyespots black, each with 2 eyes. Antennae half again as long as the head, the segments about as $10: 15: 14: 25$. The 4 th abdominal segment 2 to 3 times the 3 rd. Unguis with 2 lateral and 3 inner teeth, the paramedians not opposite, the posterior one being more proximal and larger. Unguiculus often serrate on its outer border. Tenent hair reduced. Manubrium to the dentes approximately as $3: 4$. Mucro as usual.

Taken, but not abundantly, from leaf mold.

Ames : Jan. 25 ; Apr. 2 ; Sept. 25 ; Oct. 20 ; Dec. 3.

Mass., Me., N. Y., Ohio, Tenn. Europe. 


\section{Pseudosinella violenta (Folsom), 1924}

Cyphodeirus albinus Guthrie, 1903

Length up to $1.5 \mathrm{~mm}$. White. Eyes absent. Body not strikingly broad across the mesonotum, usually spindle-shaped. Antennae half again as long as the head. The 4th abdominal segment is to the 3rd about as $5: 2$. Unguis with 2 lateral and 3 inner teeth, the paramedian tooth on the posterior lamella enlarged, and the anterior one reduced. Unguiculus lanceolate, with a large, acute outer lobe ending at about half its length. Tenent hair slender, weakly capitate. Manubrium slightly shorter than the dentes. Mucro slender.

This species resembles $P$. petterseni Börner, of Europe, from which it differs in the reduction of the anterior paramedian tooth of the unguis, and in the longer unguiculus. The species recorded from Costa Rica by Denis (1931b, p. 144) as P. petterseni forma $C . R$., is without doubt $P$. violenta. $P$. violenta is the most common species of the genus in our territory, being found in soil, in humus, under bark, in greenhouses, with ants, etc.

Ames: July 15 ; Oct. 4. Anamosa: July 25. Columbus Junction: Sept. 26. Hampton: June 18-G. C. Decker and B. V. Travis. LeGrand: Aug. 9. Rock Rapids: Aug. 16-E. L. Mills. Ruthven: Oct. 2-H. M. Harris and B. V. Travis. Valley Junction: May 1.

Ark., Calif., Ill., La., Mass., Minn., N. Y., Tenn., Tex., Utah, Wash. Ontario. Costa Rica.

\section{Pseudosinella rolfsi Mills, 1932}

Figs. 126, 127

Length up to $1.8 \mathrm{~mm}$. Eyes absent. White. Mesonotum massive, broad and cape-like. Antennae half again as long as the head. The 4th abdominal segment 3 to 4 times the 3rd. Unguis (figs. 126, 127) with 2 lateral and 3 inner teeth, the posterior paramedian tooth enlarged, and the anterior one greatly reduced. Unguiculus with a large, acute, external lobe ending at about its middle. Tenent hairs extremely heavy, enlarged basally and with a large, triangular, apical swelling. Manubrium to the dentes as 2:3. Mucrones slender, the basal spine long.

Young specimens of this species are very similar to those of the preceding species. 
Taken in the same situations as the preceding form. Ames: Apr. 20 ; July 16; Sept. 25. LeGrand: Aug. 9. Wash.

\section{TRIBE ORCHESELLINI BÖRNER, 1906}

Antennae 4-, 5-, or 6-segmented. The 4th abdominal segment less than 3 times the 3rd. Mucro as in Entomobrya. Scales present or absent.

Key to the Genera of Orchesellini

1. Body scaled

Body unscaled. Antennae 6-segmented. The 4th abdominal segment about 2 times the 3rd

Orchesella Templeton, p. 78.

2. Antennae 4-segmented, the 4th segment annulate and longer than the body. The 4th abdominal segment but slightly longer than the 3rd Typhlopodura Absolon, p. 77.

Antennae 5-segmented, the 1st segment small. The 4th abdominal segment never more than 3 times the 3rd

Heteromurus Wankel, p. 77.

GENUS TYPHLOPODURA ABSOLON, 1900

Eyes absent. Antennae 4-segmented, the 1st segment short, the last annulate and as long as the body. The 4th abdominal segment but slightly longer than the 3rd. Body scaled.

A cavernicolous genus not yet found in North America.

GENUS HETEROMURUS WANKEL, 1861

Templetonia Lubbock, 1862

Eyes present or absent. Antennae 5-segmented. The 4th abdominal segment never more than 3 times the $3 \mathrm{rd}$. Scales present.

Heteromurus nitidus (Templeton), 1835

Templetonia americana Harvey, 1892,

Lepidocyrtus marmoratus Packard, 1873.

Fig. 128

Length up to $2 \mathrm{~mm}$. White, with salmon-red spots. Eyespots weakly delineated. Antennae twice the length of the head, the 5th segment annulate; the segments about as $3: 8: 14: 17: 24$. Eyes 2 on each side. Unguis (fig. 128) with 3 inner teeth, 2 lateral teeth, and occasionally an outer tooth. Tenent hair unknobbed. Abdominal segments 3 and 4 as $2: 3$. Manubrium less than half 
the dentes. Mucro as in Entomobrya. Bare area at the apex of the dens about 5.5 times the mucro.

Taken in a cellar.

Ames : Sept. 2.

Mass., Me., N. Y. Ontario. Europe.

GENUS ORCHESELLA TEMPLETON, 1835

Eyes 8 on each side. Antennae 6-segmented. The 4th abdominal segment never more than twice the 3rd. Scales absent.

Key to the Species of Orchesella

1. The 3rd antennal segment well formed, distinctly separated from the 4th (fig. 130), and usually with an apical ring of pigment 2.

The 3rd antennal segment small, not well separated from the 4th (fig. 131), without an apical ring of pigment............ 3 .

2. Color yellow to light brown. Antennae, and rarely diffuse shadings on the cheeks and sides, purplish

albosa Guthrie, p. 80.

Yellow to brown, with 4 (rarely 5 ) longitudinal blue stripes, broadening into crossbands on each segment from the 2nd abdominal posteriorly ainsliei Folsom, p. 80.

3. Greenish yellow. Purple pigment forming broad crossbands, rarely broken laterally to form indistinct, broken, lateral lines. Front of head not blue-black.

hexfasciata Harvey, p. 79.

Tawny yellow. Front of head blue-black. Very narrow, dark, posterior borders to some of the body segments. Blue shadings sometimes present laterally

annulicornis n. sp., p. 78 .

\section{Orchesflla anNulicornis, n. sp.}

Figs 11, 129

Tawny yellow to buff, with purple pigment. Front of the head deep blue. Scattered pigment along the sutures, widening to form a fine, interrupted, mid-dorsal line which is most evident from the metathorax to the 3rd abdominal segment, and a suggestion of a ventro-lateral and a lateral line on each side. Venter blue. The 1st 2 antennal segments blue, 3rd white, 4th white basally, 5th with the apical half blue, 6th light purple but for the base. Tibiotarsi light blue, some external pigment on the femora, trochanters, coxae, and precoxae. Furcula colorless. Eyes 8 on each side. Antennae variable in length, usually more 
than 2.5 times the head, the segments approximately as $4: 16: 6$ : $20: 25: 30$; the 3rd segment rather indistinctly separated from the 4th. The 3rd abdominal segment is to the 4 th as $3: 4$. Unguis (fig. 129) slightly curving apically, with 1 outer, 2 lateral, and 3 pairs of inner teeth. Unguiculus about 0.6 the unguis, with a small outer tooth. Tenent hair well developed. Manubrium to the dentes as $9: 14$. Large, dorsal dental corrugations gradually tapering out apically, but extending minutely to the base of the mucro, which is of the usual shape. Clothing of short, reclinate setae and longer, fringed, often clavate bristles. Length up to $2.2 \mathrm{~mm}$.

This interesting and well-marked species is a resident of moss, being taken in association with Isotoma andrei and Tomocerus lamelliferus.

Ottumwa: Sept. 9-F. Andre. Garden Grove: Oct. 10-B. V. Travis.

Florida : Mar. 3-Van Hyning.

Orchesella hexfasciata (Harvey), 1895

Fig. 131

Length up to $2 \mathrm{~mm}$. Green-yellow, with purple pigment anteriorly and laterally on the mesonotum, and in crossbands anteriorly on the metanotum, brokenly across the 1st abdominal segment, anteriorly on the 2nd, across the middle of the 3rd, posteriorly on the 4 th, across the middle of the 5 th ; 6 th segment dark apically. Head lightly and irregularly pigmented, with a black, transverse line across the front. Antennae light basally, dark apically. Legs and furcula sometimes lightly colored. Lateral pigment of the body rarely broken to form 2 broken stripes on each side. Eyes 8 on each side. Antennae slightly more than twice the head, the segments about as $3: 12: 4: 16: 19: 25$; the 3rd segment rather indistinct (fig. 131), and without pigment. The 3rd abdominal segment to the 4 th as $7: 11$. Manubrium to the dentes as $11: 15$; mucro as usual. Unguis with 1 external, 2 lateral, and 3 pairs of inner teeth. Unguiculus rather broad, with a large external tooth. Tenent hair well developed.

Taken beneath bark and from humus.

Ames : Aug. 8 ; Sept. 7. Columbus Junction : Sept. 26. Eldora : Nov. 10. Hampton: June 18-G. C. Decker and B. V. Travis. 
Ledges State Park: July 16; Oct. 31-L. Weber. LeGrand: Apr. 14 -E. L. Mills.

Ill., La., Mass., Me., N. H., N. Y., Va., Wis. Ontario.

\section{Orchesella albosa Guthrie, 1903}

Length up to $2.5 \mathrm{~mm}$. White, through yellow to deep buff, rarely a tinge of blue on the genae and on the side of the body. Antennae purple, the pigment deepest at the apex, and forming apical rings on the 4 basal segments. Antennae about 3 times the head, the 5th and 6th segments obscurely annulate, the segmental proportions about as $2: 11: 5: 12: 18: 26$. Eyes 8 on each side. Unguis (fig. 132) with lateral and 3 pairs of inner teeth. Unguiculus lanceolate, with an outer tooth. Tenent hair slightly shorter than the unguis. The 3rd abdominal segment is to the 4 th as $7: 12$. Manubrium to the dentes as $11: 15$. Mucro normal.

The type series was taken beneath boards at Minneapolis by Prof. Guthrie. All of my records are from swampy areas or lake shores, where the species was associated with Isotomurus palustris. The first ones were taken while sweeping grass in a boggy pasture.

Ames : May 8, 15, 20, 29 ; June 17; Oct. 12-L. Weber. Little Wall Lake: Oct. 12-G. C. Decker. Ruthven: Oct. 2-H. M. Harris and B. V. Travis.

Mass., Minn.

Orchesella ainsliei Folsom, 1924

Fig. 130

Length up to $2 \mathrm{~mm}$. Yellow to light brown with dark pigment. Body with 2 broken lateral stripes which unite over the dorsum of each segment from the 2nd abdominal segment posteriorly. Venter, legs, furcula, and head (except the genae) light. Antennae dark toward the apex, the 5 basal segments with apical pigment rings. Antennae about 3 times the head, the last 2 segments obscurely annulate. Eyes 8 on each side. Unguis with lateral and 3 pairs of inner teeth. Unguiculus slender, with a minute apical notch. Tenent hair long. The 3rd abdominal segment is to the 4th as $12: 19$. Manubrium to the dentes as $17: 23$. Mucro normal.

A variable species. Rarely the posterior crossbands are missing, and in Texas I have seen a variety with a slender mid-dorsal line. The species is extremely abundant in the state. 
Adel : Sept. 24. Albia: Feb. 27-H. R. Knight. Ames : Mar. 30 ; Apr. 2; June 10, 17, 25 ; Aug. 4; Sept. 15-F. Andre, 22G. O. Hendrickson; Oct. 20-F. Andre; Nov. 8. Ledges State Park: July 16. LeGrand: Apr. 14; Aug. 18; Sept. 1. Mt. Pleasant: Mar. 15-H. R. Knight. New Sharon: Sept. 19-F. Andre. Shellrock: Oct 14. Valley Junction : May 1.

Ill., La., N. C., N. Y., Pa., Tenn., Tex. Ontario. Europe.

\section{TRIBE CYPHODERINI BÖRNER, 1906}

Eyes absent. Dentes not corrugated dorsally, bearing on the dorsal surface a double row of large fringed scales. Mucro long and slender, with apical and often dorsal teeth. Scales present.

\section{GENUS CYPHODERUS NICOLET, 1841}

Borecus Folsom, 1923

Postantennal organ absent. Eyes absent. Scales present. Dentes with 2 dorsal rows of fringed scales. Mucro slender, with apical and often dorsal teeth, without mucronal bristles.

\section{Cyphoderus similis Folsom, 1927}

Fig. 133

Length up to $1.2 \mathrm{~mm}$. White. Eyes absent. Antennae longer than the head, proportions of the segments $2: 5: 3: 6$. The 4 th abdominal segment about 3 times the 3rd. Unguis with large paramedian teeth, the anterior one narrow, the posterior one broad and lanceolate. Median teeth 1 or 2. Unguiculus with a large, pointed outer lobe. Tenent hair weak, shorter than the unguis. Dentes shorter than the manubrium; mucrones about half the dentes. Dens with 5 inner dorsal scales, and 6 or 7 in the outer series, the apical one slightly shorter than the mucro. Mucro (fig. 133) with an apical and an anteapical tooth, a small triangular lamella running from the apex of the anteapical tooth to the shaft of the mucro. Body covered with scales which give it a dusky appearance.

This Central American species has been taken only in the college greenhouse.

The genus probably does not occur in North America outside of such sheltered places. The records of $C$. albinus of Guthrie (1903) and Bacon (1914) refer to Pseudosinella violenta Folsom.

Ames: Jan. 8; Apr. 2; July 16; Aug. 16. 


\section{SUBFAMILY TOMOCERINAE SCHÄFFER, 1896}

Postantennal organ absent. The 4th abdominal segment subequal to or shorter than the 3rd. Antennae 4-segmented, the last 2 segments annulate, and the 3rd segment much longer than the 4th. Unguiculus and furcula present. Mucro long and slender, with apical and dorsal teeth, covered with hairs. Body scaled. Bothriotricha present. Dental spines present.

Key to the Genera of Tomocerinae

Eyes present. Tenent hair present........Tomocerus Nicolet, p. 82. Eyes absent. Tenent hair absent....Tritomurus Frauenfeld, p. 84.

\section{GENUS TOMOCERUS NICOLET, 1841}

Macrotoma Bourlet, 1839.

Eyes present, 6 on each side. Tenent hair well developed (small in T. lamelliferus), with a large distal knob.

To this genus belong our largest and most conspicuous species, some reaching a length of $6 \mathrm{~mm}$.

Börner has placed in the subgenus Pogonognathus those species of Tomocerus in which the maxilla bears a slender, bearded ap. pendage. The only Iowa species which falls in that group is T. flavescens Tullberg.

It is customary to represent the dental spines in a formula, the large spines designated by numbers in bold face type, and the small spines by numbers in the usual type, beginning at the proximal end of the series. The transverse suture of the dens which divides the series of the spines is represented by an oblique line. Extremities in variation are separated by a dash. For example, the dental formula of T. lamelliferus (fig. 134) would be represented as follows : 2-3, 1/1, 1, 2-3, 1 .

\section{Key to the Species of Tomocerus}

1. A long, narrow lamella extending from the anteapical tooth of the mucro to the inner basal tooth

lamelliferus n. sp., p. 84.

Mucro without a long, intermediate lamella 2.

2. Intermediate dental spines unequal, with a large spine near the middle of the series; 1 large distal spine

vulgaris Tullberg, p. 83.

Intermediate dental spines gradualy increasing in size distally; 2 large distal spines..........flavescens Tullberg, p. 83. 


\section{Tomocerus FLAVESCEns (Tullberg), 1871}

Length up to 5 (rarely 6) $\mathrm{mm}$. Body yellow to purple-gray when denuded of scales. Antennae shorter than the body. Unguis with 2 to 4 inner teeth, large pseudonychiae, and basal folds. Unguiculus lanceolate, usually with an inner tooth. Tenent hair heavy. Eyes 6 on each side. The last 2 antennal segments annulate, the 4th much shorter than the 3rd. Dentes with 7 to 13 inner basal spines of the formula 1-2/4-9, 2. Intermediate teeth of the mucro from 5 to 12 , usually 7 or 8 .

Very common beneath logs and in decaying leaves.

$T$. flavescens occurs in the state in 2 varieties, separated as follows :

Teeth of the unguis 3, 1 large proximal dental spine

separatus Folsom.

Teeth of the unguis 3 or 4, 2 large proximal dental spines

americanus Schött.

Ames: Apr. 1, 8; May-J. E. Guthrie; June 17, 18; Aug. 9; Oct. 31. Burlington: July-J. E. Guthrie. Columbus Junction: Sept. 26. LeGrand: Apr. 14; Aug. 18. Maquoketa Caves: May 8.

Calif., Colo., D. C., Ga., Ill., Ind., La., Mass., Md., Me., Mich., Minn., Miss., N. C., N. H., N. M., N. Y., Ohio, Ore., Pa., Tenn., Tex., Wash. Alberta. British Columbia. Nova Scotia. Ontario. Europe.

\section{Tomocerus vULGaris (Tullberg), 1871}

Length up to $4 \mathrm{~mm}$. Body yellow to gray when denuded of scales. Antennae shorter than the body, often with a purple cast. Unguis with 4 to 6 inner teeth, pseudonychiae, and basal folds. Unguiculus lanceolate, often with an inner tooth. Tenent hair heavy. Eyes 6 on each side. Last 2 antennal segments annulate, the 4 th much shorter than the 3rd. Dentes with 12 to 18 inner basal spines each, usually with 13 to 15 , of the formula 4-6, $1 / 2-5,1,2,1$; rarely $4-7,1 / 2-5,1,1-3,1$. Intermediate teeth of the mucro 7 to 11 .

Taken in cellars and in leaf mould.

Ames: Apr. 7 ; May 13-J. E. Guthrie; June 30; Sept. 2; Oct. 25. Central City: May 23; July 25; Aug. 11. LeGrand: Apr. 13. Tabor: Sept. 15.

Colo., Ill., Mass., Md., Me., Minn., N. H., N. Y., Pa., Tex., Wash. Ontario. Europe. 
Tomocerus lamelliferus n .sp.

Figs. 134-136

Head and body light blue-gray, the front darker. Pigment diffuse, lighter along the sutures. Eyespots black. Antennae blue, deeper toward the apex. Legs, furcula and venter lighter. Scales dusky. Eyes 6 on each side. Antennae about twice the head, the segments approximately as $8: 19: 60: 30$, the 3rd and 4th segments annulate. Maxilla head without a tuft of hairs. Unguis (fig. 135) broad, slightly curving apically, with a spine-like inner tooth at the extreme base, and 3 (rarely 4) beyond this basal one. Pseudonychiae and basal folds present. Unguiculus broadly lanceolate, without teeth. Tenent hair well developed but small. The 3rd and 4th abdominal segments subequal. Furcula quite slender, the proportions as $14: 21: 9$. Dental formula $2-3,1 / 1,1,2-3,1$, the basal group not in a straight line (fig. 136). Mucro with an apical and an anteapical tooth, 2 opposite basal teeth, and 1 to 4 intermediate teeth. A long, narrow lamella connects the inner basal tooth with an anteapical one, and small anterior lamellae run from the mucronal base to the apices of the 2 basal teeth. Length up to $2 \mathrm{~mm}$.

This well defined species was taken from moss, humus, and once beneath boards.

Ames : Oct. 16. Columbus Junction: Sept. 26. Ottumwa : Sept. 16-Zella Beck, 19-F. Andre. Traer: Nov. 25-H. M. Harris.

Ontario : Arnprior : May 3-C. Macnamara. Florida : Mar. 3O. C. Van Hyning.

GENUS TRITOMURUS FRAUENFELD, 1854

Eyes absent. Tenent hair absent. Otherwise very similar to Tomocerus.

Not known in Iowa. 


\section{SUBORDER SYMPHYPLEONA BÖRNER, 1901}

Body subglobose. Thorax and the first 4 abdominal segments fused into a single mass with indistinct separating sutures. The 5 th and 6 th abdominal segments usually separated from the rest of the body mass, forming the anal papilla. Sacs of the ventral tube large, often warty. Anal appendages of the female rarely absent.

\section{Key to the Families of Symphypleona}

Antennae much shorter than the head. Extremely small insects.

Dentes sometimes 2-segmented (fig. 12).

Neelidae Folsom, p. 85. Antennae longer than the head. Body size variable. Dentes 1segmented (fig. 13) Sminthuridae Lubbock, p. 86.

\section{FAMILY NEELIDAE FOLSOM, 1896}

Antennae shorter than, and inserted near the middle of, the head; 4-segmented, the 4th segment simple. Thorax greatly enlarged. Anal papilla reduced. Dentes 1- or 2-segmented. Minute forms.

Key to the Genera of Neelidae

Body segmentation obsolete. Dentes 1-segmented or indefinitely divided. Body without sense pits...........Neelus Folsom, p. 85. Body segmentation indicated. Dentes definitely 2-segmented. Body with sense pits...................Megalothorax Willem, p. 85.

GENUS NEELUS FOLSOM, 1896

Body without sense pits. Dentes 1- or 2-segmented. Not as yet found in Iowa.

GENUS MEGALOTHORAX WILLEM, 1900

Amerus Collinge and Shoebotham, 1909

Body with sense pits. Dentes 2-segmented.

Megalothorax incertoides n. sp.

Figs. 12, 137, 138

Pure white but for occasional red spots. Antennae much shorter than the head, the 3rd and 4th segments not well sep- 
arated; 3rd segment with 2 obconical sense clubs and 2 long, heavy sense hairs; 4th segment with a giant hair near the apex. Eyes absent. Body with the segmentation nearly obliterated. Sense pits as follows: 4 on the head, 2 on the mesonotum, 2 on the posterior part of the abdomen, and 1 at the base of each of the middle and posterior legs. Several little bituberculate processes on the body. A pseudocellus-like spot on each side of the midline, just behind the middle of the body. Unguis (fig. 138) with 2 lateral teeth and a spine-like tooth inserted on the posterior face toward the base. Unguiculus pointed, without an inner basal lobe, or with a suggestion of one. Manubrium with 2 ventral appendages which are quite difficult to see. Dentes divided into 2 parts. Manubrium with 2 dorsal setae. Dentes with 1 dorsal seta on the basal division, and 3 on the apical half; a pair of subapical bristles is present ventrally on the same division. Mucro (fig. 137) slender and pointed, with small, upright teeth on each edge. Length up to $0.3 \mathrm{~mm}$.

Taken from humus by means of a Berlese funnel.

This species is possibly synonymous with the European $M$. incertus Börner. I am keeping this species separate until there has been a thorough redescription of the European species. One of the important differences between Neelus and Megalothorax is the absence of segmentation in the former genus. While $M$. incertoides is a true Melagothorax in most respects, it lacks the apparent segmentation of that genus.

Ames: Apr. 27 ; Aug. 23. Columbus Junction: Sept. 26. Maquoketa: May 8. New Sharon: Sept. 19-F. Andre. Ottumwa: Sept. 9-F. Andre.

Calif., Fla., La.

\section{FAMILY SMINTHURIDAE LUBBOCK, 1870}

Antennae longer than the head, inserted near the vertex; 4 segmented, the 4th, rarely the 3rd, subsegmented. Thorax not greatly enlarged. Anal papilla very evident. Dentes 1-segmented.

Key to the Subfamilies of Sminthuridae

1. Segmentation of the thorax evident. Integument granular. Sacs of the ventral tube smooth (warty only in Neosminthurus) Sminthuridinae Börner, p. 87.

Segmentation of the thorax extremely indefinite. Integument practically smooth. Sacs of the ventral tube warty in full grown specimens 
2. The 4th antennal segment subdivided; the longest segment of the antenna. Elbow of the antenna between the 3rd and 4 th segments. Sminthurinae Börner, p. 100.

The 4th antennal segment considerably shorter than the 3rd, both of which (or neither) may be subdivided. Antennae elbowed between the 2nd and 3rd segments.

Dicyrtominae Börner, p. 105.

\section{SUBFAMILY SMINTHURIDINAE BÖRNER, 1906}

Sutures between the thoracic segments evident. Integument granular. Sacs of the ventral tube usually smooth. Anal appendages of the female present or absent.

Key to the Genera of Sminthuridinae

1. The 5th and 6th abdominal segments entirely ankylosed, broadly united with the furcal segment. Male antennae modified into clasping organs. Anal appendages of the female absent. Proximal precoxae of the middle pair of legs without anterior processes

Sminthurides Börner, p. 87.

The 5th and 6th abdominal segments separated by a constriction. Male antennae not forming clasping organs. Females with anal appendages. Proximal precoxae of the middle pair of legs with anterior papillate or clavate processes.. 2.

2. Dentes dorsally and laterally with conical pegs. The 4th antennal segment usually subsegmented. Eyes reduced in number. Both edges of the mucro alike. Tenent hairs absent. Arrhopalites Börner, p. 92.

Dentes without dorsal and lateral pegs. The 4th antennal segment not subsegmented. Eyes usually 8 on each side. Edges of the mucro usually dissimilar. Tenent hairs usually present 3.

3. Claw without a tunica. Sacs of the ventral tube smooth......... Sminthurinus Börner, p. 94.

Claw with a tunica. Sacs of the ventral tube warty or wrinkled Neosminthurus n. g., p. 98.

GENUS SMINTHURIDES BöRNER, 1900 Prosminthurus Willem, 1900

The 5th and 6th abdominal segments ankylosed and united broadly with a furcal segment. Male antennae modified to form 
clasping organs. The 4th antennal segment simple or subsegmented. Anal appendages of the female absent.

Key to the Subgenera of Sminthurides

1. Tibiotarsal organ and mucronal bristle present 2. Tibiotarsal organ and mucronal bristle absent.

Sphaeridia Linnaniemi, p. 88.

2. Mucronal edges without true lamellae. Dorsal inner edge toothed Stenacidia Börner, p. 88. Mucro usually broad; lamellate, with a middle rib.

Sminthurides s. str., p. 89.

SUBGENUS SPHAERIDIA LINNANIEMI, 1912

Tibiotarsal organ and mucronal bristle absent. Clasping organ of the male antennae simple (fig. 140).

Sminthurides (SPhAERIDIA) PUMILIS Krausbauer, 1898 Figs. 139-142

Length up to $0.3 \mathrm{~mm}$. Light tan to rose, occasionally showing a light antero-median dorsal stripe and irregular light spots. Antennae of the female 1.2 times the head, the 4th segment simple. Eyes 8 on each side. Ungues slender on the 1st pair of legs (fig 142), becoming shorter and more curving on the posterior legs (fig. 141), with lateral teeth and often an inner tooth. Subapical bristle of the unguiculus of the front pair of legs reaching beyond the apex of the unguis, shorter on the 2nd pair, minute or absent on the 3rd pair. Mucro slender, to the dens as $6: 11$, toothed inwardly and simple (or obscurely unidentate) externally (fig. 139). Mucronal bristle and tibiotarsal organ absent. Body with 5 bothriotricha on each side, 2 of which are on the anal papilla; and numerous, rather long hairs. Clasping antennae of the male simple.

Taken in humus.

Ames: Oct. 20-F. Andre. Central City: Nov. 25. Eldora: Nov. 10. Hampton: June 18-G. C Decker and B. V. Travis. LeGrand: Nov. 1. Leon: Oct. 31-B. V. Travis. Little Wall Lake: Oct. 14 G. C. Decker.

Utah. Cosmopolitan.

SUBGENUS STENACIDIA BÖRNER, 1906

Similar to Sminthurides s. str., but for the mucro, which is without true lamellae.

Unknown in North America. 
SUBGENUS SMINTHURIDES S. STR.

Tibiotarsal organ and mucronal bristle present. Mucro with 2 lateral lamellae, and often a ventral one.

Key to the Species of Sminthurides s. str.

1. Subapical bristle of the ungues of the 3rd pair of legs divided at the tip penicillifer Schäffer var., p. 90.

Subapical bristle of the ungues of the 3rd pair of legs simple

2. The 4th antennal segment of the female with whorls of hair but without definite subsegments 3.

The 4th antennal segment of the female with whorls of hair and definite subsegments

3. Mucro half as broad as long. Heavy bristles of the tibiotarsal organ reaching far beyond the apex of the tibiotarsus, not greatly enlarged basally.

aquaticus Böurlet, p. 89.

Mucro a third as broad as long. Heavy bristle of the tibiotarsal organ reaching only to the apex of the tibiotarsus, and broadly expanded basally

malmgreni Tullberg, p. 90.

4. The 4th antennal segment in the female with 4 definite subdivisions. Ventral lamella of the mucro entire.

occultus n. sp., p. 91.

The 4th antennal segment of the female with 5 definite subdivisions. Ventral lamella of the mucro ending in an acute tooth before the apex. lepus n. sp., p. 91.

Sminthurides aquaticus (Bourlet), 1842.

Sminthurus amicus Folsom, 1896.

Length of the female up to $1 \mathrm{~mm}$., male up to $0.5 \mathrm{~mm}$. Color variable, from yellow to green. Antennae slightly longer than the head. Eyes 8 on each side. Ungues of the 2 anterior pairs of legs with an inner tooth, those of the 3rd pair toothless. Subapical bristle of the unguiculus reaching beyond the apex of the unguis. Tibiotarsal organ of 2 sacs and a long, slender bristle which reaches beyond the apex of the tibiotarsus. Mucro broad, half as broad as long, trilamellate, the inner lamella plaited.

Taken from the surface of quiet water. Common.

Ames: Mar. 29 ; June 17. Gilbert: June 13. Leon: Oct. 31-B. V. Travis.

Ill., Mass., N. Y., Ohio, Tex., Wash. Ontario. Europe. 


\section{SMinthurides Malmareni (Tullberg), 1876}

Sminthurus socialis Folsom, 1896.

Length of the female up to $1 \mathrm{~mm}$., of the male $0.5 \mathrm{~mm}$. Dark violet, with various color variations. Similar to the preceding species but for the short, expanded bristles of the tibiotarsal organ, which reaches just to the apex of the tibiotarsus, and in the more slender mucro, which is 3 times as long as broad.

Occurs in the same situation as S. aquaticus.

Ruthven: Oct. 2-H. M. Harris and B. V. Travis.

Mass., N. Y., Tex. Europe.

\section{SMinthuRIDES PENICILlifer Schäffer var. BIFIDUs n. var.}

Figs. 143-145

Female blue-black, including the appendages ; male bluish with the dorsum light yellow. Antennae in the female slightly longer than the head, the segments as $9: 11: 17: 36$; the 4th segment without definitely separated subsegments but with about 9 whorls of hairs. Eyes 8 on each side. Ungues with a weak tunica; extremely long and slender on the 2 anterior pairs of legs (fig. 144), and bearing an inner tooth; each unguis accompanied by a short, slender unguiculus which bears a large subapical bristle reaching beyond the apex of the unguis. Ungues of the last pair of legs (fig. 143) short and heavy, unidentate, the inner edge coarsely serrate; unguiculus broad, with a long subapical bristle which is, in the female, divided into 2 unequal parts. Tibiotarsal organ of 2 sacs and a heavy bristle which is divided apically. Manubrium to dentes to mucrones as 11:26:9. Manubrium bare ventrally and with few dorsal setae. Dentes with numerous dorsal and lateral setae, ventrally with 2 unpaired bristles toward the base and 10 pairs on to the apex. Mucro (fig. 145) broad, trilamellate, the inner lamella plaited. Head with sparse, forward-pointing bristles; abdomen with sparse, erect, slightly curving hairs, more abundant posteriorly; 3 bothriotricha in an oblique line on each side of the abdomen and 2 on each side of the anal papilla.

Taken on stagnant water.

This is without doubt the variety of $S$. penicillifer recorded from Minnesota by Guthrie (1903).

Ames. Columbus Junction: Sept. 25.

Minn. Typical form in Europe. 
Sminthurides OcCultus n. sp.

Figs. 146-152

Deep, irregular blue to purple with 2 dorso-lateral yellowwhite stripes running from the mesothorax to the anal papilla (the stripes sometimes concentrated into an oval spot), and a mid-dorsal stripe on the anterior half of the body. Thoracic sutures lighter. Head irregularly blue, lighter on the front; antennae deep blue. Legs blue-brown. Ventral tube lightly pigmented. Furcula and venter nearly colorless. Eyes 8 on each side. Antennae of the female 1.3 times the head, the segments as $10: 22: 41: 98$, the 4th segment (fig. 151) with 2 definite annulations beyond the middle, with a suggestion of a 3rd which is never well separated. Unguis (figs. 148-150) with a tunica, an inner tooth, and 2 pairs of lateral teeth except on the front feet. Unguiculus large, broad basally, with a simple, subapical bristle extending beyond the apex of the unguis. Tibiotarsal organ of 2 sacs and a heavy, sometimes bifid bristle which reaches to the apex of the tibiotarsus. Proportions of the furcula 11:21:8. Manubrium bare ventrally, with few dorsal setae. Dentes with several ventral bristles in the apical half and numerous dorsal setae, including 3 upright ones. Mucro (figs. 146, 147) from a lateral view subcylindrical, with an apical transparent bulb; trilamellate, the ventral lamella narrow and entire, the inner one with as many as 7 large teeth, the outer one entire or with 1 or 2 small teeth. Body with few setae anteriorly, becoming long and more numerous posteriorly; 3 bothriotricha in an oblique line on each side of the body, and 2 on each side of the anal papilla. Length of female $0.4 \mathrm{~mm}$. Male smaller, similar to the female in form and color, with the usual clasping antennae (fig. 152), and with 2 dorsal tubercles on the mesothorax.

Taken from humus by means of a Berlese funnel.

Ames: Aug. 28; Oct. 20-F. Andre. Columbus Junction: Sept. 26. Hampton: June 18-G. C. Decker and B. V. Travis. Ottumwa: Sept. $9-$ F. Andre.

\section{SMINTHURIDES LEPUS n. sp.}

Figs. 13, 153-157

Blue and white, with a yellow tinge on the thorax. Body blue laterally and with a broad, blue band posteriorly. Another irregular band occurs over the dorsum, and may be broken in the middle, but usually expands on the midline. Anal papilla, fur- 
cula, the membrane at the furcula insertion, a dumb-bell-like area between the transverse blue bands of the body, and the anterior dorsum white. Venter light blue. Oral region blue, a crescent-shaped line on each side running up toward the antennal base and eyespot. Eyespots and frontal ocellus black. The rest of the head white. Antennae grading from brown at the base to purple at the tip. Legs beyond the trochanters white. Vertex and thorax, and rarely all white areas, tinged with yellow. Eyes 8 on each side. Antennae of the female a little less than twice the head, the segments about as $4: 5: 11: 21$, the 4 th segment with 3 basal swellings, 3 distinct subsegments, and an apical piece. Unguis (figs. 153, 154, 157) with a tunica, bearing lateral teeth and 1 inner tooth. Unguiculus well developed, broad basally, the subapical bristle extending well beyond the apex of the unguis on the 1st pair of legs, to the apex on the 2nd pair, and nearly to it on the 3rd pair. Tibiotarsal organ rather far from the apex of that segment, composed of 2 sacs and a short, weakly bifid bristle. Mucro (fig. 156) elongate, subcylindrical, with an apical bulb and 3 lamellae, the outer entire, the inner toothed, and the ventral one ending subapically in a sharp tooth. Length of female $0.53 \mathrm{~mm}$., of male $0.36 \mathrm{~mm}$. Males similar to the females, smaller, with the usual clasping antennae (fig. 155), and with 2 dorsal mesothoracic tubercles.

Taken from humus and moss. The distinct dorsal pattern of this species renders it rather conspicuous.

Ames: Aug. 28 ; Oct. 20-F. Andre.

Ontario.

GENUS ARRHOPALITES BöRNER, 1906

Eyes and pigment usually reduced. The 5th and 6 th abdominal segments separated by a constriction. Male antennae not modified for clasping. Females with anal appendages. The 4th antennal segment usually subsegmented. Both edges of the mucrones similar. Dentes dorsally and laterally with conical pegs. Tenent hairs absent.

Key to the Species of Arrhopalites

1. The 4th antennal segment simple..........diversus n. sp., p. 93. The 4th antennal segment with subsegments....................... 2.

2. Eyes unpigmented. Anal appendage nearly straight, slender...............................................caecus Tullberg, p. 93.

Eyes pigmented. Anal appendage curving and definitely branched at the apex. binoculatus Börner, p. 93. 


\section{Arrhopalites caecus (Tullberg), 1871}

Sminthurus benitus Folsom, 1896.

Fig. 162

Length up to $0.8 \mathrm{~mm}$. White, with red spots. Antennae with 4 segments, the apical segment with 3 annulations near the middle. Eyes 1 on each side, without pigment. Unguis with a tunica and an inner tooth. Unguiculus lamellate, with an inner tooth. Tenent hairs absent. Mucro (fig. 162) uniformly toothed on each margin, with an apical enlargement, and more than half the length of the dens. Anal appendages slender, minutely serrate at the tip.

Taken rarely from humus.

Ames: June 25 ; Sept. 4.

Ill., Mass., Minn., N. Y., Pa. Europe.

Arrhopalites binoculatus Börner, 1901b

Figs. 163-166

Length up to $1 \mathrm{~mm}$. Color variable, from white (var. pallidus Linnaniemi), through purple-red (var. binoculatus f. p.), to gray (var. grisea Axelson). Antennae with 4 segments, of the proportions $2: 3: 5: 12$, the 4 th segment (fig. 164) with 3 or 4 annulations near the middle. Eyes 1 on each side, pigmented. Unguis (fig. 165) with a small tunica, unidentate inwardly. Unguiculi bearing subapical bristles; with an inner and an outer lamella. Tenent hairs absent. Dentes less than twice the length of the mucrones, which are toothed uniformly on both edges (fig. 163), and which end in a pointed tip. Anal appendages enlarged (fig. 166 ), palmately divided at the tip.

Rather common in humus.

Bixby Ice Cave: May 8. Columbus Junction : Sept. 26. Hampton: June 18-G. C. Decker and B. V. Travis. Leon: May 20; Oct. 10-B. V. Travis. Maquoketa : May 8. Rock Rapids: Aug. 16-E. L. Mills. Shellrock: Oct. $14-$ B. V. Travis.

Mass. Ontario. Europe.

Arrhopalites diversus n. sp.

Figs. 158-161

White, with ferruginous spots on the vertex and dorsum. Eyes 1 on each side, pigmented. Body shape typical of the genus. Antennae (fig. 161) about 1.3 times the head, the seg- 
ments approximately as $1: 2: 3: 5$, the 3rd segment enlarged basally, and the 4th segment without subsegmentation. The 4th segment with 8 or 9 erect hairs in each longitudinal row, with 4 or 5 reclinate hairs between these rows in the apical half. Basal precoxal segments of the middle pair of legs with an anterior process. Unguis (figs. 158, 159) with a tunica ; curving, with lateral teeth, and a long, spine-like inner tooth inserted on the posterior face. Unguiculus sometimes with an inner tooth, the subapical seta reaching the apex of the unguis. Proportions of the furcula as $10: 13: 9$. Dentes with 2 pegs situated laterally beyond the middle, and with 2 dorsal, external, subapical pegs. Manubrium bare ventrally, and with few dorsal setae. Mucro as in A. caecus (fig. 162). Anal appendages slender (fig. 160), curving slightly at the apex. Body and head with short, straight hairs, longer on the mouthparts and anal papilla. Body with 3 bothriotricha on each side, and a single bothriotrix on each side at the base of the 5th abdominal segment. Length up to $0.7 \mathrm{~mm}$.

This is the only species of the genus in which the 4th antennal segment is without subsegmentation, and it is necessary to enlarge the generic description to include it. It is a rare inhabitant of leaf mould.

Jefferson: Dec. 5-G. C. Decker. Leon: Oct. 31-B. V. Travis. Ill.

\section{GENUS SMINTHURINUS BöRNER, 1901}

The 5th and 6th abdominal segments distinct. Male antennae not forming clasping organs. Females with anal appendages. The 4th antennal segment simple. Eyes not reduced in number. Edges of the mucrones usually dissimilar. Claws without a tunica. Tenent hairs present. Dentes without dorsal and lateral pegs. Sacs of the ventral tube smooth, not extremely long.

This genus comprises a number of extremely similar complexes, the specific determination of which is difficult from a structural basis. To add to the difficulty, all of the specimens of S. minutus MacGillivray available to me are mounted in balsam and the details of the claws and mucrones are invisible.

Key to the Species of Sminthurinus

1. Outer edge of the mucro entire or indistinctly toothed. Bladder-like swelling of the 3rd antennal segment simple or absent. Proportions of the furcula about as $29: 49: 22 \ldots . .2$.

Outer edge of the mucro toothed, like the inner. Bladder-like swelling of the 3rd antennal segment weakly 4-lobed as a rule. Proportions of the furcula about as $36: 43: 21$........ 3 . 
2. Hairs at the apex of the dens as in fig. 168. Body hairs rather long. aureus Lubbock, p. 95.

Hairs at the apex of the dens as in fig. 167. Body hairs short elegans Fitch, p. 96.

3. Body blue-black, lighter ventrally on the anal papilla and at the insertion of the furcula. Head yellow anterior to the eyespots, blue-black posteriorly

minutus MacGillivray, p. 97.

Color pattern not as above 4.

4. Gray to black, the extremities lighter...niger Lubbock, p. 97. Gray to black with 2 pearly white spots on each side of the abdomen and 2 on the vertex

quadrimaculatus Ryder, p. 97.

Sminthurinus aureus (Lubbock), 1862

Sminthurus henshawi Folsom, 1896.

Fig. 168

Length up to $1 \mathrm{~mm}$. Body hairs rather long. Hairs of the 4th antennal segment less than 12 in each longitudinal row. Dens with 4 lateral subapical setae and 3 pairs of ventral setae as in fig. 168. Organ of the 3rd antennal segment absent or present as a simple swelling. Outer edge of the mucro entire or obscurely toothed. Unguis with 1 inner tooth and a series of lateral ones. Unguiculus broad, with an inner notch, on the front legs bearing a subapical bristle. Tenent hairs 4 to 8 , overhanging the base of the unguis.

Ames : Feb. 21; Mar. 21; Apr. 6 ; Oct. 20. Central City: Nov. 25. Maxwell: Mar.-H. M. Harris. Smithland: Dec. 5-G. C. Decker.

Ill., Mass., Minn., N. Y., Tex., Utah. Europe.

S. aureus is not uncommonly found in leaf mould, beneath boards, and on grass. Its varieties may be separated as follows: 1. Color yellow aureus f. $\mathrm{p}$.

Color not yellow 2.

2. White, without other pigment than that on the antennae albus Krausbauer. White with lateral blue stripes, 2 crossbands anteriorly, and a transverse, dorsal loop on the posterior half of the abdomen which is connected with the anal papilla along the midline novus n. var. 


\section{SMinthuRINUS AUREUS NOvUS n. var.}

Body white to gray with a broad lateral band of blue on each side, 2 crossbands in the anterior half, and a mid-dorsal stripe in the posterior half beginning in a transverse loop and ending in a broad band anterior to the anal papilla; 5th abdominal segment colored posteriorly, and the 6th with a mid-dorsal spot. The anterior margin of the loop and the 2 anterior crossbands may be broadly broken dorsally, and always show a fine middorsal break. Head often with a brownish cast; a dark spot on the vertex, a dark $V$-shaped line between the eyespots and including the frontal ocellus, and a broken band across the front; lower half of the head light. Legs, venter, and furcula light. Antennae varying from light at the base to brownish-black apically. Structurally as in the principal form. Length up to $1 \mathrm{~mm}$.

This variety is unknown in Europe, according to Dr. Stach.

Ames: Oct. 20.

\section{Sminthurinus elegans (Fitch), 1863}

Sminthurus quadrilineatus Tullberg, 1871

Length up to $1 \mathrm{~mm}$. Body yellowish white, with a lateral and a dorso-lateral stripe, and often a fine, interrupted, necklace-like, anterior, mid-dorsal line. Vertex with a long mid-dorsal spot running anteriorly to the frontal ocellus. Genae and a band across the front dark. Legs, furcula, and venter light. Antennae dark brownish-black toward the apex. Body hairs very short and sparse; those of the 4th antennal segment less than 12 in each longitudinal row. Tenent hairs 4 or 5 . Dens with 2 lateral subapical bristles and a ring of subapical lateral and ventral ones as in fig. 167. Organ of the 3rd antennal segment absent or represented by a simple lobe. Outer edge of the mucro entire or obscurely toothed; inner margin serrate. Unguis and unguiculus as in S. aureus.

Taken in humus and on grass.

The species occurs in Iowa in 2 forms:

Body light, with 4 or 5 longitudinal stripes..............elegans $\mathrm{f}$. p. Head and body black ...........................................atratus Börner

Ames: May 19, 29-J. E. Guthrie; Nov. 21. Central City : Nov. 25. Ledges State Park: July 16. Little Wall Lake-Oct. 14 G. C. Decker. Rock Rapids : Aug. 16-E. L. Mills.

Ill.. Mass., N. Y., Ohio, Tenn. Canada. Europe. 


\section{Sminthurinus minutus (MacGillivray), 1894}

Length up to $1 \mathrm{~mm}$. Body blue-black, the venter of the anal papilla and the insertion of the furcula yellowish. Head yellow from the eyespots anteriorly. Furcula and legs light. Antennae yellow basally and blue-gray apically. Lobe of the 3rd segment simple.

S. igniceps Reuter is similar to this species, in color at least. I cannot tell from the balsam mounts at my disposal whether or not it is structurally similar to the European form.

The specimens recorded by MacGillivray and by Guthrie (1903) were taken in greenhouses. The Iowa specimens were taken among mossy stones of a walk.

Burlington: July-J. E. Guthrie.

Minn., N. Y., R. I.

\section{Sminthurinus quadrimaculatus (Ryder), 1878}

Sminthurus sexmaculatus Harvey, 1892

Length up to $1 \mathrm{~mm}$. Gray to black with 2 pearl-white spots on each side of thie abdomen (rarely 1 on each side), and a white spot just mesad and posterior to each eyespot. Furcula and legs lighter. Unguis with 1 inner tooth and lateral teeth near the base. Unguiculus broad basally, with an inner tooth, and a short subapical bristle on the front pair. Tenent hairs overhanging the base of the claw, 4 to 8 on each tibiotarsus. Segments of the furcula are of the proportions $36: 43: 21$. Mucrones toothed on both sides. Body hairs short, sparse. Hairs of the 4th antennal segment 13 or 14 in each longitudinal row.

Taken rarely beneath bark.

Ames : Oct. 3, 17, 25; Nov. 1.

Ill., Mass., Me., Minn., N. Y., Pa. Ontario.

\section{SMINThURINUS NIGER (Lubbock), 1867}

Length up to $1 \mathrm{~mm}$. Entirely black, occasionally with 2 lighter spots on the vertex. Appendages lighter, often with diffuse pigment. Structurally quite similar to the preceding species, and often taken in its company.

Ames : May 5, 7; Aug. 8; Oct. 25.

Mass., Minn., N. Y., Tex. Europe. 


\section{GENUS NEOSMINTHURUS NEW}

Genotype: Sminthurus curvisetis Guthrie (1903).

Eyes 8 on each side. Integument granulate. The 5 th and 6 th abdominal segments well separated. Male antennae not fitted for clasping, the 4th segment not subsegmented. Female with anal appendages. Mucronal edges dissimilar. Claws with a tunica. Sacs of the ventral tube long, tuberculate or wrinkled. Tenent hairs present or absent. Proximal precoxal process of the middle legs large. Dorsum usually set with truncate bristles.

In general appearances this genus resembles Sminthurinus, the 4th antennal segment being simple, the thoracic segments being indicated, the integument being granular, and the proximal precoxa of the middle legs bearing an anterior process. The sacs of the ventral tube, however, are long, and are either tuberculate or wrinkled, and the antennae are rather long and slender, thus resembling the genera of the Sminthurinae. This genus is then a connecting link between the subfamilies Sminthuridinae and Sminthurinae.

\section{Key to the Species of Neosminthurus}

1. Body without heavy, truncate bristles

Body with heavy, truncate bristles

sminthurinus n. sp., p. 99.

2. Tenent hairs present. Sacs of ventral tube wrinkled, not tuberculate. longisetis Guthrie, p. 98.

Tenent hairs absent. Sacs of ventral tube tuberculate.

curvisetis Guthrie, p. 99.

\section{Neosminthurus Longisetis (Guthrie), 1903}

Length up to $2 \mathrm{~mm}$. Brownish-black with vague yellow markings. Legs and furcula dark, lighter toward the apex. Eyes 8 on each side. Antennae 1.5 times the head, the segments as $4: 12: 11: 15$; 4 th segment simple with about 8 irregular whorls of hairs. Unguis broad, unidentate inwardly, with toothed lateral pseudonychia and a large tunica. Transtarsus with a large fleshy lobe at the base of the unguiculus. Unguiculus without an inner notch, the apex attenuate, with a heavy subapical bristle reaching beyond the apex of the unguis. Tenent hairs 4 . Proportions of the furcula $6: 8: 3$. Dens with 1 ventral bristle in the basal half, and 3 large and several small dorsal setae. Mucro ending in 3 blunt teeth, the outer edge nearly entire, the inner crenulate. Proximal precoxal process of the middle legs large, 
hyaline, clavate. Anal appendage of the female curving, many branched. A large, straight hair, above and laterad to each anal appendage, bears several apical branches. Sacs of the ventral tube long, heavily and irregularly corrugated. Hairs of the head and body long, heavy, pinnate, ending bluntly in several teeth; those of the 2nd and 3rd antennal segments strikingly long, pointed, serrate, occasionally bifid apically.

Taken from humus by means of a Berlese funnel.

Shellrock: Oct. $14-$ B. V. Travis.

Minn.

Neosminthurus curvisetis (Guthrie), 1903

Figs. 14, 169

Length up to $1 \mathrm{~mm}$. Blue-brown to light brown, the back often lighter. Lighter along sutures and at muscle insertions. Antennae to the head as $11: 9$, the segments as $7: 12: 15: 21$, the 4 th segment simple. Eyes 8 on each side. Sacs of the ventral tube long, coarsely warty. Unguis with a tunica, 1 inner tooth, and lateral toothed pseudonychia. Unguiculus blade-like, with a long subapical filament. Tenent hairs absent. Anal appendages of the female curving, pointed, simple. Proportions of the furcula $5: 6: 2$, bare ventrally. Mucro (fig. 169) with the apex bifid, the edges dissimilar, the outer edge with 5 to 10 rounded teeth, the inner with 1 blunt tooth. Head and body dorsally with numerous heavy, serrate, truncate bristles.

Not uncommon in humus and moss.

Ames : Sept. 16-F. Andre. Bixby Ice Cave: May 8. Columbus Junction: Sept. 26. Hampton :- June 18-G. C. Decker and B. V. Travis. Jefferson: Dec. 5-G. C. Decker. Ottumwa: Sept. 9F. Andre. Woodbury Co. : Sept. 28-G. C. Decker.

Fla., La., Minn.

\section{Neosminthurus sminthurinus $n$. sp.}

Fig. 171

Slate-black, occasionally tinged with brownish, and with irregular, rather obscure brown spots which are more abundant on the head. A white patch just mediad and proximad to each eyespot. Legs lighter, speckled with brown. Furcula insertion pale, the furcula varying from dark on the manubrium to yellowbrown on the dentes. Eyes 8 on each side. Antennae long and slender, nearly twice the length of the head, of the proportions $1.2: 2: 3: 8$, the 4 th segment without definite subsegmentation but 
with about 16 whorls of hairs; entirely blue-black. Unguis nearly straight, broad basally, with an inner notch at about the middle. Unguiculus broadly lanceolate, rarely with a minute inner tooth; a little shorter than the unguis. A posterior fleshy lobe is present on the transtarsus at the base of the unguiculus. Tenent hairs 10 or 11. Proportions of the furcula about as $35: 34: 12$. Dens with 5 dorsal, erect setae, and several lateral and ventral ones. Mucro (fig. 171) obliquely truncate in lateral aspect, the two sides dissimilar, the inner edge with small rounded teeth, and the outer edge entirely or minutely crenulate, occasionally with a notch in the basal half. Sacs of ventral tube long, with large, hemispherical warts anteriorly. Process of middle precoxae elongate. Anal appendage of female palmately pinnate in the apical half; rather slender. Hairs of the body short, curving, sparse anteriorly, rather abundant posteriorly and on the anal papilla. Short and rather abundant on the frons and genae. Length $1.7 \mathrm{~mm}$.

Walking about on moist sticks.

Ledges State Park, Boone: April 8.

\section{SUBFAMILY SMINTHURINAE BÖRNER, 1906}

Segmentation of the thorax extremely indefinite. Integument usually smooth. Sacs of the ventral tube tuberculate. The 4 th antennal segment subsegmented; being the longest segment of the antenna. Antennae elbowed between the $3 \mathrm{rd}$ and 4 th segments. Anal appendages of the female present.

Key to the Genera of Sminthurinae

1. Several appressed tenent hairs present at the apex of the tibiotarsus. Claw without a tunica

Tenent hairs absent, or, when present, usually 1 in number, which does not overhang the base of the claw 3.

2. Numerous short hairs curved to form a clasping organ dorsally on the anal segment of the male.

Bourletiella Banks, p. 101.

Hairs on the dorsum of the anal segment of the male not modified into a clasping organ

Deuterosminthurus Börner, p. 102.

3. The 3rd antennal segment with long hairs on the basal half, which are the longest hairs of the segment

Hairs on the basal half of the 3rd antennal segment not the longest hairs of the segment. Mucronal bristle absent. 
Claw with a tunica. Tenent hair absent. Bristles of the dorsum heavy, the apices truncate .

Sphyrotheca Börner, p. 105.

4. Mucronal bristle present or absent. Abdomen without dorsal gland openings

Sminthurus Latreille, p. 103.

Mucronal bristle present. Claw with a conspicuous tunica. Abdomen dorsally with 2 round gland openings.

Allacama Börner, p. 105.

GENUS BOURLETIELLA BANKS, 1899

Several large, appressed tenent hairs overlie the base of the unguis, which is without a tunica. Spine-like hairs form a clasping organ and are present dorsally on the anal segment of the male.

Key to the Species of Bourletiella

1. The 4 th antennal segment with about 20 subsegments

spinata MacGillivray, p. 102.

The 4th antennal segment with about 7 definite annulations and 10 whorls of hairs hortensis Fitch, p. 101.

Bourletiella hortensis (Fitch), 1863

Sminthurus pruinosus Tullberg, 1871, Smynthurus albamaculatus Harvey, 1896, Smynthurus quadrisignatus Packard, 1873, Sminthurus signatus (Nicolet) Ågren, 1903.

Fig. 170

Length up to $1.2 \mathrm{~mm}$. Color variable, from slate-blue with the vertex lighter, to yellow. Antennae 4-segmented, the apical segment with about 10 whorls of hairs and 7 subsegments. Eyes 8 on each side. Unguis without a tunica, with lateral teeth and 1 inner tooth. Unguiculus lamellate, with a subapical bristle. Tenent hairs 3 (or 2) on each tibiotarsus. Dentes less than 3 times the length of the mucro, which is spoon-shaped, with entire margins. Anal appendages flat, broad, nearly as wide as long, the edges entire (fig. 170). Males with bristles modified for clasping, on the dorsum of the anal segment.

Very common in the spring on grass and moist, cleared soil.

Ames: Apr. 16; May 7, 9, 13, 19-J. E. Guthrie; June 20J. E. Guthrie; Aug. 27. LeGrand: Aug. 9. Ontario: May 3; June 12.

Conn., Ill., Mass., Md., Me., Minn., N. J., N. Y., Ohio, Pa., Tenn., Va. Alberta, Nova Scotia, Ontario. Cosmopolitan. 
Bourletiella spinata (MacGillivray), 1893

Figs. 173, 174

Length up to $2 \mathrm{~mm}$. Olive, brown, or yellow, with lighter spots and usually an anterior median light line dorsally. Antennal segments as $3: 7: 9: 19$, the last segment with about 20 subsegments. Eyes 8 on each side. Unguis with an inner tooth. Unguiculus spine-like on the first pair of legs, a fourth the length of the claw on the middle pair, and well developed, with an inner and outer lamella and an apical spine on the last legs. Tenent hairs 3. Dentes granulate dorsally. A row of long hairs on each side of each dens, those on the inside bilamellate. Mucro broadly spoon-shaped, the lamellae entire. Anal appendages long, curving, the tip truncate and serrate, with pubescence throughout its length (fig. 173). Clasping organ of the male as in fig. 174. Male with a nasal organ of heavy spines.

Taken on water surfaces.

Gilbert: June 13. Ruthven: Oct. 2-H. M. Harris and B. V. Travis.

Ill., Kans., Ky., Mass., Me., Minn., N. Y. Ontario.

\section{GENUS DEUTEROSMINTHURUS BÖRNER, 1901}

Large tenent hairs present as in Bourletiella. Claw without a tunica. No clasping organ dorsally on the anal segment of the male.

\section{Deuterosminthurus Repandus (Ågren), 1903}

Fig. 172

Length up to $1.2 \mathrm{~mm}$. Color bright yellow, often with minute orange spots on the dorsum, especially posteriorly. Antennae pale yellow basally, brownish apically. Legs and furcula lighter. Abdomen with a transverse depression behind the middle. Eyes 8 on each side. The 4th antennal segment with 5 definite annulations, besides 2 basal and 3 distal whorls of hair. End club evident. Unguis rather straight, with or without an inner tooth. Unguiculus bristle-like, not lamellate. Tenent hairs 2 or 3 . Mucro spoon-shaped, to the dens as 1:2.5. Anal appendage of female blade-shaped, the edges serrate and often more ragged than is shown in fig. 172.

Common in grass in the spring.

Ames : May 18, 19 ; July 15-H. M. Harris and F. Andre. 
GENUS SMINTHURUS LATREILLE, 1804

Tenent hairs present or absent, when present not overhanging the base of the unguis but extending out at an angle from the tibiotarsus; usually 1 in number. The hairs on the basal half of the 3rd antennal segment are the longest of the segment. $\mathrm{Mu}$ cronal bristle present or absent. Claw with or without a tunica. Abdomen without dorsal gland openings.

Key to the Species of Sminthurus

1. Antennae with about 7 distinct subsegments of the 4 th segment. Anal appendages of female pinnate.

minnesotensis Guthrie, p. 103.

Antennae with about 18 subsegments of the 4th segment. Anal appendages of female simple, smooth, pointed......... 2.

2. Mucronal bristle absent........................medialis n. sp., p. 103.

Mucronal bristle present......................obscurus n. sp., p. 104.

Sminthurus minnesotensis Guthrie (1903)

Length up to $1.5 \mathrm{~mm}$. Purple-brown, with irregular, transverse, yellow bands and spots. Legs, antennae and furcula blue, with some pigment even in the mucrones. Eyes 8 on each side. Head 0.7 the antennae, the proportions of the segments being $8: 13: 20: 37$, the 4 th segment with 7 distinct, pear-shaped subsegments and about 10 whorls of hair. Unguis weakly tunicate, with 1 inner tooth and weakly toothed pseudoynchia. Unguiculus broad basally, with a subapical bristle extending beyond the apex of the unguis. Tenent hairs absent. Dentes 2.5 times the mucrones, which are apically blunt, with the outer edge simple and the inner edge roundly crenulate. Anal appendages of the female pinnate. Hairs of the head and body strikingly heavy, pointed and minutely pubescent; especially short and broad between the eyespots.

Taken in humus and beneath bark.

Ames : Aug. 8. Leon: May 8; June 6-B. V. Travis.

Minn. Ontario.

SMinthuRUS MEdialis n. sp.

S. dorsalis Mills, 1930.

Figs. 175-177

Light greenish yellow, varying to buff. Body with an intricate mosaic work of blue pigment laterally and over the dorsum posteriorly. Anal papilla with dorsal and lateral pigment. A 
buff stripe margined laterally with white begins on the vertex and extends posteriorly to the middle of the dorsum. Head with irregular lateral pigment and an indefinite line on each side beginning in the occipital region and extending forward through the eyespots and antennal bases onto the front, where it bends outward just above the oral region. Antennae blue-brown, darker apically. Medain ocellus weakly or not at all pigmented. Legs, furcula, and venter colorless. Eyes 8 on each side. Antennae more than 2 times the head, about as $13: 28$; the segments as $1: 2: 3: 8$, the 4 th segment with about 18 subsegments. Unguis slender, tunicate, with lateral toothed pseudoynchia, externobasal teeth, and 1 inner tooth (fig. 176). Unguiculus with an inner basal spine and a subapical bristle reaching beyond the apex of the unguis. Tenent hairs absent. A lateral setiferous tubercle on each side of the genital segment (fig. 177). Furcula of the proportions $26: 39: 11$. Dentes with 3 upright dorsal setae, numerous shorter dorsal and lateral ones, and 5 pairs and 1 single one ventrally. Mucro (fig. 175) with the apex obliquely truncate, the outer edge wavy or weakly toothed, the inner with definite rounded crenulations. Mucronal bristle absent. Anal appendages of the female simple, curving, pointed. Heavy, erect, pointed, pinnate bristles behind the eyes, curving anteriorly on the front; those of the body similar but longer and pointing posteriorly. Bothriotricha 3 on each side of the body and 1 from each of the papillae of the genital segment. Length up to $2 \mathrm{~mm}$.

Swept from grass.

Adel : Sept. 4. Ames : Apr. 6; May 7, 8, 9, 19, 20; Sept. 4, 19. Malvern : Sept. 9, 17. Ontario: May 9; June 12.

\section{SMinthuRUS OBSCURUS $\mathrm{n}$. sp.}

Deep purple-black, vertex and dorsum pale yellow. Antennae white to pale blue, slightly darker at the apex of the 4th segment. Legs deeply pigmented to femora, which, with the tibiae, are dusky. Furcula pigmented to the bases of the mucrones; insertion pale. Ventral tube deeply pigmented. Eyes 8 on each side. Antennal segments approximately of the proportions $9: 13: 21: 56$, the 4 th segment with about 18 annulations. Unguis rather broad, unidentate inwardly, with large, toothed pseudonychia, and bearing a well developed tunica. Unguiculus broad basally, with an inner tooth and a subapical bristle attaining or exceeding the apex of the unguis. Tenent hairs absent. Several heavy hairs on the inner face of the tibiotarsus near the apex. 
Dens with several ventral hairs in the apical half, numerous dorsal ones including 3 long upright ones. Mucro a third the dens, trough-shaped, obliquely truncate at the apex, the inner lamella with several (as many as 7) irregular teeth, the outer lamella with a few (1 to 4) tuberculate teeth. Mucronal bristle present. Anal appendage of the female simple, curving in its entire length, pointed. Body covered with long, pointed, serrate hairs. Two similar hairs on the vertex behind each eyespot, and other shorter, forward-pointing ones on the front. Body with 3 bothriotricha on each side, and a 4th emerging from the lateral setiferous tubercle of the genital segment. Length $1.8 \mathrm{~mm}$.

This species is very similar to the preceding one in most respects. It differs, however, especially in the presence of a mucronal bristle, the dentition of the mucrones, the broader unguis, and the color. Both species are close relatives of S. fitchi Folsom.

Swept from grass, 3 specimens.

Ames: June.

GENUS ALLACAMA BöRNER, 1906

Mucronal bristle present. Claw with a conspicuous tunica. Dorsal mucronal edges dissimilar. Abdomen dorsally with 2 round gland openings.

Not known in North America.

GENUS SPHYROTHECA BÖRNER, 1906

Hairs of the basal half of the 3rd antennal segment not the longest of the segment. Mucronal bristle absent. Claw without a tunica. Tenent hairs absent. Bristles of the dorsum heavy, with truncate tips. Otherwise as in Sminthurus.

Not recorded from North America.

\section{SUBFAMILY DICYRTOMINAE BÖRNER, 1906}

Segmentation of the thorax indefinite. Anal papilla evident, but its division into genital and anal segments obscure. Sacs of the ventral tube tuberculate. The 3rd and 4th antennal segments subsegmented or not, the 4th segment much shorter than the 3rd. Elbow of the antenna between the 2nd and 3rd seg. ments. A dorso-lateral tubercle present on each side of the abdomen. Anal appendages of the female present.

Key to the Genera Dicyrtominae

1. Claw with a tunica. Dentes without heavy, serrate, dorsal 
bristles. The 3rd and 4th antennal segments not subsegmented Dicyrtomina Börner, p. 106.

Claw without a tunica. Dentes with heavy, serrate bristles dorsally 2.

2. The 3rd and 4th antennal segments simple

Dicyrtoma Bourlet, p. 106.

Either the 3rd or 4th antennal segments (or both) subsegmented .Ptenothrix Börner, p. 107.

GENUS DICYRTOMINA BöRNER, 1906

Papirius Lubbock, 1862, ad. p.

Claw with a tunica. Dentes without dorsal, serrate setae. The 3rd and 4th antennal segments simple.

Not recorded from Iowa.

GENUS DICYRTOMA BOURLET, 1843

Papirius Lubbock, 1862, ad. p.

Claw without a tunica. Dentes dorsally with large, serrate bristles. The 3rd and 4th antennal segments not subsegmented.

\section{DicYRTOMa quadRangularis n. sp.}

Figs. 187-189

Head deep blue but for the oral region. Body blue but for an elongate, irregularly diamond-shaped white area covering the dorsum. Anal papilla blue laterally, otherwise white. Antennae white, darker near the elbow. Legs and spring white. Head threefifths the length of the antennae; proportions of the antennal segments $7: 27: 28: 11$, without subsegments, but the 4th segment with definite whorls of hairs. First segment with an apical, external tubercle. Unguis (figs. 187, 188) rather straight and pointed, with 2 inner teeth and 1 tooth near the middle of the outer margin. Unguiculus with a small inner spine and a short subapical bristle, reaching to or slightly beyond the apex of the unguis. Dentes 4 times the length of the mucro, with dorsal setae indistinctly serrate, 3 resupinate ventral external hairs near the apex and 5 in the inner row, and a single bristle near the base. Mucro (fig. 189) with coarse, saw-like teeth. Heavy, stiff bristles on the front and vertex, larger ones anteriorly on the dorsum and on the anal papilla. Large postero-dorsal field of short, peg-like bristles on the abdomen. Lateral hairs of the body rather long and fine. Length $1.6 \mathrm{~mm}$. 
One specimen taken from leaf mould, Bixby State Park: May 8.

\author{
GENUS PTENOTHRIX BÖRNER, 1906 \\ Papirius Lubbock, 1862, ad. p.
}

Claw without tunica. Dentes dorsally with large, serrate setae. The 3rd or 4th antennal segment (or both) subsegmented.

Key to the Species of Ptenothrix

1. Rich purple-brown, with irregular pearl-white and yellow markings. marmorata Packard, p. 108.

Light purple to orange-yellow, without strongly contrasting lighter markings 2.

2. Bright orange-yellow. The 3rd antennal segment about 3 times the 4th, which is not annulate (fig. 181)

aurata n. sp., p. 107.

Purple to light brown. The 3rd antennal segment about 5 times the 4th, which is annulate (fig. 186)

unicolor Harvey, p. 108.

Ptenothrix aurata n. sp.

Figs. 178-183

Bright orange-yellow; venter, legs, and furcula lighter. Antennae purplish toward the tip. Eyespots orange, the eyes black. Frontal ocellus double, deep brown. Eyes 8 on each side. Antennae to the head as $8: 5$, the segments as $12: 50: 51: 17$, thus the 3rd segment is 3 times the 4th; 3rd segment with about 3 annulations in the apical half, the 4th segment simple but bearing 8 whorls of hair (fig. 181). Unguis (figs. 179, 180) with 2 inner and several lateral teeth, and sometimes a suggestion of an external one. Unguiculus with a basal spine and a capitate, subapical bristle which reaches beyond the apex of the unguis. Manubrium to dentes to mucrones as $34: 47: 14$. Dentes with dorsal, serrate bristles, and 4 upright, pinnate hairs; ventrally with 2 outer and 4 inner closely appressed setae toward the apex and a single seta in the basal half. Mucro (fig. 178) with both lamellae finely and roundly toothed. Hairs of the head and body short and sparse, heavier posteriorly, longer on the vertex, front, and anal papilla. Bothriotricha 3 on each side. Each posterior tibiotarsus bears on its posterior face 2 heavy, bilaterally serrate setae. Anal appendages of the female bristle-like, curving in the apical half (fig. 183). Length up to $1.6 \mathrm{~mm}$.

This interesting and distinct species was taken from humus.

Ames : Oct. 20-F. Andre. 
Ptenothrix unicolor (Harvey), 1893

Papirius pini Folsom, 1896

Figs. 184-186

Length up to $2.5 \mathrm{~mm}$. Light purple to tan. Eyespots black. Antennae darker, twice the length of the head, the segments as $12: 66: 75: 16$; the 3rd segment with 6 annulations toward the apex, and the 4th with about 3 definite annulations and 7 or 8 whorls of hair (fig. 186). Eyes 8 on each side. Unguis slender (fig. 185) with 2 inner teeth, 2 pairs of lateral teeth (the basal pair may bear smaller serrations), and 1 external tooth. Unguiculus with a sharp basal spine and a subapical bristle reaching to or slightly beyond the apex of the unguis. Dentes 3 times the length of the mucrones, which are toothed on both lamellae. Body with strong bristles on the anterior part, giving way posteriorly to a field of short, peg-like setae on the dorsum. Heavy, short spines on the vertex and front. Hind tibiotarsi with 2 heavy, bilaterally serrate setae on the posterior surface. Anal appendages of the female bristle-like, curving throughout their entire length (fig. 184).

Taken on agarics and in humus.

The species recorded by Denis $(1931 b$, pp. 159, 160) questionably as $P$. setosa (Krausbauer) is very likely $P$. unicolor.

Ames : Mar. 8 ; June 10, 14 ; Aug. 24 ; Oct. 3 ; Nov. 15 . Columbus Junction: Sept. 25. Ledges State Park: July 16. LeGrand: Ang. 9, 18; Oct. 27. Leon: Oct. 31-B. V. Travis.

Ill., Mass., Me., Minn., N. H., N. J., N. Y., Ohio, Wis. Ontario.

\section{Ptenothrix marmorata (Packard), 1873}

Papirius testudineatus Folsom, 1896

Length up to $2.5 \mathrm{~mm}$. Rich purple-brown, sometimes nearly black, with pearly or waxy markings over the head and dorsum. A mid-dorsal white stripe on the anterior half of the body. Furcula, antennae, and legs dark, the latter banded with white. Structurally this species is much like the preceding one.

Taken on agaries and beneath logs.

Ames: May 28-J. E. Guthrie; Nov. 8. Columbus Junction: Sept. 25.

Ill., Mass., Me., N. Y., Ohio, Tex. Ontario. 
ÅGREN, Hugo

\section{SELECTED BIBLIOGRAPHY}

1903. Zur Kenntnis Apterygoten-Fauna Süd-Sehwedens. Stettiner Entomologische Zeitung, 64:113-176.

BACON, GERTRUdE

1912. Some Collembola of Laguna Beach. Pomona College Journal of Entomology, $4: 841-845$.

1914. The distribution of Collembola in the Claremont-Laguna Region of California. Journal of Entomology and Zoology, 6:137-178.

BaNKS, NaTHAN

1897. Descriptions of two new Smynthurids. Journal of the New York Entomological Society, 5:33-34.

1899. The Smynthuridae of Long Island, New York. Journal of the New York Entomological Society, $7: 193-197$.

1903. New Smynthuridae from the District of Columbia. Proceedings of the Entomological Society of Washington, $5: 154-155$.

BARBER, H. S.

1913. Luminous Collembola. Proceedings of the Entomological Society of Washington, 15:46-50.

BONET, F.

1931. Estudios sobre Colémbolos Cavernicolas con Especial Referencia a los de la Fauna Espanôla. Memorias de la Sociedad Espanola do Historia Natural, 14:231-403.

BörNer, CARL

1901a. Zur Kenntnis der Apterygoten-Fauna von Bremen und der Nachbardistrikte. Abhandlungen des Naturwissenschaftlichen Vereins zu Bremen, $17: 1-147$.

1901b. Über enige Theilweise neue Collembolen aus den Höhlen der Gegend von Letmathe in Westfalen. Zoologischer Anzeiger, 24:333-345.

1903. Neue altweltliche Collembolen nebst Bemerkungen zur Systematik der Isotominen und Entomobryinen. Sitzungsberichte der Gesellschaft naturforschender Freunde, Jahrg. 1903, p. 160.

1906. Das System der Collembolen. Mitteilungen aus dem Naturhistorischen Museum in Hamburg, $23: 147-188$.

BROOK, GEORGE

1883. A revision of the genus Entomobrya. Journal of the Linnaean Society Zoölogy, 17:270-283.

Brown, J. M.

1932. Report of the Collembola collected by the Oxford University Expedition to Hudson Strait, 1931. Annals and Magazine of Natural History, Ser. 10, 10:330-340.

Collinge, W. E., and Shombotham, J. W.

1909. Notes on some Collembola new to Great Britain. Journal of Economic Biology, 4, Part 3, pp. 87-90. 
DENIS, J. R.

1923. Notes sur les Aptérygotes. Annales de la Société Entomologique de France, $92: 209-246$.

1924. Sur les Collemboles du Muséum de Paris lre Partie. Annales de la Société Entomologique de France, 93:211-260.

1931a Collemboles des Collections C. Schäffer et du "Zoologisches Staatsinstitut und Zoologisches Museum in Hamburg', Mitteilungen aus dem Zoologischen Museum Staatsinstitut und Zoologischen Museum in Hamburg, 44:197-242.

1931b. Collemboles de Costa Rica avee une Contribution au Species de l'Order. Bollettino del Laboratoro di Zoologica Generale ed Agraria di Portici, 25:69-170.

Fitch, Asa

1847. Winter insects of eastern New York. American Journal of Science and Agriculture, $5: 274-284$.

1863. Insects infesting gardens. Eighth Annual Report of the State Entomologist of New York, pp. 186-193.

Folsom, J. W.

1896a. New species of Papirius. Psyche, 7:344-345.

1896b. Two new species of Papirius. Canadian Entomologist, 28:119-121.

1896c. Notes on the types of Papirius texensis Pack. and the description of a new Smynthurus. Psyche, 7:384-385.

1896d. Neelus murinus, representing a new Thysanuran family. Psyche, 7:391-392.

1896e. New Smynthuri, including myrmecophilos and aquatic species. Psyche, 7:446-450.

1898. Deseriptions of a species of Machilis and Seira from Mexico. Psyche, 8:183-184.

1901a. The distribution of Holarctic Collembola. Psyche, 9:159-162.

1901b. Review of the Collembolan genus Neelus and description of N. minutus n. sp. Psyche, 9:219-222.

1902a. The identity of the Snow Flea (Achorutes nivicola Fitch). Psyche, 9:315-321.

1902b. Papers from the Harriman Alaska Expedition. Proceedings of the Washington Academy of Sciences, 4:87-116.

1902e. Collembola of the grave. Psyche, 9:363-367.

1908. The Golden Snow Flea, Aphorura cocklei n. sp. Canadian Entomologist, $40: 199-201$.

1913. North American springtails of the subfamily Tomocerinae. Proceedings of the United States National Museum, 46:451-472. 
1916. North American Collembolous insects of the subfamilies Achorutinae, Neanurinae, and Podurinae. Proceedings of the United States National Museum, 50:477-525.

1917. North American Collembolous insects of the subfamily Onychiurinae. Proceedings of the United States National Museum, $53: 637-659$.

1918. A new Isotoma of the snew fauna. Canadian Entomologist, $50: 291-292$.

1919a. Collembola of the Canadian Aretic Expedition, 1913-1918. Report of the Canadian Arctic Expedition, 3, Part A, Collembola, pp. 1-29.

1919b. Collembola from the Crocker Land Expedition. Bulletin of the American Museum of Natural History, 41, Art. 3, pp. 271-303.

1924. New species of Collembola from New York State. American Museum Novitates, No. 108, pp. 1-12.

1927. Insects of the subclass Apterygota from Central America and the West Indies. Proceedings of the United States National Museum, 72, Art. 6, pp. 1-16.

1932. Hawaiian Collembola. Proceedings of the Hawaiian Entomological Society, 8, No. 1. pp. 51-80.

Franklin, H. J.

1905. A new species of Entomobrya. Entomological News, 16:77-78.

GUTHRIE, J. E.

1903. The Collembola of Minnesota. Geological and Natural History Survey of Minnesota. Zoological Series IV, pp. 1-110.

HANDSCHIN, E.

1926. Materialem zur Revision der Collembolen Sira platani Nic. Tätigkeitsbericht der Naturforschenden Gesellschaft Baselland, 7:85-98.

1928. Collembola from Mexico. Journal of the Linnaean Society, $36: 533-552$.

1929. Die Tierwelt Deutschlands, 16 teil, Urinsekten oder Apterygoten, pp. 1-150. Gustav Fischer, Jena.

HARVEY, F. L.

1892a. An American species of Templetonia. Entomological News, $3: 57-59$.

1892b. A new Smynthurus. Entomological News, 3:169.

1893a. A new Papirius. Entomological News, 4:65-67.

1893b. A new Achorutes. Entomological News, 4:82-84.

1894a. The American species of the Thysanouran genus Seira. Psyche, $7: 159-162$.

1894b. A new species of Lepidocyrtus. Entomological News, 5:324-326.

1895. Two new species of Entomobrya. Psyche, 7:196-199. 
1896. A new Thysanouran of the genus Anoura. Psyche, 7:422-423.

1898. A new Poduran of the genus Gnathocephalus. Entomological News, 9:216-217.

1900. New Maine Collembola. Entomological News, 11:549-553. JACKSON, A. D.

1907. Sypopsis of the American species of the genus Papirius. Ohio Naturalist, 7:159-177.

1909. A study of the Ohio forms of Lepidocyrtus. Ohio Naturalist, 9:525-538.

JAMES, HEDLEY G.

1933. Collembola of the Toronto Region with notes on the biology of Isotoma palustris Mueller. Transactions of the Royal Canadian Institute, 19, Part 1, pp. 77-116.

LinNANIEMI, W. M.

1912. Die Apterygotenfauna Finlands. II, Spezieller Teil. Acta Societatis Scientiarum Fennicae, 40:1-361.

LUBRoCK, J.

1873. Monograph of the Collembola and Thysanura. Ray Society, London.

MaCGILLIVRaY, A. D.

1891. A catalog of the Thysanura of North America. Canadian Entomologist, $23: 267-276$.

1893a. North American Thysanura. Canadian Entomologist, 25 :127128.

1893b. North American Thysanura. Canadian Entomologist, 25 :313318.

1894a. North American Thysanura. Canadian Entomologist, $26: 105-$ 110.

1894b. Florida Aphoruridae. Canadian Entomologist, 26:165-166.

1896. American species of Isotoma. Canadian Entomologist, 28:47-58. Macnamara, C.

1920. A new species of Pseudachorutes (Collembola). Canadian Entomologist, 52:173-176.

1921. A new species of Friesea (Collembola). Canadian Entomologist, $53: 126-129$.

1922. Two new species of Achorutes (Collembola). Canadian Entomologist, $54: 149-153$.

MARLATT, C. L.

1896a. A house infesting springtail. Canadian Entomologist, 28:219220.

1896b. The American springtail. American Naturalist, 31:163-164.

Maynard, E. A.

1931. Seventeen additions to the Collembola of New York. Bulletin of the Brooklyn Entomological Society, 26:217-220. 
Mills, H. B.

1930. A preliminary survey of the Collembola of Iowa. Canadian Entomologist, $62: 201-204$.

1931. New Nearctic Collembola. American Museum Novitates, No. 464, pp. 1-11.

1932. New and rare North American Collembola. Iowa State College Journal of Science, 6, No. 3, 263-276.

1933. Collembola from the State of Washington. The Pan-Pacific Entomologist, $9: 77-83$.

NrCOLET, H.

1841. Recherches pour Servir à l'Histoire des Podurelles. Memoir de la Société Helvétique, $6: 1-88$.

PaCkard, A. S.

1873. Synopsis of the Thysanura of Essex County, Masachusetts. Fifth Annual Report of the Trustees of Peabody Academy of Sciences, pp. 23-51.

1877. On a new cave fauna in Utah. Bulletin of the United States Geological and Geographic Survey, 3:157-169.

1888. The cave fauna of North America. Memoir of the National Academy of Sciences, Washington, 4; Part I, pp. 1-156.

RYDFR, J. A.

1879. Description of a new species of Smynthurus. Proceedings of the Academy of Natural Sciences of Philadelphia for 1878, p. 335.

SAY, THOMAS

1883. The complete writings of Thomas Say on the Entomology of North America. Edited by John L. LeConte, M. D., 2:7-9.

SсHӧтт, H.

1893. Beitrage zur Kenntnis Kalifornischer Collembola. Bihang till K. Svenska Vetenskaps Akademiens Handlingar, 17, afd. 4, No. 8, pp. 1-25.

1896. North American Apterygogenea. Proceedings of the California Academy of Sciences, Second Series, 6:169-187.

STACH, JAN

1922a. Apterygoten aus dem Nordwestlichen Ungarn. Annales Musei Nationalis Hungarici, 19:1-75.

1922b. Collembola. A Magyar Tudományos Akadémia Balkán-kutatasainik tudomanyos eredmenyea, 1:109-139.

1929. Die Gattung Brachystomella Ågren (Collembola) und ihr Arten. Bulletin de l'Académie Polonaise des Sciences, et des Lettres, 'Série B., pp. 355-369.

WAHLGREN, EINAR

1900. Collembola während der Schwedischen Grönlandexpedition 1899 auf Jan Mayen und Ost-Grönland eingesammelt. Forhandlingar öfversigt af $\mathrm{k}$. Vetenskaps-Akademiens, $57: 353-376$.

WILLEM, VICTOR

1900a. Un Type Noveau de Sminthuridae: Megalothorax. Annales de la Société Entomologique de Belgique, 44:7-10. 
1900b. Recherches sur les Collemboles et Thysanoures. Mémoirs Couronnés et Mémoirs des Savants Étrangers, Academie Royale des Sciences, des Lettres, et des Beaux-Arts de Belgique, 58:3-144.

1902. Note Préliminaire sur les Collemboles des Grottes de Han et de Rochefort. Annales de la Société Entomologique de Belgique, 46:275283. 


\section{INDEX}

Achorutes s. str., 9.

Achorutes, 29.

armatus, 10.

boletivorus, 10.

copiosus, 11.

harveyi, 11.

macgillivrayi, 13.

marmoratus, 10.

maturus, 10.

nivicolus, 12.

nothus, 12.

packardi, 13.

packardi dentatus, 13.

pratorum, 10.

schneideri, 11.

schötti, 10.

tigrina, 15.

Achorutinae, 8.

Ågrenia, 50.

Allacama, 105.

Anurida, 26.

granaria, 26.

tullbergi, 26.

Anurophorus, 42.

laricis, 42.

Aphorura, 31.

Archisotoma, 50.

Architomocerura, 50. crassicauda, 50 .

Arrhopalites, 92.

binoculatus, 93 .

caecus, 93.

diversus, 93.

Arthropleona, 7.

Axelsonia, 50 .

Beckerella, 15.

Borecus, 81.

Börneria, 36.

Bourletiella, 101.

hortensis, 101.

spinata, 102.

Brachystomella, 18.

parvula, 18.

stachi, 19.

Chondachorutes, 18.

Classification, 3.
Collembola, 6 .

Cyphoderini, 81.

Cyphoderus, 81.

similis, 81.

-albinus, 81.

Degeeria, 66.

Desoria, 55.

Deuterosminthurus, 102.

repandus, 102.

Dicyrtoma, 106.

quadrangularis, 106.

Dicyrtomina, 106.

Dicyrtominae, 105.

Drepanocyrtus, 73.

Drepanura, 71 .

Entomobrya, 66.

assuta, 69.

bicolor, 70 .

caeca, 65.

clitellaria, 70 .

decemfasciata, 69.

dissimilis, 67.

griseo-olivata, 68.

marginata, 67, 68 .

multifasciata, 69 .

purpurascens, 67.

Entomobryidae, 39.

Entomobryinae, 63.

Entomobryini, 64.

Folsomia, 47. diplophthalma, 48.

elongata, 48.

fimetaria, 48.

fimetaria caldaria, 49.

fimetaria dentata, 49.

prima, 47.

Folsomides, 42.

parvula, 44.

parvus, 43.

stachi, 45.

Folsomina, 49.

onychiurina, 49.

Friesea, 20.

claviseta, 21.

grandis, 21. 
pentacantha, 20 . sublimis, 21.

Gnathocephalus, 22.

Guthriella, 49.

Heteromurus, 77. nitidus, 77.

Hypogastrura, 9.

Isotoma, 55.

aequalis, 54.

albella, 62.

albella leonina, 62 .

andrei, 58.

arborea, 57.

arborea nigra, 57.

Belfragei, 63.

bidenticula, 48.

capitola, 63 .

cinerea, 57.

eunotabilis, 58 .

glauca, 63.

grandiceps, 60.

maonamarai, 60 .

minor, 57.

nigrifrons, 60 .

olivacea, 61.

olivacea grisea, 62 .

plumbea, 63.

purpurascens, 63.

tricolor, 54, 63 .

trispinata, 62 .

viridis, 63.

viridis catena, 63 .

viridis riparia, 63 .

Isotomina, 50.

Isotominae, 39.

Isotomodes, 46. tenuis, 46.

Isotomurus, 54 . palustris, 54 .

Kalaphorura, 35.

Lepidocyrtinus, 73 .

Lepidocyrtus, 72. americanus, 77. curvicollis, 73 .

cyaneus, 72 .

cyaneus aenescens, 72 . cyaneus cinereus, 72 . metallicus, 72. sexoculatus, 72.

Lipura, 31.

Macrotoma, 82.

Megalothorax, 85. incertoides, 85 .
Mesaphorura, 36.

Micranurida, 26.

furcifera, 27.

pygmaea, 27.

Microgastrura, 14. duodecemoculata, 1 t.

Morphology and Terminology, 2.

Morulina, 29.

gigantea, 29 .

Neanura, 29.

barberi, 29.

gibbosa, 29.

muscorum, 29.

persimilis, 30 .

sextuberculata, 29.

quadrioculata, 29.

Neanurinae, 19.

Neanurini, 28.

Neelidae, 85.

Neelus, 85.

Neosminthurus, 98.

curvisetis, 99 .

longisetis, 98.

sminthurinus, 99.

Odontella, 25.

cornifer, 25.

Onychiurinae, 30.

Onychiurus, 31.

armatus, 32.

encarpatus, 32 .

obesus, 35 .

parvicornis, 33.

pseudofimetarius, 34 .

ramosus, 34 .

subtenuis, 34 .

zschokkei armatus, 33 .

Orchesella, 78 .

albosa, 80 .

ainsliei, 80 .

annulicornis, 78 .

hexfasciata, 79 .

Orchesellini, 77 .

Papirius, 106, 107.

pini, 108.

testudineatus, 108.

Paranura, 27.

caeca, 27.

sexpunctata colorata, 28.

Podura, 8.

aquatica, 8.

granulata, 8.

Poduridae, 7.

Podurinae, 8.

Polycanthella, 20.

Proisotoma, 50.

americana, 51. 
bulbosa, 52 .

minima, 52.

minuta, 54.

thermophila, 53.

schötti, 52.

Prosminthurus, 87.

Protanura, 28.

Pseudachorutes, 22

aureofasciatus, 23.

corticolus, 22.

lunatus, 23.

saxatilis, 24.

subcrassoides, 24.

Pseudachorutini, 19.

Pseudisotoma, 56. sensibilis, 56.

Pseudosinella, 73.

alba, 75.

candida, 74 .

octopunctata, 74 .

petterseni forma C.R., 76 .

rolfsi, 76.

sexoculata, 75 .

violenta, 76, 81 .

Ptenothrix, 107.

aurata, 107.

marmorata, 108.

setosa, 108.

unicolor, 108.

Schöttella, 13.

glasgowi, 14.

minutissimus, 14 .

Sinella, 65.

curviseta, 65.

höfti, 65 .

tenebricosa, 65.

Sira, 71.

buski, 71.

mimica, 71.

nigromaculata, 71.

platani, 71.

Sminthuridae, 86.

Sminthurides, 87.

aquaticus, 89.

lepus, 91.

malmgreni, 90.

occultus, 91.

penicillifer bifidus, 90 .

Sminthuridinae, 87.

Sminthurinae, 100.

Sminthurinus, 94.

aureus, 95.

aureus albus, 95.

aureus novus, 95,96 .

elegans, 96.

minutus, 97.

niger, 97.

quadrimaculatus, 97.
Sminthurus, 103.

albamaculatus, 101.

amious, 89.

benitus, 93.

curvisetis, 98.

dorsalis, 103.

henshawi, 95.

medialis, 103.

minnesotensis, 103.

obseurus, 104.

pruinosus, 101.

quadrilineatus, 96.

quadrisignatus, 101.

sexmaoulatus, 97.

signatus, 101.

socialis, 90.

Sphaeridia, 88. pumilis, 88.

Sphyrotheca, 105.

Spinisotoma, 54.

Stenacidia, 88.

Stenaphorura, 36.

Symphypleona, 85.

Templetonia, 77. americana, 77.

Tetracanthella, 42.

Tetrodontophora, 31.

Tomocerinae, 82.

Tomocerus, 82.

flavescens, 83.

flavescens separatus, 83 .

flavescens americanus, 83 .

lamelliferus, 84.

vulgaris, 83 .

Triaena, 20.

Tritomurus, 84.

Tullbergia, 36 .

clavata, 38.

collis, 36 .

granulata, 37.

krausbaueri, 37.

iowensis, 37.

Typhlopodura, 77.

Uzelia, 42.

Willemia, 17. anophthalma, 17.

intermedia, 17 .

similis, 17.

Xenylla, 15. gracilis, 15. grisea, 15.

maritima, 16. subwelchi, 15. welchi, 15.

Xenyllodes, 26. 



\section{PLATES}




\section{PLATE 1}

Figure

\section{FIGURES 1-9}

1. Micranurida furcifera n. sp. X66.

2. Onychiurus obesus n. sp. X46.

3. Folsomides parvus Folsom, n. sp. X66.

4. Isotomodes tenuis Folsom, n. sp. X66.

5. Isotoma andrei n. sp. X46.

6. Entomobrya purpurascens Packard. X46.

7. Entomobrya assuta Folsom. X46.

8. Entomobrya assuta Folsom. X46.

9. Lepidocyrtus curvicollis Nicolet. X46. 


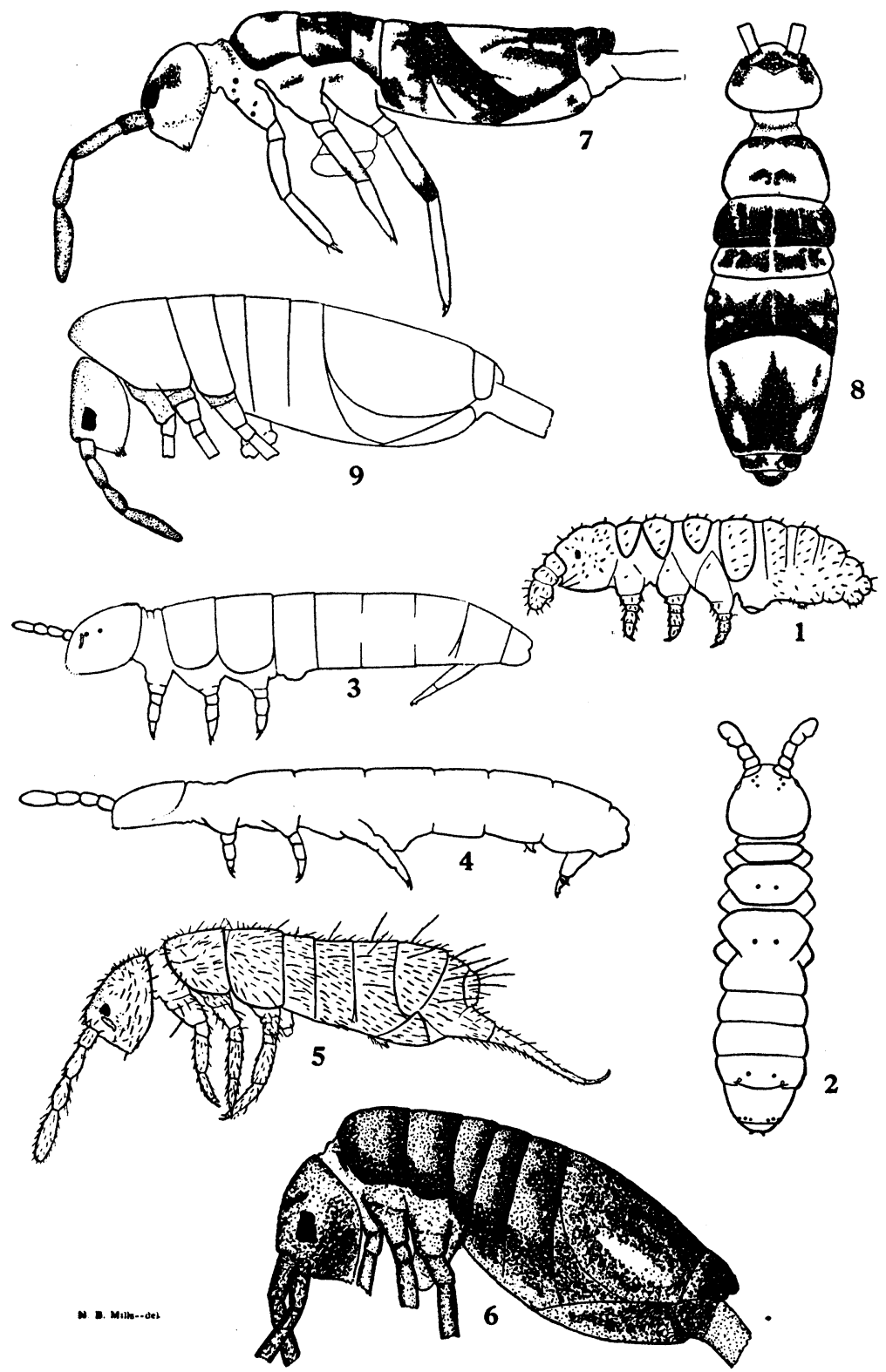




\section{PLATE 2}

\section{FIGURES 10-14}

\section{Figure}

10. Entomobrya clitellaria Guthrie. X46.

11. Orchesella annulicornis n. sp. X46.

12. Megalothorax incertoides n. sp. X151.

13. Sminthurides lepus n. sp. X66.

14. Neosminthurus curvisetis Guthrie. X66. 
Collembola of Iowa
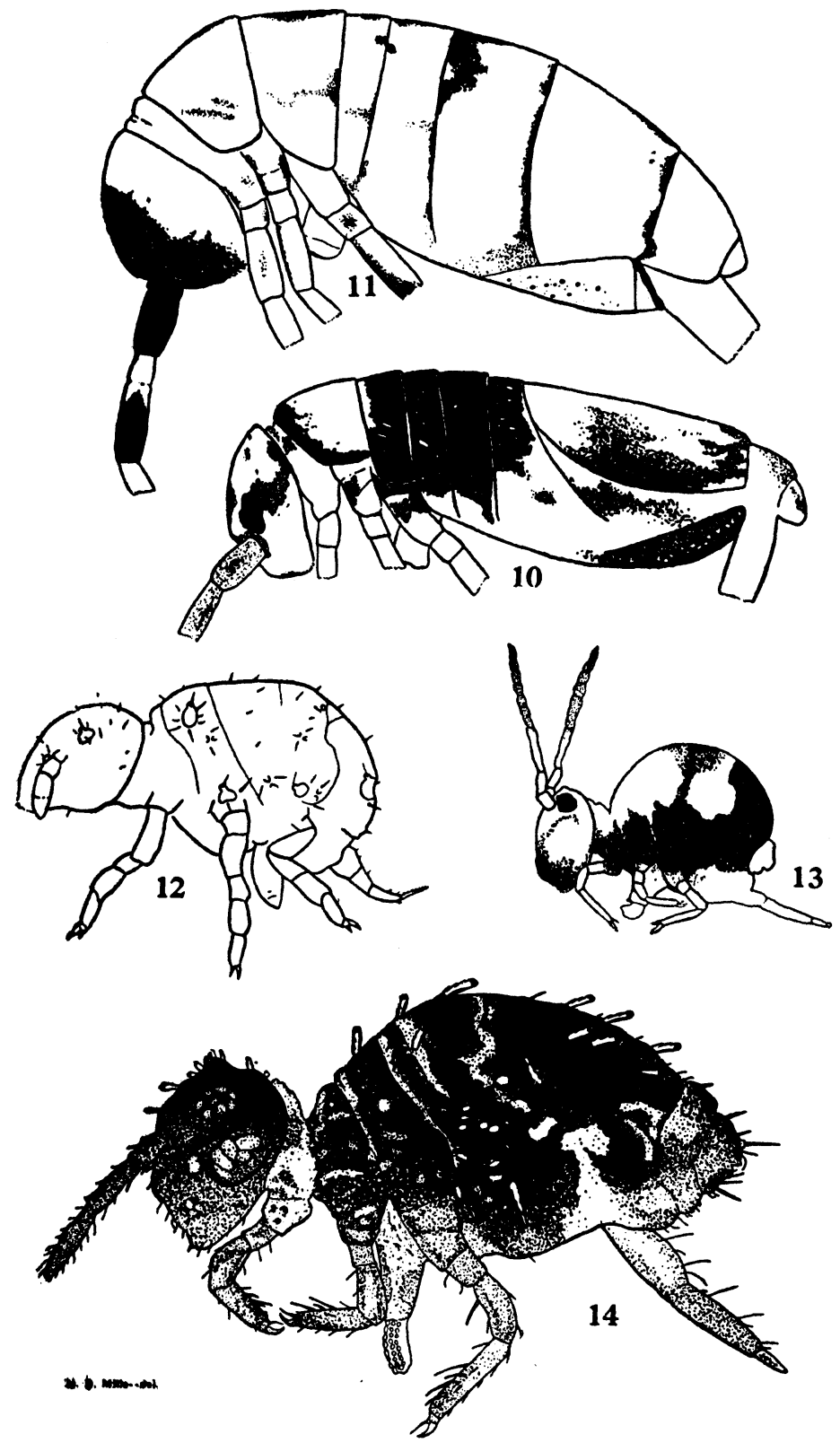


\section{PLATE 3}

Figure

\section{FIGURES 15-35}

Achorutes (Schöttella) minutissimus n. sp.

15. Right eyes and postantennal organ.

16. Right mandible.

17. Right maxilla.

18. Left middle foot.

19. Dens and mucro.

Schöttella glasgowi Folsom.

20. Furcula, right view.

Xenylla maritima Tullberg.

21. Furcula, right view.

Xenylla welchi Folsom.

22. Furcula, right view.

23. Furcula, right view.

Xenylla grisea Axelson.

Willemia intermedia $\mathrm{n}$. sp.

24. Postantennal organ.

25. Organ of the 3rd antennal segment.

Willemia similis $\mathrm{n}$. sp.

26. Postantennal organ.

27. Organ of the 3rd antennal segment.

Brachystomella parvula Schäffer.

28. Right hind foot.

29. Left eyes and postantennal organ.

30. Furcula, left view.

Brachystomella stachi $\mathbf{n}$. sp.

31. Left maxilla.

32. Organ of 3rd antennal segment.

33. Right eyes and postantennal organ.

34. Left hind foot.

35. Furcula, left view. 
Collembola of Iowa
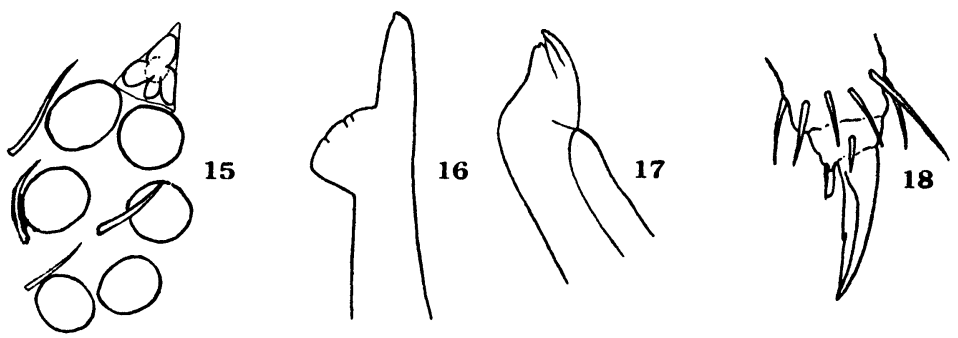

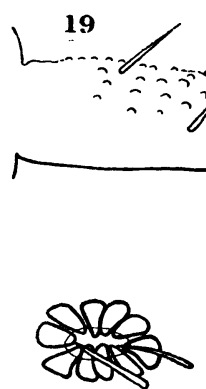

26

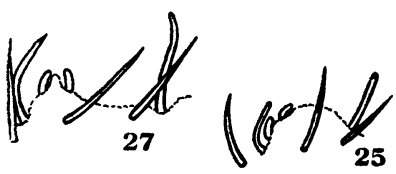

24

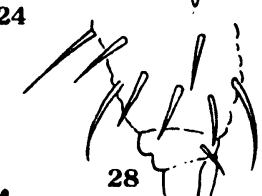

28

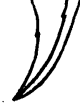

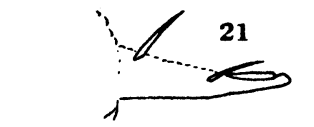

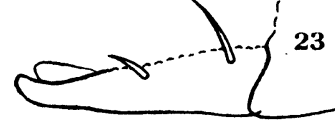

) $\operatorname{los}_{29}^{0} \cup^{\circ}$
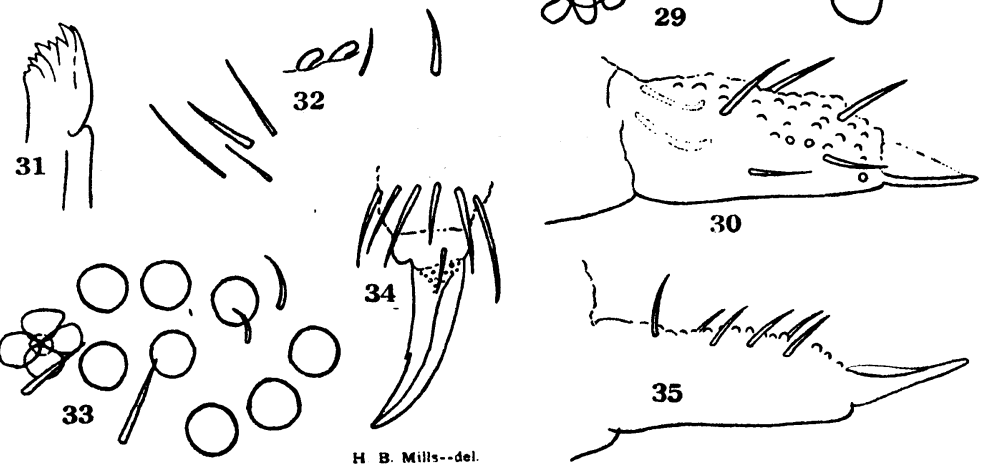


\section{PLATE 4}

\section{FIGURES 36-57}

Figure

Friesea grandis n. sp.

36. Left fore foot.

37. Furcula and tenaculum, ventral view.

38. Mandible.

39. Maxilla.

40. Anal horn.

41. Furcula, lateral view.

42. Types of hairs from 6th abdominal segment. Friesea pentacantha n. sp.

43. Apex of the abdomen.

44. Right front foot.

45. Left hind foot.

46. Maxilla.

47. Furcula, right view.

48. Left hind foot.

49. Right eyes and postantennal organ.

50. Apex of right antenna.

Pseudachorutes saxatilis Macnamara.

51. Right postantennal organ and adjacent eyes.

52. Left hind foot.

53. Right mucro.

54. Maxilla head.

55. Mandible.

Pseudachorutes subcrassoides n. sp.

56. Postantennal organ and adjacent eyes.

57. Left mucro. 
Collembola of Iowa
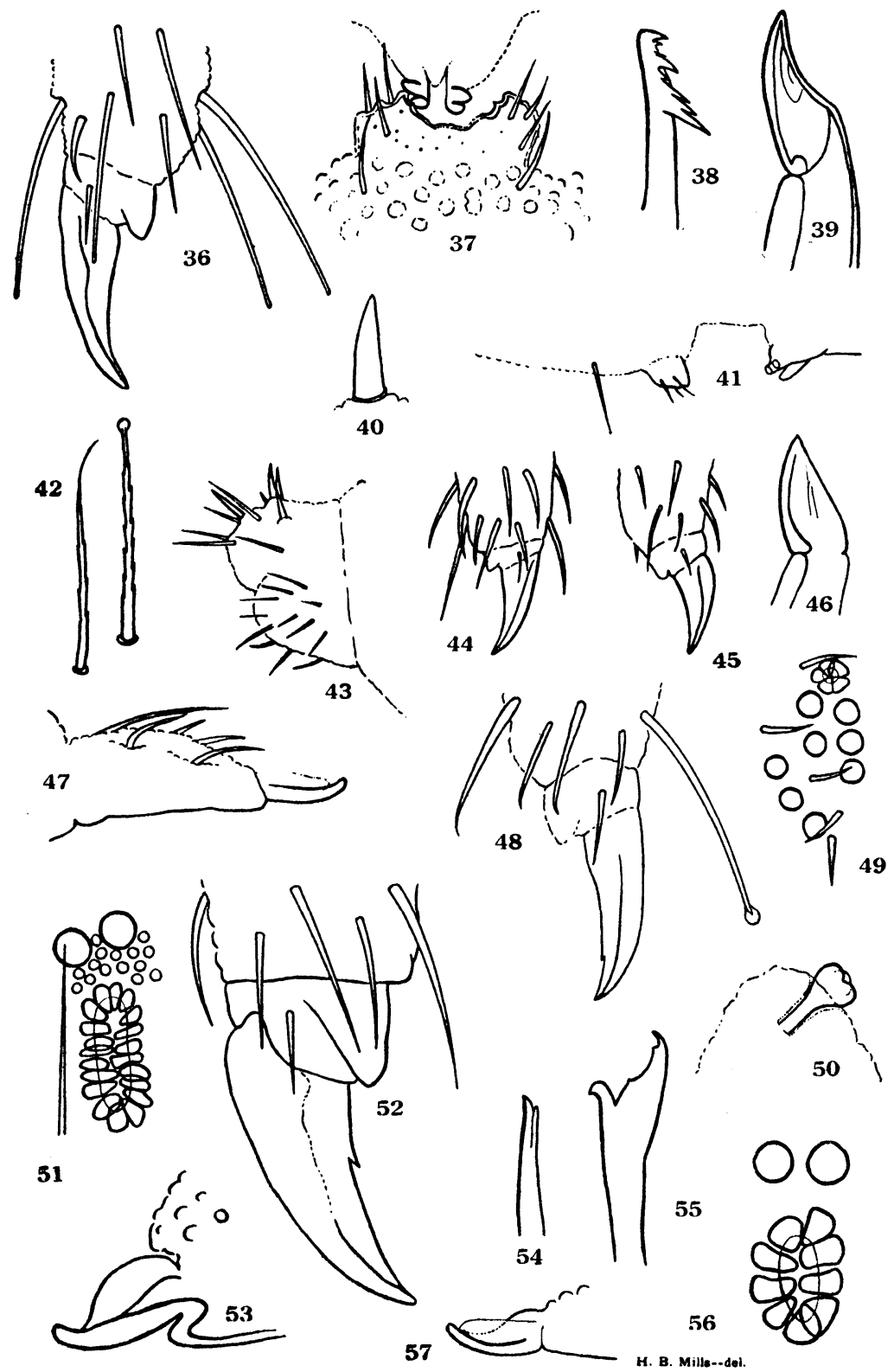


\section{PLATE 5}

\section{FIGURES 58-79}

Figure

58. Anal horns.

Odontella cornifer n. sp.

59. Organ of the 3rd antennal segment.

60. Head.

61. Right middle foot.

62. Right hind foot.

Anurida tullbergi Schött.

63. Postantennal organ.

Micranurida pygmaea Börner.

64. Apex of right antenna.

65. Eyes and postantennal organ.

66. Apex of left antenna.

Micranurida furcifera $\mathbf{n}$. sp.

67. Postantennal organ.

68. Right middle foot.

69. Furcula.

Neanura persimilis n. sp.

70. Left eyes and ocular tubercle.

Onychiurus parvicornis $\mathrm{n}$. $\mathrm{sp}$.

71. Postantennal organ.

72. Left hind foot.

73. Anal horn.

74. Right eyes.

$$
\text { Paranura 6-punctata Axelson. }
$$

75. Postantennal organ.

Onychiurus ramosus Folsom.

76. Postantennal organ.

Onychiurus subtenuis Folsom.

77. Postantennal organ.

Onychiurus obesus n. sp.

78. Anal horn (Specimen from Maquoketa).

79. Apex of abdomen (Specimen from Bixby State Park). 


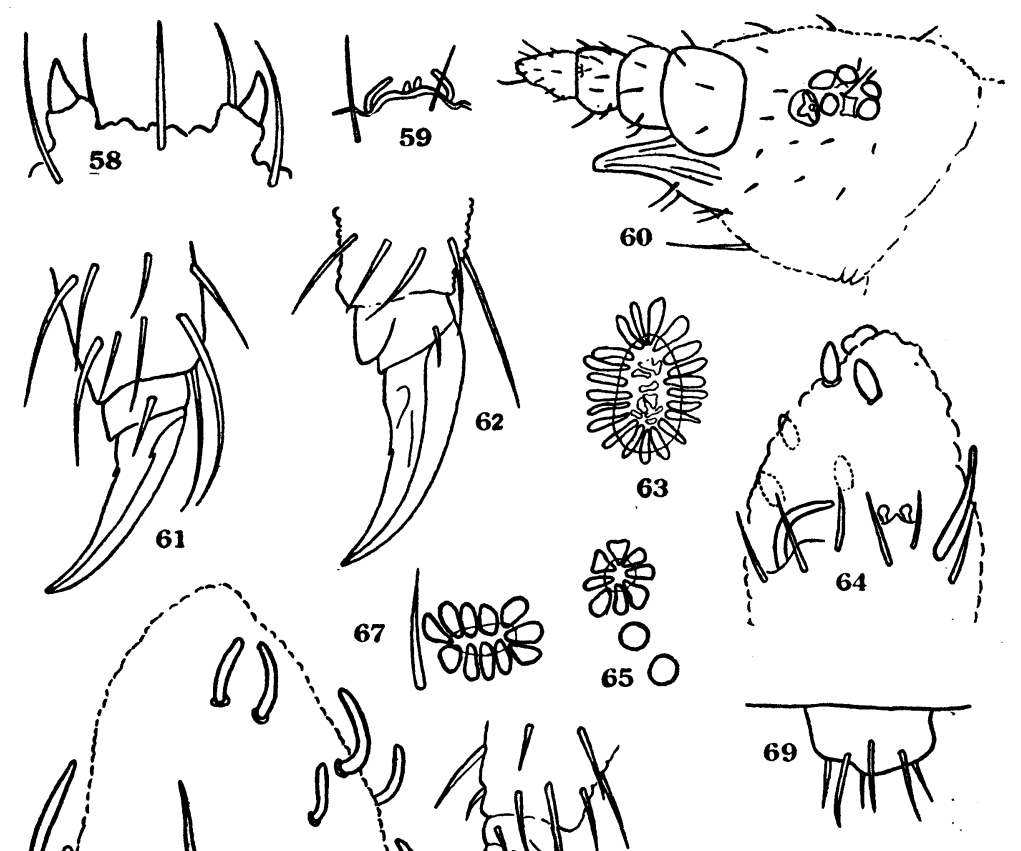




\section{PLATE 6}

Figure

\section{FIGURES 80-98}

80. Left hind foot.

Onychiurus obesus $\mathbf{n}$. sp.

81. Furcula.

Tullbergia clavata $\mathbf{n}$. sp.

82. Organ of the 3rd antennal segment.

83. Right antenna.

84. Right hind foot.

85. Ventro-lateral sense club, 3rd antennal segment.

86. Head.

$$
\text { Isotomodes tenuis Folsom, } \mathbf{n} \text {.sp. }
$$

87. Mucro.

$$
\text { Folsomina onychiurina Denis. }
$$

88. Apex of right antenna.

$$
\text { Proisotoma americana } \mathrm{n} \text {. sp. }
$$

89. Left eyes and postantennal organ.

90. Left hind foot.

91. Furcula, left side.

$$
\text { Proisotoma bulbosa Folsom, n. sp. }
$$

92. Mucro and apex of dens, left side.

93. Right mucro.

$$
\text { Proisotoma schötti Dalla Torre. }
$$

94. Right fore foot.

95. Left mucro.

Proisotoma thermophila Axelson.

96. Left hind foot.

Isotomurus palustris Müller.

97. Claw regenerated from base of tibiotarsus.

98. Left mucro. 
Collembola of Iowa
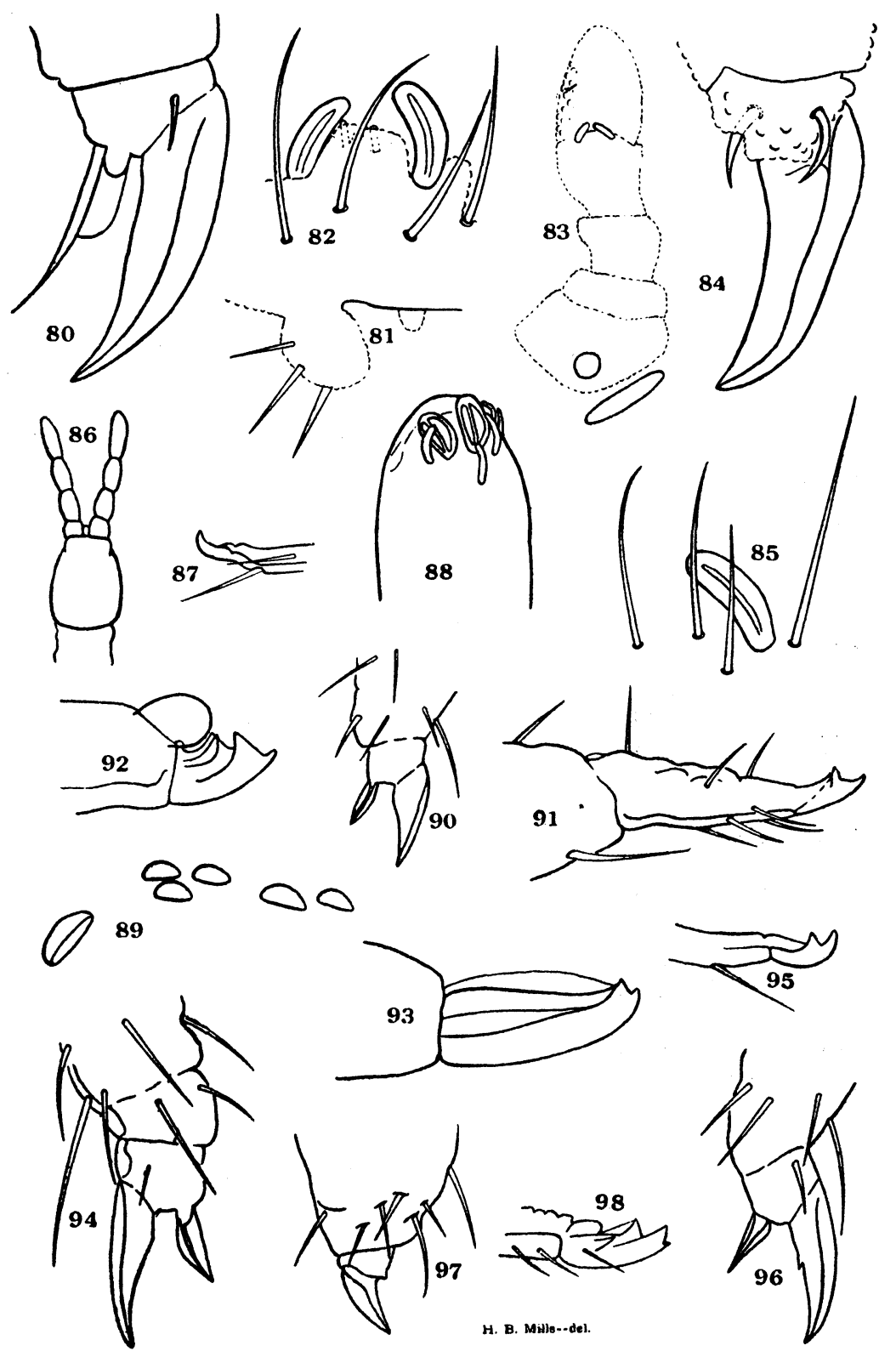


\section{PLATE 7}

FIGURES 99-114

Figure

Isotoma (Pseudisotoma) sensibilis Tullberg.

99. Right hind foot.

100. Right mucro.

Isotoma minor Schäffer.

101. Apex of left antenna.

102. Left mucro.

Isotoma andrei $\mathrm{n}$. $\mathrm{sp}$.

103. Left hind foot.

104. Left eyes and postantennal organ.

105. Left mucro.

Isotoma grandiceps Reuter.

106. Right hind foot.

107. Left mucro.

Isotoma nigrifrons Folsom, n. sp.

108. Left fore foot.

Isotoma olivacea grisea Lubbock.

109. Right mucro.

Isotoma olivacea Tullberg, f. p.

110. Right mucro.

Isotoma viridis Bourlet.

111. Left mucro.

112. Left hind foot.

113. Left fore foot.

Sinella höfti Schäffer.

114. Left mucro. 
Collembola of Iowa

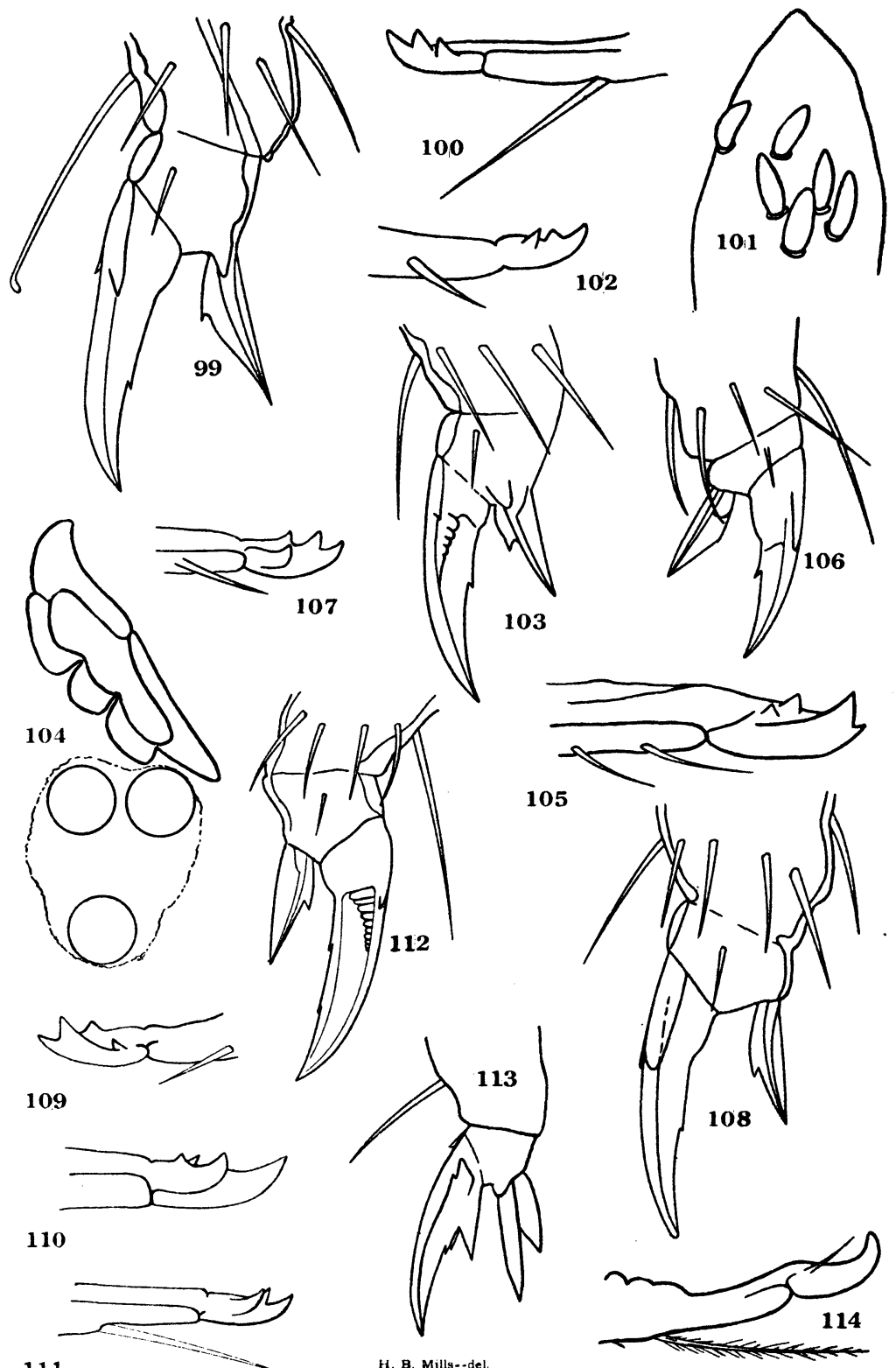

H. B. Mills-.del. 


\section{PLATE 8}

Figure

\section{FIGURES 115-129}

\section{Entomobrya purpurascens Packard.}

115. Two types of hairs from inner face of tibiotarsus.

116. Right fore foot.

117. Left mucro.

Entomobrya marginata Tullberg.

118. Left hind foot.

Entomobrya griseo-olivata Packard.

119. Left fore foot.

Entomobrya clitellaria Guthrie.

120. Left hind foot.

Lepidocyrtus curvicollis Bourlet.

121. Left mucro.

122. Eyes.

Pseudosinella candida Folsom.

123. Right fore foot.

124. Eyes.

Pseudosinella octopunctata Börner.

125. Eyes.

Pseudosinella 6-oculata Schött.

126. Right hind foot.

Pseudosinella rolfsi Mills.

127. Left middle foot, inner view.

128. Left fore foot.

Heteromurus nitidus Templeton.

129. Right hind foot.

Orchesella annulicornis n. sp. 
Collembola of Iowa

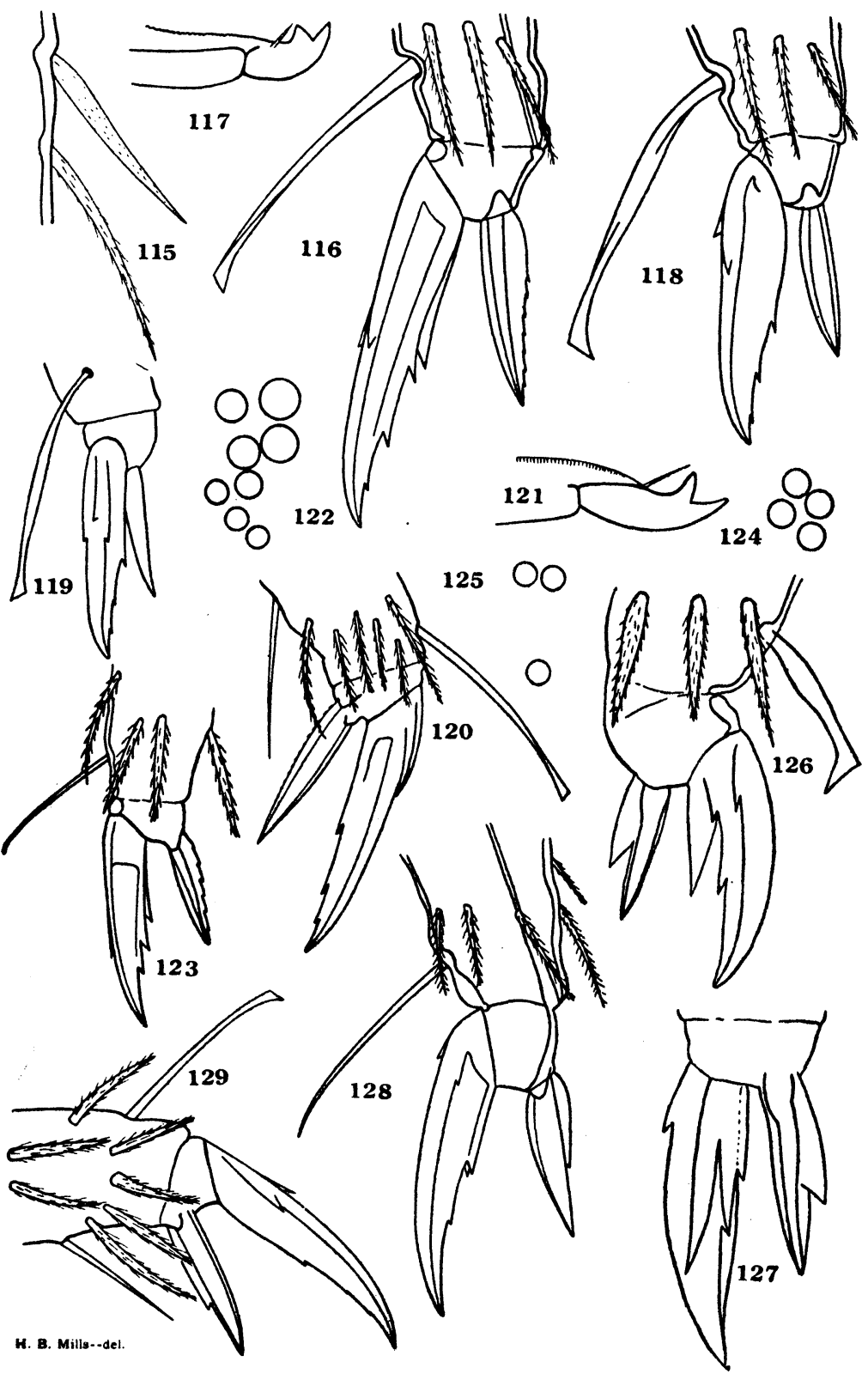




\section{PLATE 9 \\ FIGURES 130-145}

Figure

Orchesella ainsliei Folsom.

130. Base of the antenna.

Orchesella hexfasciata Harvey.

131. Base of the antenna.
Orchesella albosa Guthrie.

132. Right fore foot.

133. Mucro.

Cyphoderus similis Folsom.

134. Left dental spines.

Tomocerus lamelliferus $\mathrm{n}$. sp.

135. Right hind foot.

136. Left mucro.

Megalothorax incertoides $\mathbf{n}$. sp.

137. Left mucro.

138. Right hind foot.

Sminthurides (Sphaeridia) pumilis Krausbauer.

139. Right mucro.

140. Male antenna.

141. Right hind foot.

142. Right fore foot.

Sminthurides penicillifer bifidus n. var.

143. Right hind foot.

144. Left fore foot.

145. Left mucro. 
Collembola of Iowa

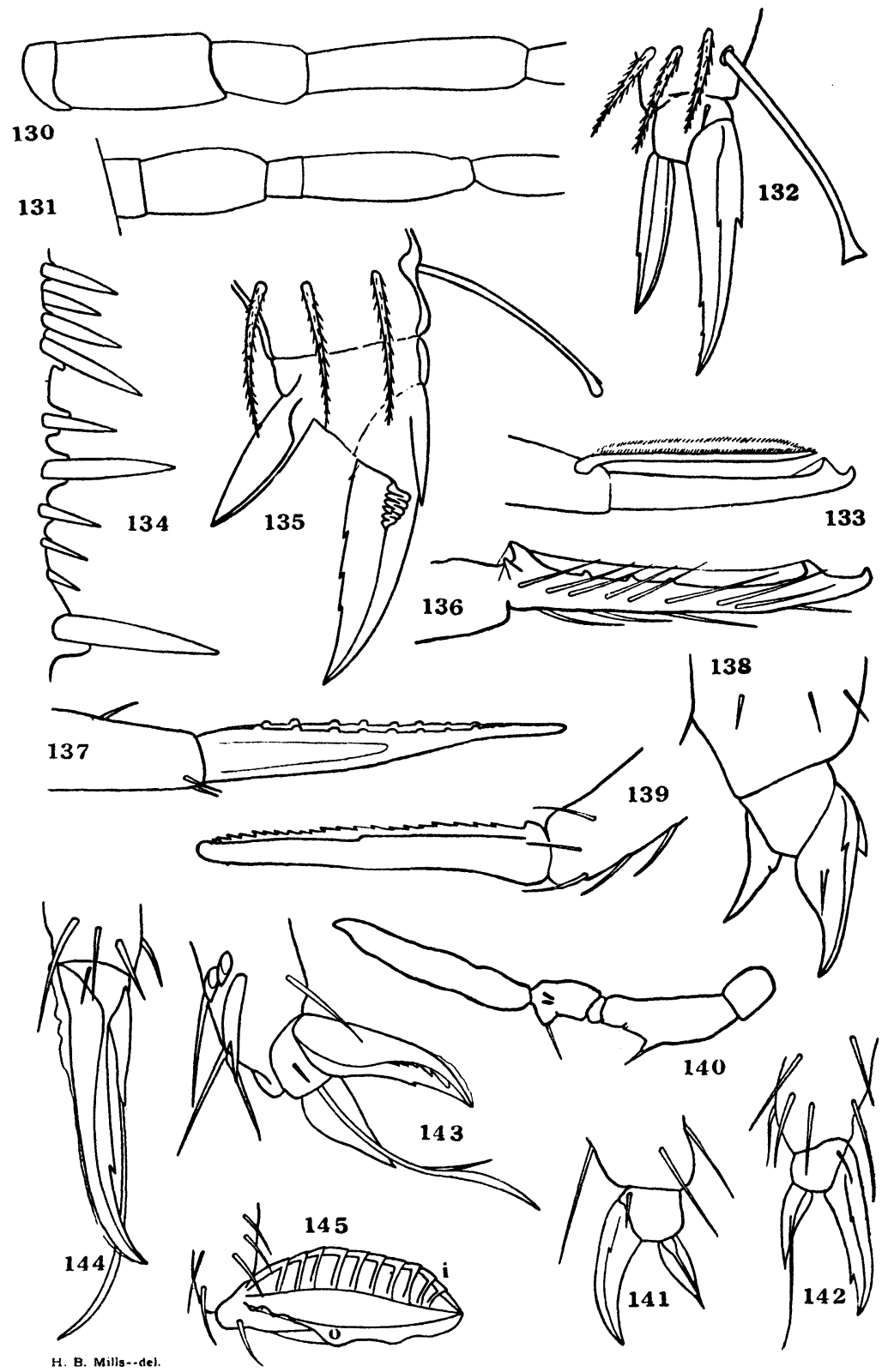


Eigure

\section{FIGURES 146-160}

Sminthurides occultus n. sp.

146. Mucrones, dorsal view.

147. Left mucro.

148. Right hind foot.

149. Left fore foot.

150. Left middle foot.

151. Last antennal segment of female.

152. Antenna of male.

153. Right fore foot.

Sminthurides lepus n. sp.

154. Right middle foot.

155. Male antenna.

156. Right mucro.

157. Right hind foot.

158. Left fore foot.

Arrhopalites diversus n. sp.

159. Right hind foot.

150. Anal appendage of female. 
Collembola of Iowa
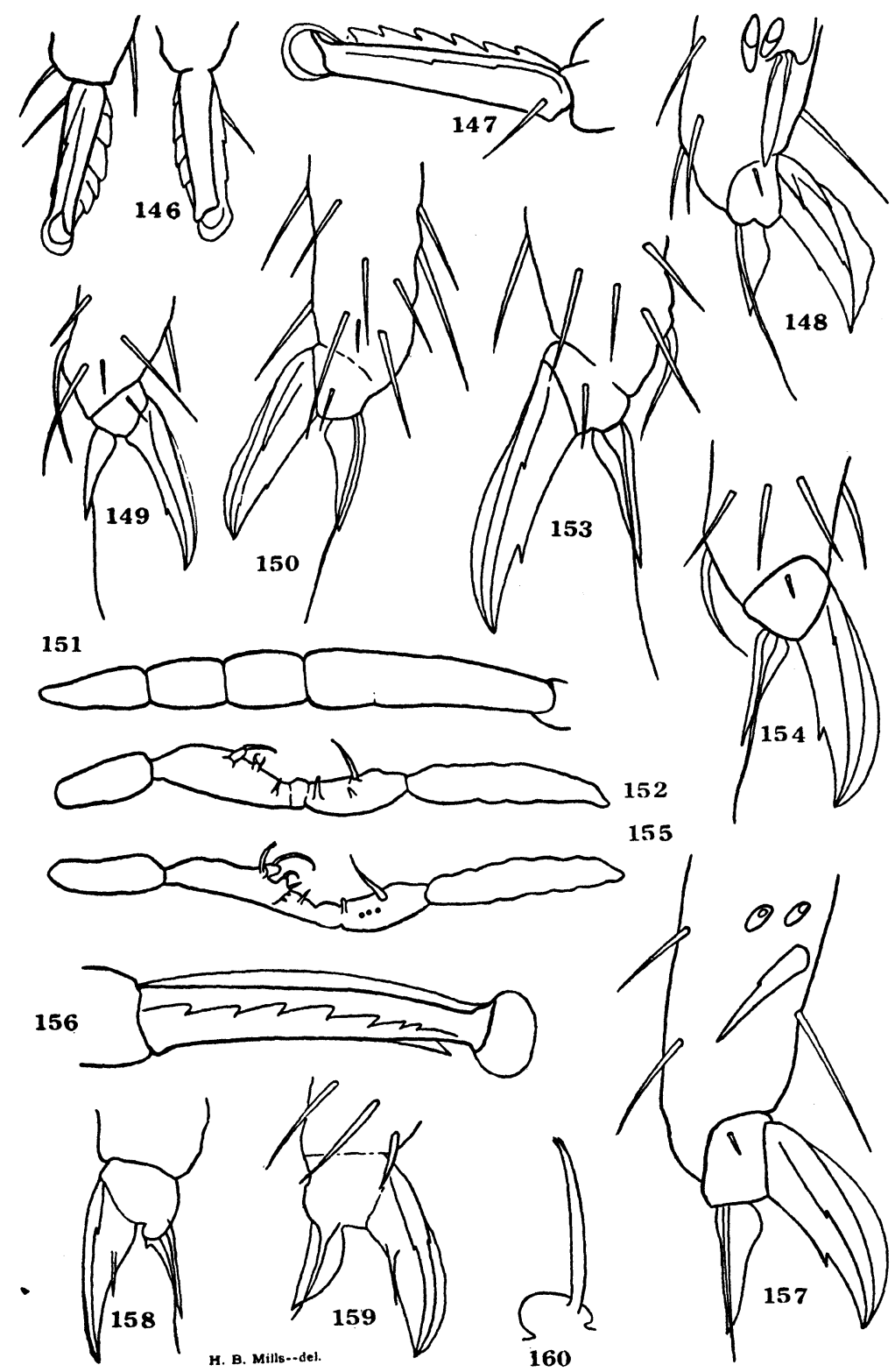


\section{PLATE 11}

\section{FIGURES 161-177}

Figure

161. Antenna.

Arrhopalites diversus n. sp.

162. Mucro.

Arrhopalites caecus Tullberg.

163. Left mucro.

Arrhopalites binoculatus Börner.

164. Apex of antenna.

165. Left hind foot.

166. Anal appendage of female.

Sminthurinus elegans Fitch.

167. Furcula, left view.

Sminthurinus aureus Lubbock.

168. Furcula, left view.

169. Right mucro.

Neosminthurus curvisetis Guthrie.

Bourletiella hortensis Fitch.

170. Anal appendage of female.

171. Left mucro.

Neosminthurus sminthurinus n. sp.

Deuterosminthurus repandus Ågren.

172. Anal appendage of female.

Bourletiella spinata MacGillivray.

173. Anal appendage of female.

174. Apex of abdomen of male.

175. Left mucro.

Sminthurus medialis $\mathrm{n}$. sp.

176. Left hind foot.

177. Apex of abdomen showing lateral papilla of genital segment. 

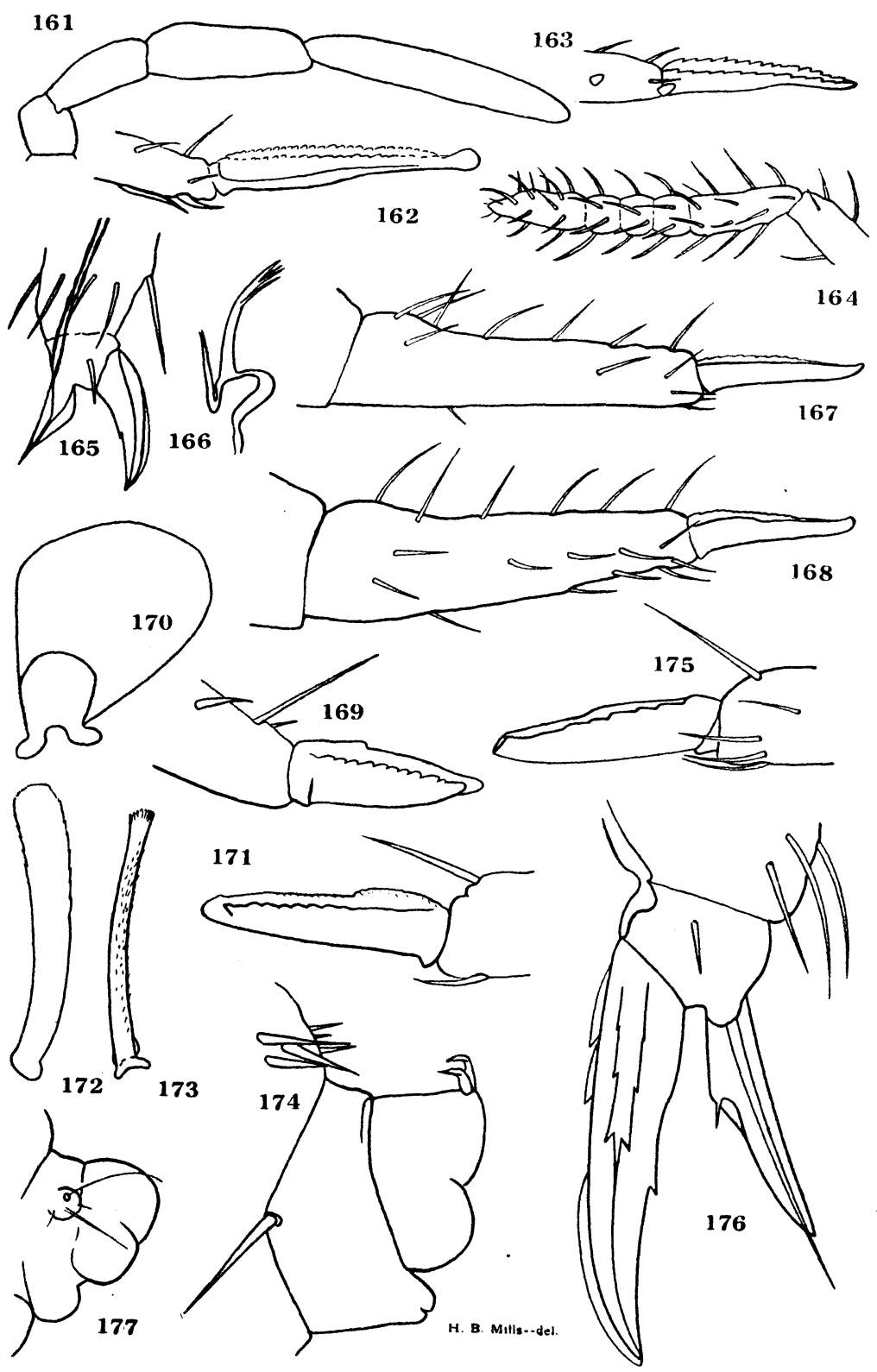


\section{PLATE 12}

\section{FIGURES 178-189}

Figure

178. Right mucro.

Ptenothrix aurata n. sp.

179. Right fore foot.

180. Right hind foot.

181. Apex of antenna.

182. Organ of 3rd antennal segment.

183. Anal appendage of female.

Ptenothrix unicolor Harvey.

184. Anal appendage of female.

185. Left hind foot.

186. Apex of antenna.

187. Left fore foot.

Dicyrtoma quadrangularis $\mathbf{n}$. sp.

188. Right hind foot.

189. Mucro. 


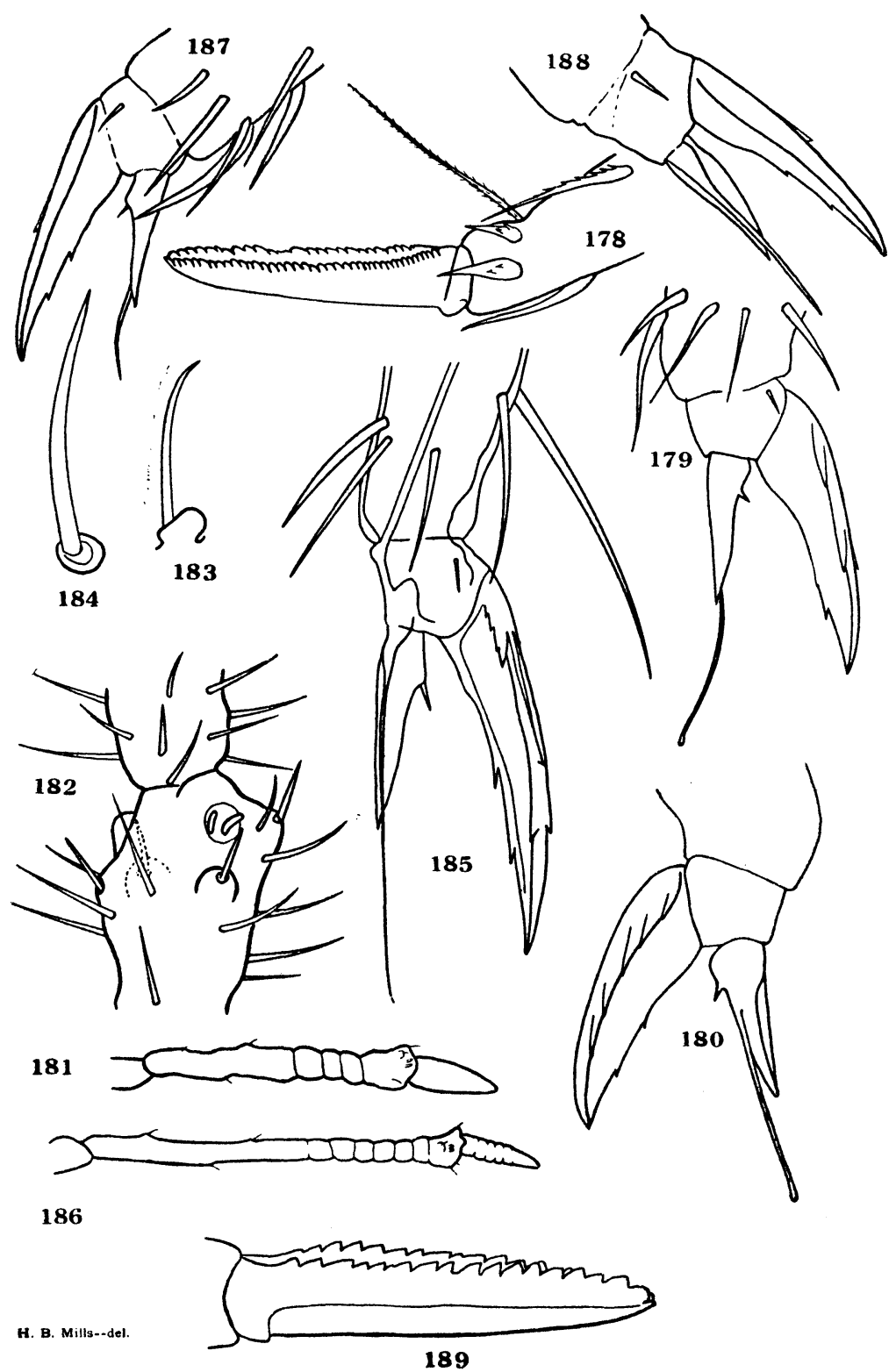

